University of San Diego

Digital USD

2000-05-16

\title{
The Role of Education in the Treatment of Chronic Pain Patients: A Quantitative Study of Factors that Influence the Self -Management of Chronic Pain
}

Donna L. Agan EdD
University of San Diego

Follow this and additional works at: https://digital.sandiego.edu/dissertations

Part of the Leadership Studies Commons

\section{Digital USD Citation}

Agan, Donna L. EdD, "The Role of Education in the Treatment of Chronic Pain Patients: A Quantitative Study of Factors that Influence the Self -Management of Chronic Pain" (2000). Dissertations. 669. https://digital.sandiego.edu/dissertations/669

This Dissertation: Open Access is brought to you for free and open access by the Theses and Dissertations at Digital USD. It has been accepted for inclusion in Dissertations by an authorized administrator of Digital USD. For more information, please contact digital@sandiego.edu. 
THE ROLE OF EDUCATION IN THE TREATMENT OF CHRONIC PAIN

PATIENTS: A QUANTITATIVE STUDY OF FACTORS THAT INFLUENCE THE SELF-MANAGEMENT OF CHRONIC PAIN

\title{
DISSERTATION
}

\author{
Donna L. Agan \\ School of Education \\ University of San Diego
}

May 16,2000

Dissertation Committee

\author{
Susan Zgliczynski, Ph.D., Director \\ Jerome Ammer, Ph.D. \\ Bill McCarberg, M.D. \\ Samuel Herrick, Ph.D.
}


(C) Copyright 2001

Donna L. Agan

All Rights Reserved 


\begin{abstract}
The factors involved in the successful self-management of chronic pain are not well understood. Many issues complicate addressing these factors. Individual suffering, exhaustion of family resources, and the costs to society for medical care, lost wages, welfare and disability benefits demand increasingly more resources each year. At the micro level, patients who live the daily rigors of chronic pain want medical science to solve their malady. At the macro level, health plan administrators want their patients to successfully self-manage pain with the least medical intervention and cost, because they know a cure is not probable. In the middle, the medical provider must balance the patient's needs with the limited resources of the medical system. As managed care becomes the fountain of medical treatment, health care systems must apportion the magnitude of services and quality of life only as far as it balances with the bottom line.
\end{abstract}

Chronic pain is one of the most frustrating problems facing medical practitioners today because research has yet to provide definitive solutions. While researchers, pain specialists, and patients demand adequate pain control, including the aggressive use of opioid medications, frontline providers, medical review boards, governmental regulators and society fear the potential crossover into addiction. Medical science can offer care, compassion, pain management, and some modalities of treatment, but $a$ cure is unlikely.

In a quantitative study, I examined various characteristics of chronic pain patients, their environments, and their utilization of the health care system, including outpatients' office visits and opioid medications. Included was an analysis of available data on 2,561 patients referred to a cognitive-behavioral pain management program in a Southern California HMO. Employing a linear model, I explored statistical relationships of various factors and their apparent importance in managing chronic pain. Briefly, chronic pain knew no boundaries. Demographically, pain was similarly reported irrespective of age, gender, marital status, education, employment, or disability. Also, the higher the reported level of physical pain, the more pain affected each aspect of one's quality of life. The collected data suggested that chronic pain was under treated in the health care setting and that women received significantly less opioid medication to manage pain.

People who were referred to an education-based, cognitive-behavioral pain management program reported significantly less pain and utilized fewer health care services over time. Patients attending the program reported high levels of satisfaction and found the pain management tools useful. However, financial outcomes were similar among patients who attended the program, those who dropped out, and those who never attended class. This population, at best, taxes health care resources at a rate of four times that of the mean population. If, as it appears, chronic pain patients were consistently under treated for pain, educational programs for patients will not significantly impact medical costs. Only when the current pain management standards of care are in place and established treatments for chronic pain management are supported by health care providers would we expect the financial aspect of pain management to improve. 


\section{This dissertation is dedicated to:}

Johnna and Geoff, my beautiful children, for encouraging me in this lofty goal,

and

To all those with chronic pain. I pray that God and caring professionals may hasten the healing process and help you find new meaning and purpose, even if a cure is not yet possible. 


\section{ACKNOWLEDGMENTS}

Any undertaking of this magnitude cannot possibly be done by one person alone. As it takes a village to raise a child, it also takes a village to complete a dissertation study. Support came from many sources and in a variety of forms.

First, I want to thank my Committee members. Susan Zgliczynski, Ph.D., my chair, went out of her way to support me and allowed me the opportunity to do this research project the way I had envisioned. Also, it has been my pleasure to work with Sue for the last five years tutoring and lecturing in the doctoral quantitative research classes for the School of Education and the School of Nursing. Thanks, too, for the adjunct faculty position in the M.Ed. Counseling program. Teaching the basic principles of research to others helped me to better understand this process.

To Jerome Ammer, Ph.D., I appreciate his working under quick and unpredictable deadlines. Jerry's vast experience with SPSS and the health care field was comforting and his critiques were always right-on.

For Samuel Herrick, Ph.D., I appreciate his statistical skills, knowledge of economics, experience with large data sets, and encouragement to attempt a study of this magnitude. Between Sam and his beautiful wife, Marguerite, they provided powerful emotional and spiritual support as well.

Bill McCarberg, M.D. was also a huge supporter and fan. Thanks for believing this dream was possible from beginning to end. I look forward to co-authoring many journal articles with him and helping to improve the treatment of chronic pain patients.

I want to thank Janet Wolf for the part-time position in the Pain Management Program and for taking the time to teach me how to read medical charts, work with chronic pain patients, understand physicians' handwriting, and your friendship. Also, thanks for gathering information off the Program's database so I could use it in this study.

My appreciation goes out to Karen Stolz, a friend and a talented former high school English teacher. Karen's editing skills helped to make this paper more readable to a larger audience.

To Dennis Turk, Ph.D., I want to thank him for his time, input, and for allowing me to use the different versions of the MPI for this study. As this was the largest study to 
use these instruments, $I$ hope that the information gathered here will be useful in refining the tools and inventories used to assess pain patients and help increase understanding of the many variables underlying chronic pain.

Without the generous grant from the Kaiser Foundation, which paid for all the printing and postage costs, a study of this size would not have been economically feasible. Many thanks go out to all those within the organization who helped to make this study possible, including the Internal Review Board as well as Diana Mc Rae and the IT Department.

Many thanks go to Brad Phillips Ph.D. and Anouk in the Research and Planning Department at the Grossmont/Cuyamaca Community College District office. Working with them as a graduate intern, I learned everything I needed to know about SPSS so that I could, on my own, set up and transfer data bases and perform all of the statistical calculations used in this study.

To the many doctoral students I tutored over the last five years, I thank them for increasing my understanding of quantitative research. Through all of them, I discovered a passion for teaching. In return, I enjoy new friendships and potential collaborators. They remain great sources of encouragement for me, especially Sue Hoyt, NP, and Sue DeSimone, DNSc (Cand.).

Finally, and most important, I want to thank my family and friends, who stuck by me and provided incredible support though this long journey. To Mom and Dad, I wish you had lived long enough to see this day, but feel secure that you have always been with me. For Brian Ruggles, we have been through a lot in the last 35 years. Thanks for believing in me and for all your fatherly advice and generous support. To Steve and DJ, while we do not see each other often, it always comforts me to know you are there for me, your little sister. To Joan Cook-Loth and Judy Anderson, your long-term friendship and counsel helped to keep me on track even through my darkest hours. For Melinda Mesmer, Fr. Fred Bartlett, Fr. Ted Atwood, and the community at St. Dunstan's Church, my thanks for all your prayers and encouragement.

And to God, thanks for listening. I may not have gotten what I wanted, but I wanted what I got. 


\section{TABLE OF CONTENTS}

Acknowledgments $\ldots \ldots \ldots \ldots \ldots \ldots \ldots \ldots \ldots \ldots \ldots \ldots \ldots \ldots \ldots \ldots \ldots$ ii

Table of Contents $\ldots \ldots \ldots \ldots \ldots \ldots \ldots \ldots \ldots \ldots \ldots \ldots \ldots \ldots \ldots$

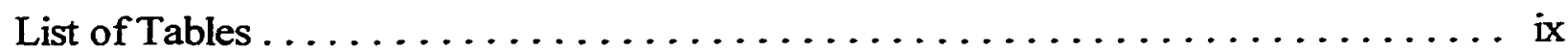

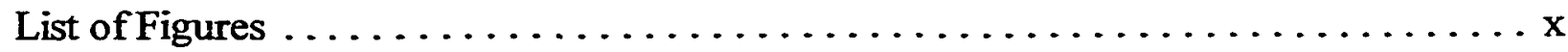

List of Appendices $\ldots \ldots \ldots \ldots \ldots \ldots \ldots \ldots \ldots \ldots \ldots \ldots \ldots \ldots \ldots \ldots \ldots \ldots$

CHAPTER 1 - The Problem

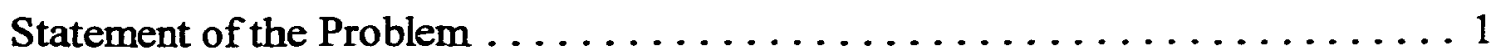

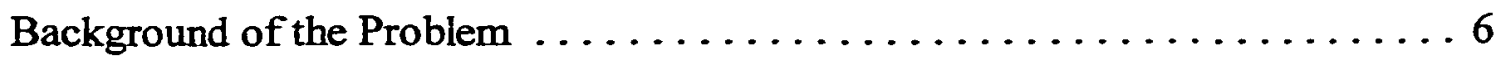

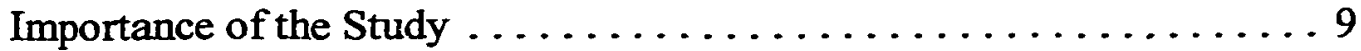

Purpose of the Study. . . . . . . . . . . . . . . . . . . . 10

Research Questions ............................ 11

Assumptions Related to the Study $\ldots \ldots \ldots \ldots \ldots \ldots \ldots \ldots \ldots \ldots \ldots \ldots$

Limitations of the Study ............................ 13

CHAPTER 2 - Review of Literature

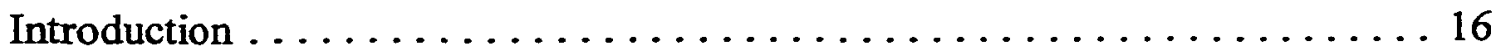

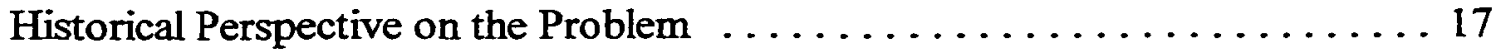

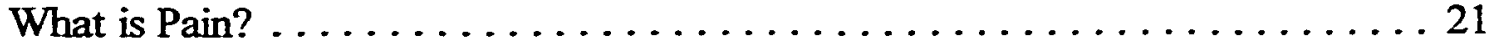

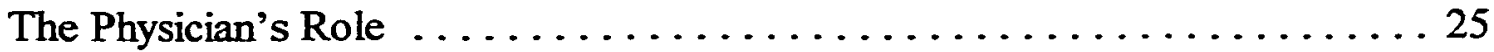

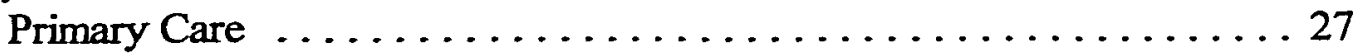

Secondary Care ................................ 27

Pain Treatment Facilities ...................... 27

Modality-oriented Clinic . . . . . . . . . . . . . . . . . 28

Pain Clinic . . . . . . . . . . . . . . . . . . . . 28

Multidisciplinary Pain Clinic . . . . . . . . . . . . . . . . 29

Multidisciplinary Pain Center .................... 30

Cognitive-Behavioral Pain Management ................... 30

Cognitive-Behavioral model $\ldots \ldots \ldots \ldots \ldots \ldots \ldots \ldots \ldots \ldots \ldots \ldots$

Pain Management Program ....................... 34

Medications used in Chronic Pain Management $\ldots \ldots \ldots \ldots \ldots \ldots \ldots \ldots \ldots$

Nonsteroidals ........................... 36

V 
Opioids . . . . . . . . . . . . . . . . . . . . . . . . 36

Analgesic Adjuvants .......................... 37

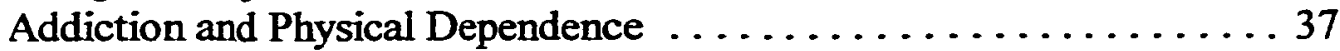

Intractable Pain Treatment . . . . . . . . . . . . . . . . . 39

Euthanasia and Physician-Assisted Suicide (PAS) $\ldots \ldots \ldots \ldots \ldots 40$

Placebo Effect . . . . . . . . . . . . . . . . . . . . . . 43

Measurements to Assess Chronic Pain Patients . . . . . . . . . . . . 46

The Multidimensional Pain Inventory (MPI) $\ldots \ldots \ldots \ldots \ldots \ldots \ldots 48$

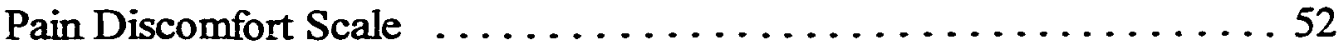

Eleven point Box Scale . ................... 53

Individual Factors that Influence Chronic Pain . . . . . . . . . 53

Measuring Effectiveness of Pain Treatment ............... 53

Size and Scope of Typical Research Projects in Chronic Pain ............ 54

Size and Scope of Past Research at the Pain Management Program ........ 57

Validity and Reliability . . . . . . . . . . . . . . . . . . . . 58

Leadership Issues in Chronic Pain . . . . . . . . . . . . . . 58

CHAPTER 3 - Methodology

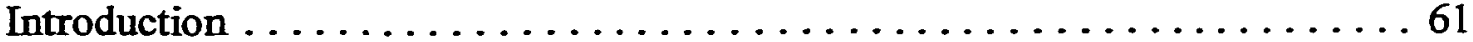

Methodological Overview $\ldots \ldots \ldots \ldots \ldots \ldots \ldots \ldots \ldots \ldots \ldots \ldots \ldots \ldots \ldots \ldots$

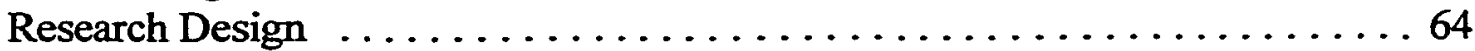

Data Collection .................................. 70

Entry to the Population $\ldots \ldots \ldots \ldots \ldots \ldots \ldots \ldots \ldots \ldots \ldots \ldots \ldots \ldots \ldots \ldots \ldots \ldots$

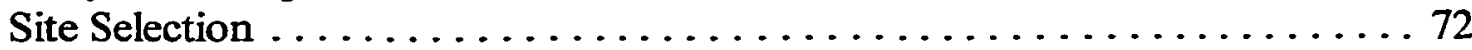

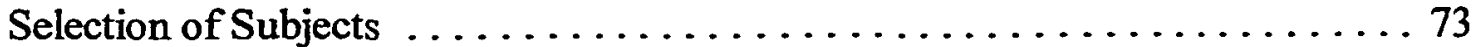

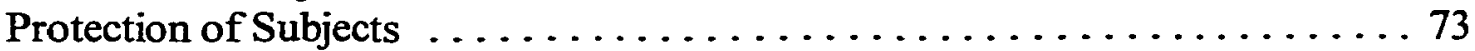

Data Analysis . . . . . . . . . . . . . . . . . . . . . . 75

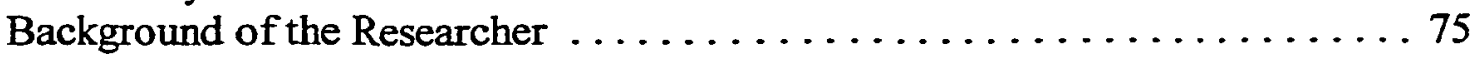

Summary . . . . . . . . . . . . . . . . . . . . . . . . 77

CHAPTER 4 - Data Analysis

Introduction . . . . . . . . . . . . . . . . . . . . . . . . . 79

Systemwide Demographics . . . . . . . . . . . . . . . . . 82

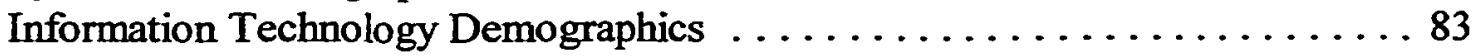

Gender ............................ 83

Age of the Total Group. . . . . . . . . . . . . . . . . . . 84

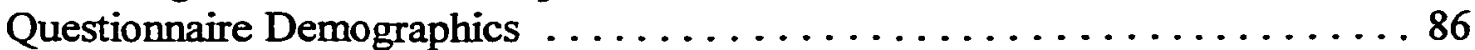

Marital Status . . . . . . . . . . . . . . . . . . . . . . 86

Education .............................. 88

Employment Status . . . . . . . . . . . . . . . . . 89

Years in Pain . . . . . . . . . . . . . . . . . . . . . 90

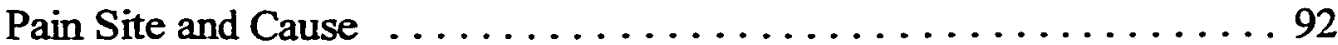

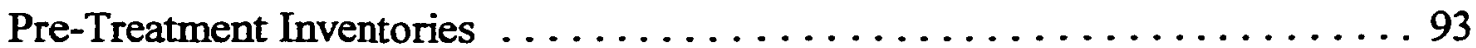

vi 
Eleven Point Box Scale ........................ 94

Pain Discomfort Scale (PDS) .................... 95

Multidimensional Pain Inventory (MPI) $\ldots \ldots \ldots \ldots \ldots \ldots \ldots .96$

How Gender Affected the MPI . . . . . . . . . . . . . . 99

How Age Associated with the MPI . . . . . . . . . . . . 100

PDS and the 11 Point Box Scale ................... 101

MPI and the 11 Point Box Scale ................... 103

Pain Severity . . . . . . . . . . . . . . . . 103

Interference . . . . . . . . . . . . . . . . . . 103

Life Control ........................... 104

Affective distress . . . . . . . . . . . . . . . . . 105

Activity level . . . . . . . . . . . . . . . . 105

Attendance ............................... 105

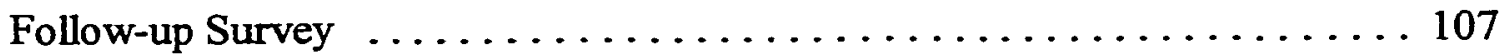

Eleven Point Box Scale - Post-Treatment . . . . . . . . . . 108

MPI - Post-treatment . . . . . . . . . . . . . . . . . 110

Total Quality Questions on Follow-up Surveys . . . . . . . . 112

Medical Utilization $\ldots \ldots \ldots \ldots \ldots \ldots \ldots \ldots \ldots \ldots \ldots \ldots \ldots \ldots \ldots \ldots \ldots$

Outpatient DOVs .......................... 114

Visits by specialty $\ldots \ldots \ldots \ldots \ldots \ldots \ldots \ldots \ldots \ldots \ldots \ldots \ldots \ldots \ldots$

Family Practice $\&$ Internal Medicine . . . . . . . . . . . 119

Physical Therapy \& Occupational Therapy ........... 119

Psychiatry and Social Services .................. 119

Emergency Department (ED) $\ldots \ldots \ldots \ldots \ldots \ldots \ldots \ldots \ldots$

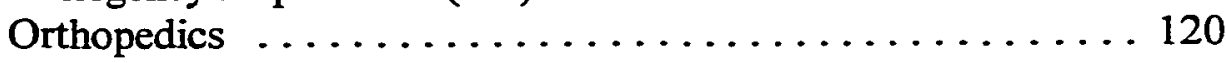

Ophthalmology \& Optometry ................. 120

Obstetrics \& Gynecology (OB/GYN) $\ldots \ldots \ldots \ldots \ldots \ldots 120$

Dermatology . . . . . . . . . . . . . . . . . 121

Neurology \& Neurosurgery . . . . . . . . . . . . . 121

Physical Medicine and Rehabilitation (PM\&R) . . . . . . 121

Chemical Dependency and Recovery Program (CDRP) . . . . 122

Annualized Doctor Office Visits (DOVs) $\ldots \ldots \ldots \ldots \ldots \ldots \ldots \ldots .122$

Opioid Medications . . . . . . . . . . . . . . . . . . 123

Prescriptions and Doctor Office Visits $\ldots \ldots \ldots \ldots \ldots \ldots \ldots \ldots \ldots \ldots$

Questionnaires \& Outcome Data ................. 130

Can MPI Help Predict the Number of DOVs? . . . . . . . . . 131

Opioid Medication and the MPI ................... 131

Chemical Dependency Visits and Opioid Medications ........ 132

CHAPTER 5 - Discussion

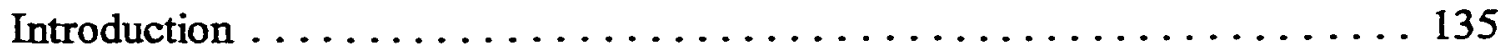

Presentation of Results . . . . . . . . . . . . . . . . . . . . . 135

Research Questions $\ldots \ldots \ldots \ldots \ldots \ldots \ldots \ldots \ldots \ldots \ldots \ldots \ldots \ldots \ldots \ldots$

vii 
Outcome Data and the MPI .................... 149

Prescription Pain Medications and Outcomes ............ 152

Eleven Point Box Scale $\ldots \ldots \ldots \ldots \ldots \ldots \ldots \ldots \ldots \ldots \ldots \ldots \ldots$

Review of Stakeholders $\ldots \ldots \ldots \ldots \ldots \ldots \ldots \ldots \ldots \ldots \ldots \ldots$

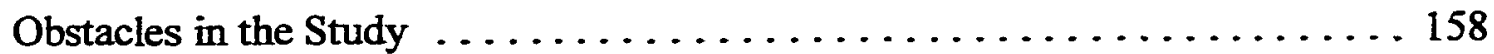

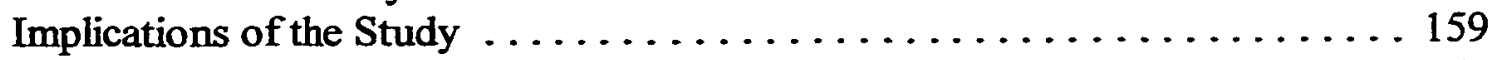

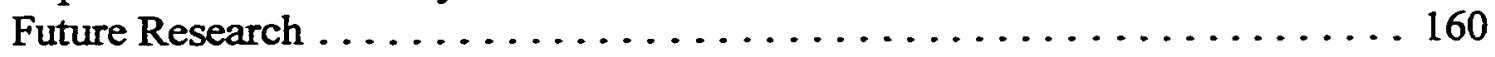

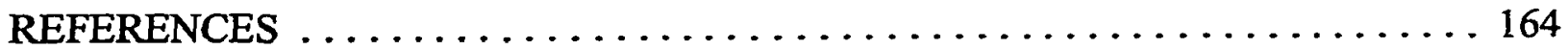

viii 


\section{TABLE OF TABLES}

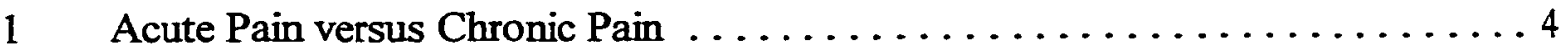

2 The Breakdown of MPI Parts and Scales ................... 49

3 MPI Cluster Comparison . . . . . . . . . . . . . . . . . . . . . . 51

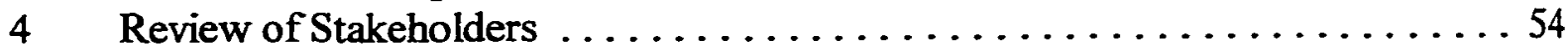

5 Profiles of Populations in Chronic Pain Research ................ 56

$6 \quad$ Pain Management Program Outline $\ldots \ldots \ldots \ldots \ldots \ldots \ldots \ldots \ldots \ldots \ldots \ldots \ldots$

7 Available Variables (Factors) and Their Attributes . . . . . . . . . . . . . 69

8 Utilization Data from January 1, 1994 to August 31, $1997 \ldots \ldots \ldots \ldots$. . . . 80

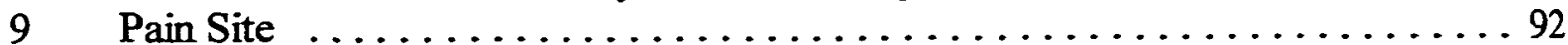

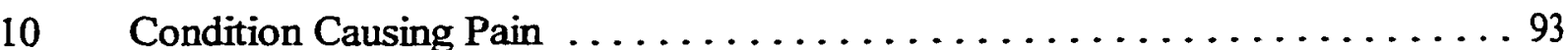

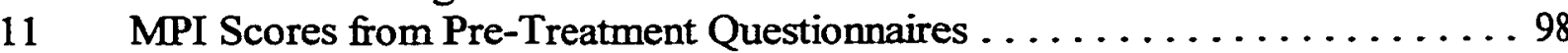

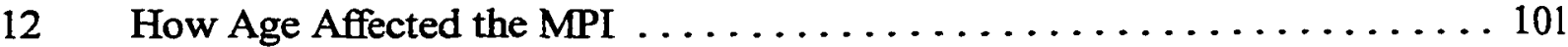

13 Comparison of the PDS with the 11 Point Box Scale $\ldots \ldots \ldots \ldots \ldots \ldots 102$

14 Interference Scale and the 11 Point Box Scale $\ldots \ldots \ldots \ldots \ldots \ldots \ldots . . \ldots 4$

15 Comparison for Scales on the MPI . . . . . . . . . . . . . . . . . 110

16 Summary of DOVs by Department ..................... 114

17 Analysis of Medical Services used by Chronic Pain Patients . . . . . . . . 116

$18 \quad$ Gender and Age by Department ......................... 117

19 Summary of Utilization Group DOVs . . . . . . . . . . . . . . . 123

20 Class II and Class III Medications Dispensed through the HMO Pharmacy ... 125

21 The Profile of a Typical Chronic Pain Patient ................. 138

22 Data and Calculated $\chi^{2}$ Test for Frequency of Gender by Work Status . . . . 140

23 Association between Work Status and Age .................. 141

24 Difference in Reported Pain Levels by Program Attendance . . . . . . . . . . 143

25 Average Annual DOVs by Program Attendance ................. 144

26 Associations Between Gender and the MPI ................ 150 


\section{TABLE OF FIGURES}

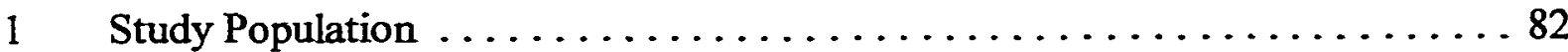

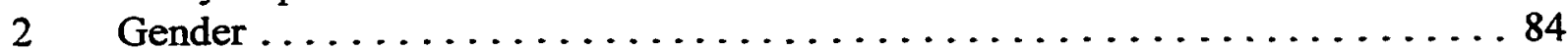

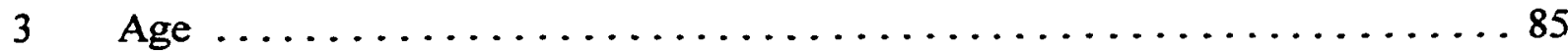

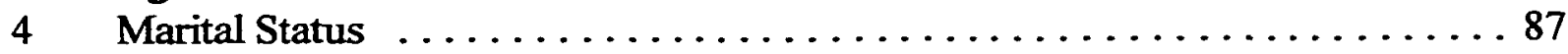

$5 \quad$ With Whom are You Currently Living? $\ldots \ldots \ldots \ldots \ldots \ldots \ldots \ldots \ldots$

$6 \quad$ Educational Level $\ldots \ldots \ldots \ldots \ldots \ldots \ldots \ldots \ldots \ldots \ldots \ldots \ldots$

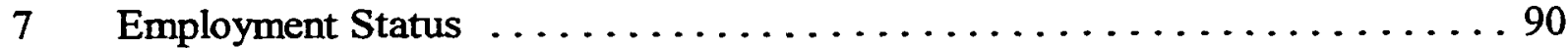

8 Years in Pain ..................................... 91

$9 \quad$ Eleven Point Box Scale .............................. 94

10 Pain Affect as Measured by the PDS $\ldots \ldots \ldots \ldots \ldots \ldots \ldots \ldots \ldots \ldots$

11 Sexual Activity . ................................ 97

12 Referred Patient Outcomes ............................ 106

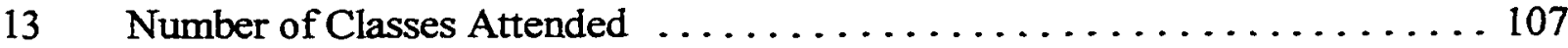

14 Eleven Point Box Scale (Post-Treatment) . . . . . . . . . . . . . . 108

15 Comparison of Pre-Treatment and Post-Treatment 11 Point Box Scale . . . . 109

16 Class II and Class III Drugs Dispensed . . . . . . . . . . . . . . . 127 


\section{LIST OF APPENDICES}

Appendix A: Pre-treatment Questionnaire $\ldots \ldots \ldots \ldots \ldots \ldots \ldots \ldots \ldots \ldots \ldots$

Appendix B: Post-treatment Survey . . . . . . . . . . . . . . . . . 180 


\begin{abstract}
A Student's Prayer
Now I lay me down to rest, I pray the Lord I pass this test. If I should die before I wake, It's one less test I'll have to take.
\end{abstract}

Anon. 


\section{CHAPTER 1}

The Problem

\section{Statement of the Problem}

Pain is essential to basic life, an instinct of one's self-preservation. Without pain, many species simply could not survive. In rare instances, people are born with congenital indifference to pain, a disorder where one does not possess the ability to feel pain despite being healthy in every other way. For them, life is short and full of disorder because the pain they do not feel acts as an early warning system, there is no system to alert them to withdraw from noxious substances or situations.

Conversely, chronic pain in America has reached epidemic proportions. By the early 1990s, people identified as chronic pain sufferers reached an estimated 11 percent of all adults ( 50 million disabled by pain), with acute pain adding another 5 percent (Sheridan, 1992). By the mid-1990s, the population of chronic pain patients increased to an estimated 90 million Americans with the annual cost of pain treatment at $\$ 125$ billion (Turk \& Okifuji, 1998). Chronic pain not only drains our financial resources, but our spiritual and social resources as well.

Great successes in medical science have lengthened our expected life span. However, the very science that increases our life expectancy has failed 'to cure the pains of medically produced old age" (Tyrer, 1992, p. ix). Our diverse culture no longer enforces that we endure pain in silence. 
Since we experience pain internally, we know the sensation only as we individually interpret that sensation. We consider this subjective information because the only one having access to the experience is the person reporting the pain. With indisputable findings (e.g., X-rays, laboratory tests, or the appearance of a physical abnormality), we may understand the cause and appreciate the possible intensity of pain. Using a positivist ontology, the presence of any physical evidence makes the reported pain believable to others, since positivists only acknowledge that which is tangible. Therefore, "patients who do not have lesions but do have pain are liable to be considered as not genuine" (Merskey, 1990, p. 11).

A singular, comprehensive definition of pain has yet to be established. In 1979, the International Association for the Study of Pain (IASP) offered the following definition: "An unpleasant sensory and emotional experience associated with actual or potential tissue damage, or described in terms of such damage" (Morris, 1991, p.16).

Interestingly, Merriam-Webster (1991) defined pain first as "punishment." Only in the second definition is pain described as "usu. localized physical suffering associated with bodily disorder (as a disease or an injury)" (p. 846).

The American Pain Society (APS) emphasizes that the patient is an integral part of the pain assessment. "Pain is always subjective ... The clinician must accept the patient's report of pain" (Laskin, 1998, p. 207). 
According to Donovan, Evers, Jacobs, and Mandelblatt (1999), the notions about chronic pain before APA's guidelines included:

- Chronic pain is a behavior that is learned.

- Opioid medications should not be used; patients will become addicted to pain medications; doctors risk losing their medical license if they prescribe narcotics.

- Psychological tests are needed to discover if the pain is real.

- Nobody ever died of pain.

- Chronic pain patients just need to learn to live with the pain.

Nursing scholar Margo McCaffrey describes pain as "whatever the patient says it is, existing whenever the patient says it does" (Laskin, 1998, p. 207). This definition, while criticized by some as nonscientific (i.e., not positivistic), reveals how much we have to learn about pain, both chronic and acute.

The problem with these and other definitions of pain and chronic pain is that they fail to encompass the complex interrelationship among the physical, emotional, social and causal factors affecting those with long-term painful conditions. While these definitions are a beginning, medicine is far from understanding the total implications and inner workings of pain.

When health professionals train to combat disease and disorder under the Western medical model, their focus is treating acute pain. On the surface, one might assume that acute pain treatment regimens work for all types of pain. Not so, according to Laskin (1998), who summarizes the differences between acute and chronic pain in the Table 1: 
Table 1

Acute Pain versus Chronic Pain

\begin{tabular}{|l|l|l|}
\hline \multicolumn{1}{|c|}{ Acute } & \multicolumn{1}{|c|}{ Chronic } \\
\hline Time span & Less than six months & More than six months \\
\hline Location & $\begin{array}{l}\text { Localized, associated with a } \\
\text { specific injury }\end{array}$ & Difficult to pinpoint \\
\hline $\begin{array}{l}\text { Physiologic } \\
\text { signs }\end{array}$ & $\begin{array}{l}\text { Often described as sharp, } \\
\text { diminishes as healing occurs }\end{array}$ & $\begin{array}{l}\text { Elevated heart rate } \\
\text { Elevated blood pressure } \\
\text { Elevated respirations } \\
\text { and aching } \\
\text { Dilated pupils }\end{array}$ \\
\hline Behavioral signs & $\begin{array}{l}\text { Crying and moaning } \\
\text { Rubbing site } \\
\text { Guarding } \\
\text { Frowning } \\
\text { Grimacing } \\
\text { Complaints of pain }\end{array}$ & $\begin{array}{l}\text { Normal vital signs } \\
\text { No diaphoresis } \\
\text { May have loss of weight }\end{array}$ \\
\hline
\end{tabular}

Note. From Pain Management (p. 208), by M. E. A. Laskin, 1998, Albany: Delmar. Copyright 1998 by Delmar Publishers. Reprinted with permission of the author.

No matter the definition or characteristics, patients want medical science to eradicate pain and suffering. Suspecting that a cure may not be possible, providers want their patients to self-manage pain with the least medical intervention and cost. The price of managing chronic pain patients far exceeds that of the general population. One HMO in the Pacific Northwest estimates that chronic pain patients have twice the inpatient (hospitalization) days and three times the outpatient (medical office) visits per capita when compared to patients without a chronic pain disorder (Donovan, 1999). Most health care systems offer a one-size-fits-all model for a variety of illnesses, injuries and medical 
mysteries causing chronic pain. As managed care becomes our primary source of medical treatment, we must balance the health care offered to maintain a certain quality-of-life standard with the financial well-being of the service institution.

Since most patients do not die of a chronic pain condition, the allocation of limited resources creates three ethical dilemmas. First, at what point ought we try more expensive treatments when the anticipated positive outcomes are unknown or are less likely to resolve the condition? To wit, when does the cost of treatment outweigh the expected benefits?

Second, how should we rank resources for chronic pain treatment with the multitude of other medical maladies? Accordingly, who receives treatment when complex patients and their specialists compete for the same resources? Liver transplantation illustrates this dilemma. The population of patients awaiting transplantation may include, but not be limited to: (a) those who can pay for the services, but unresolved addictive behavior created their condition, (b) those who have something to contribute to our society, and (c) those most likely to recover and lead normal lives but who cannot pay for the operation or subsequent medications. If only one liver is available for the three hypothetical patients, who chooses the recipient and how are those decisions mediated?

Third, at what level of suffering or disability ought pain be considered tolerable? At what point are patients expected to live with their condition? Similarly, which stakeholders should possess the power to decide? 


\section{Background of the Problem}

The difference between acute pain and chronic pain is not standardized. Clearly, acute pain signals tissue damage, warns the body of harm, and usually requires some form of medical attention and rest (e.g., sprained muscle, broken bone, heart attack). However, the sensation of chronic pain attaches no such meaning; pain is present but disuse may even aggravate the condition. "In many textbooks, the major distinguishing characteristic is time, that is, chronic pain is said to persist six months or longer" (Karoly \& Jensen, 1987). Using IASP guidelines, Bates (1996) reports that three months may be the dividing line between acute and chronic pain. Further, she cites chronic pain as having "persisted past the expected normal time of healing and that failed to respond to usual forms of biomedical intervention" (p. 28). Merskey (1990) suggests that acute pain is primarily physical, where chronic pain is primarily psychological. Karoly and Jensen (1987) feel that "chronic pain sufferers ... are seldom expected to get better or function normally, in part because of the enormity of their encumbrances (presumed and actual) and partly as a result of the expense and marginal effectiveness of organized, professionally managed intervention programs" (p. 1).

The types of chronic pain conditions sent to pain management programs are as varied as the definition of pain itself. Categories include neurological pain (e.g., reflex sympathetic dystrophy, carpal tunnel syndrome, amputation stump pain, diabetic neuropathy), musculoskeletal pain (e.g., low back pain, arthritis), ischemic disorders (e.g., angina pectoris), and others, including dental pain, headache or migraine pain, temporal mandibular joint pain, and myofascial pain dysfunction (Karoly \& Jensen, 1987). 
Drug therapy is the traditional method of treating chronic pain. With increased litigation and public awareness in drug abuse, many physicians have become wary of prescribing inexpensive, opioid medications. Prolonged use is associated with addiction, although a major study conducted in 1980 on opioid (narcotic) prescription use showed that only four patients out of 12,000 became addicted to their pain medicine (Duerksen, 1992).

Although chronic pain touches many fields of medicine, family practitioners have the primary responsibility for care and referral. With daily news of medical miracles, patients demand a cure. While the caring physician tries many things, available tools and knowledge do little to provide relief.

With rapidly advancing technology, the need for more focused pain specialties emerged. Physician groups banded together to treat chronic pain patients aggressively. Specialities developed, such as Anesthesia with block therapies, Physical Medicine, Rheumatology, and Oncology. The results have led to the development of pain treatment centers, also known as multidisciplinary pain programs. Today, these programs, varying from two to eight weeks in length, include a comprehensive medical work-up, exercise, work hardening programs, biofeedback, relaxation, physical therapy, cognitive restructuring and a variety of other treatment modalities (Barkin, Lubenow, Bruehl, Husfeldt, Ivankovich, \& Barkin, 1996a). Centers are expensive, but offer relief to many. However, problems arise when patients return to their home environment. While the active patient receives the benefit of much attention and practices coping strategies under close 
supervision, the post-treatment world offers its own set of challenges (Tunks, Bellissimo, \& Roy, 1990).

Three treatment models are found today, depending upon the facility, the scope of a patient's disorder, and the pain pathology. The most basic model involves one medical provider, usually but not always a physician, offering a single modality or method of treatment (e.g., drug therapy, acupuncture). The next level, a pain center, incorporates the services of one or more physicians coupled with a psychology professional (e.g., cognitive-behavioral programs operating outpatient workshops using a psychological and educational approach to self-manage pain). The most elaborate programs, called comprehensive multidisciplinary pain centers, include an array of physicians and may be associated with a research institution. Here, professors, medical students, interns, and residents conduct research using multimodality treatments (Barkin, et al., 1996a). Presently, all types of pain programs are being scrutinized because of limited resources and the lack of research justifying the expense and effectiveness of any one treatment method. Multidisciplinary centers and cognitive-behavioral approaches appear to do a good job at managing pain, but have not shown significant, long-term effectiveness in the self-management of chronic pain. As the influence of managed care increases, facilities must regularly justify their costs and results. Without evidence of effectiveness and efficiency, pain programs are either terminated (i.e., in a health maintenance organization) or removed from lists of approved providers.

Unarguably, cost controls are important. However, the patient's need for screening, more refined diagnoses, tailored treatment plans, and a method to preserve 
health coverage must also receive high priority. Plan providers want to offer the best medical care to the most people at a competitive rate. While health care providers want to cut costs and reduce the need for high-cost specialties, they also need to maintain enrollment and patient satisfaction. Customer dissatisfaction and the unavailability of affordable coverage attract government attention, regulation, and legislation, ultimately to the point of socializing health care.

\section{Importance of the Study}

The medical costs associated with chronic pain far exceed those in the general population without pain. Some patients seek relief by using high cost multidisciplinary pain centers. While these programs enjoy high compliance and short-term effectiveness, over time patients often report pain levels similar to those without treatment. The health care industry must tackle this problem by offering cost efficient and effective treatment(s).

One-half of the information given to new doctors in today's medical school is outdated within five years. Continuing education and training are necessary expenses of modern health care. Also, more effective treatment will occur with a better understanding of pain (Brookoff, D., 1999a).

Patients want to be pain-free. Under the current medical model, many believe that doctors are responsible for pain management, can fix the problems associated with a chronic pain condition, or both. Shifting to a perspective where the patient discovers a self-fulfilling approach to his or her own pain management promises individual control over one's own quality of life. Families, friends, colleagues, the medical provider, and one's community all benefit from the patient's increased level of function and purpose. 
This study proposes to amass a data base for a large population of chronic pain patients. Not only does this study propose to look at various features and characteristics of pain patients, but also proposes to look at patients' ability to self-management chronic pain over time.

Both large and longitudinal projects are lacking in the study of chronic pain. This proposal provides an opportunity to explore both aspects of time and size and lend another perspective to this complex problem.

\section{Purpose of the Study.}

By studying one cognitive-behavioral pain management program and analyzing responses to an assessment questionnaire, I am seeking relationships, if any, from assessment information and program attendance. Also, by gathering post-treatment data on medical utilization and responses to a similar but briefer assessment questionnaire, I will study long-term trends in the ability to self-manage chronic pain. Some indicators from a patient's perspective might be: reported lower levels of pain, increased activity, or both. From a provider's point of view, a patient's ability to self-manage chronic pain may be seen in lower medical utilization, fewer surgeries, and a decrease in the cost of pain related services. By unifying the micro and macro issues, patients and providers may discover an interdependence between the needs of patients and the duties of the medical community, uncovering a policy perspective to help resolve the crisis in treating chronic pain in America. 


\section{$\underline{\text { Research Questions }}$}

What was the profile of patients referred to the Pain Management Program and how does that profile compare with the research literature on chronic pain? Eighteen hundred thirty-two of 2,561 patients referred to the Pain Management Program from August 1, 1991 to May 15, 1996 completed pre-treatment assessment questionnaires, including demographic information, plus responses to the West Haven-Yale Multidimensional Pain Inventory (MPI), the Pain Discomfort Scale (PDS), and the 11 Point Box Scale. Also, program attendance records for these patients were maintained. By establishing a data base of assessment questionnaires and corresponding attendance records, certain variables may present a profile to help understand the characteristics leading to program non-participation or dropout. If the patients in this pain program compare with the prevailing research on chronic pain populations, features of this group may be generalized for a better understanding of pain patients in other settings and may help uncover potential barriers to effective treatment. If the profile of this group differs from those previously studied or from the general population, then differences may help uncover characteristics and possible factors affecting patients referred to this pain management program. Analyzing a large patient population such as this provides a unique opportunity to contribute to an understanding of the factors that may influence the selfmanagement of chronic pain.

Does referral to or participation in the Pain Management Program influence a patient's ability to self-manage chronic pain? From the patient's perspective, can one measure the effectiveness of being referred to or participating in a pain management 
program? Using an abbreviated version of the pre-treatment assessment form, I will send surveys to the same set of patients. Pre-and post-treatment assessment values will be compared (e.g., the patient's sense of self-control, the patient's pain affect, the amount of physical activity), and differences may be discovered that demonstrate post-treatment progress. If the results are mixed, then possible relationships between individual factors and the ability to self-manage pain will be explored. The survey will also include questions measuring patient satisfaction and soliciting quality improvement needs.

\section{What is the economic impact of referring patzents to the Pain Management} Program, particularly the costs of and possible savirags to the medical provider? Using medical utilization records (e.g., the number and cost of visits to doctors' offices, the emergency room, and urgent care), how does the post-treatment use of medical services compare to pre-treatment utilization? If results are mīxed, then what relationships exist between economic outcomes and program participation, individual factors, or other characteristics? This study will look at various factors in chronic pain patients, including demographic information, coping styles, support systems, the ability to perform activities of daily living, and the levels of reported pain. The variations in these factors may influence one's medical needs and may indicate the level of medical attention demanded by the patient. Does referral to the Pain Management Program and/or a patient's participation in the program decrease those needs? 


\section{Assumptions Related to the Study}

- Because this site is a health maintenance organization (HMO), the provider conducts all medical treatment within the system and patients' charts record all visits.

- Chronic pain will remain a problem until we better understand the factors contributing to and retarding pain self-management.

- A variety of factors interrelate with the patients' pain experience and the medical management of that experience.

- The available data from one pain management program will reveal factors that influence how well patients as a whole self-manage chronic pain.

- If one can identify factors or characteristics that present barriers to self-managing chronic pain, then one can design interventions to improve a patient's ability to self-manage chronic pain.

\section{Limitations of the Study}

This study focuses on patients referred to a cognitive-behavioral pain management program in a Southern California HMO. The research subjects are those patients who have already received most, if not all, known standard medical treatments and do not present with major psychopathic problems. Physicians refer patients to the pain program after thorough medical evaluation, including referral to related specialities, and where patients have failed conventional treatments. Therefore, the only patients under study are those who, in their physicians' view, appear to have difficulty self-managing their own pain. This study does not include all chronic pain patients treated in the HMO, but only those who, 
Chronic Pain 14

in their provider's opinion, demonstrate difficulty with pain management and for whom no known medical cure exists. 
Chronic Pain 15

Pain is a more terrible lord of mankind than even death itself.

Albert Schweitzer

Reproduced with permission of the copyright owner. Further reproduction prohibited without permission. 


\section{CHAPTER 2 \\ Review of Literature \\ Introduction}

Since the beginning of time, the art of healing and the advent of medicine have uncovered astounding mysteries in understanding the complexities of the human body. With Hippocrates and the arrival of rational thought, the meaning of human suffering and disease were separated from the will of the gods or punishment for past evils. When physical evidence began supporting symptoms and physicians exercised mastery over certain disease processes, the science (rather than the art) of medicine gained a reputation for the ability to cure or control many afflictions.

As the result of that progress, however, medicine may have created a new set of disorders. Curing epidemic disease with immunization, successfully treating cancer with surgery, chemotherapy, and radiation, as well as managing a host of other life-shortening ailments have prolonged our lives, leaving open new systems of disease and breakdown of functions.

This chapter explores the evolution of health care as it pertains to chronic pain. A comprehensive examination of where chronic pain treatment is today, in addition to a multitude of factors that influence that treatment, will lay the foundation for understanding the complexities of this medical, psychological, social, and spiritual problem. Reviewing the roles of physicians and their patients, exploring medications and alternative therapies, 
and examining biological and non biological components in chronic pain, we may gain an understanding of how to assess and measure the quality and effectiveness of health care interventions. Chronic pain conditions require that patients and their providers negotiate a change process to improve both the quality of life and longevity. In using principles set forth by leadership scholars and knowledge from medical researchers, we may create opportunities for enhancing the well-being of chronic pain patients.

\section{Historical Perspective on the Problem}

In ancient times, people often interpreted pain as a message from the gods. Aristotle, "considered pain an emotion, like joy, whereas Descartes saw it as a sensation, like heat or cold" (Morris, 1991, p. 15). Asian thought suggests pain is the absence of harmony.

Hippocrates first steered Western medicine in the direction of rational thought. Separating disease from the supernatural, followers of Hippocrates developed models of scientific inquiry emphasizing a disease's tangible cause and cure. Today, medical examinations rely heavily on tactile and visual cues, patterns, and quantifiable laboratory tests. The physical aspect of the individual is isolated, almost surgically removed, from the psychological, social, and spiritual components that make up one's being.

The history of Western medicine shows little differentiation between chronic and acute pain. However, chronic pain is different from acute pain. In numerical terms, chronic pain is any painful condition lasting six months or more, whereas acute pain is of shorter duration and has a beginning and an end. In a biological sense, acute pain signals the incidence or increased harm of injury, but rest and reprieve can reverse the sensation of 
pain. Because the onset of acute pain has a well-defined proximal cause and is autonomically activated, the concentration on the physical self works well in healing acute (time-limited) injury and disease. On the other hand, chronic illnesses are long-term, meaningless, irreversible, persistent, often obscure, with autonomic adaptation and vegetative signs (Brookoff, 1999b). The word cure is not often used.

We may compare acute pain with a play performance where the patient plays a sick role of predetermined length. The patient is a mere observer and the actor is the pain. In the last scene, the pain predictably ends with either complete recovery or dramatic death. With chronic pain, the patient's part is not as the audience, but as the star character. The performer is married to the pain, which constantly interferes with the actor's other demanding roles (Good, Brodwin, Good, \& Kleinman, 1992).

While Western medicine has made remarkable advances in the quality and longevity of human existence, chronic pain has not responded well to the mechanistic models of modernist thought. Different pain treatment regimens are currently in place using a variety of time-honored and research-supported techniques. Multidisciplinary programs are enhanced medical models, typically combining the fields of anesthesiology, psychology, physical medicine, and family practice. Cognitive-behavioral programs work to improve function while ignoring or working through the pain sensation. Techniques outside Western medicine, such as acupuncture, acupressure, chiropractic, herbal remedies, massage, and mind-body-spirit connections, are slowly gaining respect by patients and some medical practitioners. 
In the present Western medical model, the role of the physician is to treat the acute injury while the patient endures the chronic condition. Arthur Kleinman (1988) labeled these notions sickness and disease. "(S)ickness (is) the understanding of a disorder in its generic sense across a population in relation to macrosocial (economic, political, institutional) forces" (p. 6). Sickness is what the patient experiences. "Disease, however, is what the practitioner creates in the recasting of illness in terms of theories of disorder" ( $p$. 5). Disease is central to treatment, but by concentrating solely on the biological component, the practitioner treats the patient for only a fraction of the sickness.

By ignoring the larger part of sickness, chronic conditions serve no purpose in the medical establishment. The scientific community assumes a positivistic stance where every symptom must have a tangible explanation. The disease itself becomes suspect when it defies rational thought. In positivism, if no tangible evidence exists explaining the cause and level of pain, then the pain must not be real. If the suffering accompanying an illness has no explanation in Western medicine, it holds no meaning. Since American culture is based on rational thought and mastery over nature, the failing of science to cure or explain chronic pain leaves the patient with little hope.

To find meaning in chronic pain, one must question one's own existence, as chronic conditions influence many areas that form one's identity. Viktor Frankl (1985) spent considerable time contemplating the meaning of life and suffering during and after his experiences in Nazi concentration camps. One problem, as he quoted Edith WeisskopfJoelson, is that our culture views happiness as the meaning of life. "(O)ur current mentalhygiene philosophy stresses the idea that people ought to be happy, that unhappiness is a 
symptom of maladjustment. Such a value system might be responsible for the fact that the burden of unavoidable unhappiness is increased by unhappiness about being unhappy" (p. 136). Suffering and unhappiness are the inevitable, opposing forces to happiness. This tension between adverse powers creates options, albeit difficult or unpleasant ones. These new, difficult choices generate opportunities to develop moral values and beliefs. According to Frankl, the key to a successful life is therefore not dependent upon achieving happiness, but in finding meaning in one's suffering.

Much of Western medicine proves effective in short-lived (acute) conditions while Eastern medicine enjoys a reputation for its long-term emphasis on health and harmony. Eastern philosophy concentrates on achieving balance, believing that equilibrium is the key to wellness. "(B)odily complaints are also moral problems: They are icons of disharmonies in social relationships and in the cultural ethos" (Kleinman, 1988, p. 12). By successfully treating physical, psychological, social, and spiritual components, health and wellness follow.

Morris (1991) described a study by Mark Zborowski that looked at responses to pain by various ethnic groups. Zborowski noted that ethnic origin predicated the verbalization of pain (e.g., Jews and Italians being expressive, Irish and Old Americans being silent and stoic). Also, one's social class influenced the assignment of meaning to pain, with lower classes interpreting pain as a threat to one's job and financial security. Zborowski deduced 'People responded to their pain not only as individuals, but also as Italians, Jews, Negroes, or Nordics" (Morris, 1991, p. 52). 
One cannot overlook the social structure of various cultures. In most cultures, the extended family assumes the financial and physical maintenance of those who suffer from most chronic conditions. In the United States, chronic ailments often lead to job loss, massive medical bills, disability claims, lawsuits, and welfare. If the family fails to support its suffering members, then the larger community (i.e., American society) must grapple with the ethics of what ought to be done to support the individual. When individualistic, privately-funded health and disability coverages become inadequate, sufferers expect a caring society to provide at least subsistence-level support.

The evolution of America's management of chronic pain is relatively short. In this chapter, we explore chronic pain treatment and those who provide care. As important as the medical interventions themselves, the support mechanisms that address the psychological, social, spiritual, and financial aspects of pain are investigated. Also, the increased emphasis on individualism as a cultural value in the United States affects the role of science and societal support.

A review of the more common assessment measurements for diagnosis and treatment helps us understand how our society, including the scientific community, views chronic pain. Finally, as with any research document incorporating leadership studies, the role of leadership and the ability to influence change also will be scrutinized.

\section{What is Pain?}

Before discussing how to treat pain, a rationale of how pain occurs under the Western medical model is needed. Today, the most commonly accepted model of pain is the gate control theory. 
In 1965, Patrick Wall and Ronald Melzack proposed a simplified explanation of how the body perceives pain (Laskin, 1998). Melzack \& Wall believed that nerve impulses descend from the brain to the spine (motivational-affective and cognitive components), as well as ascend from the extremities to the spine (sensory components). At the convergence of these nerve fibers in the dorsal horn of the spine, a gate-like mechanism directed pain messages, causing certain communications to be sent to the cerebral cortex for interpretation (perception). "So many nerve cells converging in one place creates [sic] something of a bottleneck, like a toll booth on an expressway, profoundly affecting the perception of pain. Some messages have to wait to get through, while others may not get through at all" (Brand \& Yancy, 1988, pp. 70-71). Instead of the simple cause-and-effect pain model introduced some three centuries early by Descartes, this new model explains why, in some circumstances, people have a heightened sense of pain (e.g., anticipating a heart attack), while the same people also display remarkable pain tolerances (e.g., running away from danger with a broken leg). When the pain gate is open, the pain sensation (i.e., sensory, cognitive, and/or motivational-affective messages) gets through to the brain. If the gate is closed, no pain message is received.

Since chronic pain has no meaning (e.g., does not signal further tissue damage), an effective model of alleviating chronic pain would need to interfere with the pain messages at some point along the conduction path. Four known steps to create or advance pain impulses are transduction, transmission, perception, and modulation (Laskin, 1998).

The transduction phase occurs in the periphery, the noxious site where pain originates. Here, two types of nerve fibers transmit signals. Imagine a paper cut. The first 
pain sensation is from the A-delta fibers and feels sharp and stabbing. The specific location of pain is clear in one's mind. Because A-delta nerve fibers have myelinated (insulated) sheaths, the pain impulse travels rapidly to the brain. Soon after, the C-nociceptors (unmyelinated sheaths) send signals of diffuse, deep aching pain. A-delta pain is typically associated with acute pain, while $\mathrm{C}$-nociceptive messages are more aligned with chronic pain.

Pain is electrochemically transmitted along afferent nerve fibers to the spine. In the transmission phase, chemicals called neuropeptides (including substance $P$ ) are released from the nerve endings, travel across the synaptic gap, and attach to pain receptors in the spinal cord. When this transmission is complete, pain impulses are received in the thalamus of the brain.

Perception, or the subjective sense of pain, is interpreted by how the thalamus transmits nociceptive messages to the cortex of the brain. The pain impulse "terminates in two areas in the parietal lobe: the somatosensory cortex (associated with the intensity and quality of pain), and the association cortex (associated with affective types of pain). The signal also terminates in the limbic system (associated with anxiety)" (Laskin, 1998, p. 210).

Once pain is perceived, the brain can modulate the pain signals by releasing chemicals such as serotonin, norepinephrine, and endorphins. These substances "bind to the afferent neuron and prevent the release of substance $P^{\prime \prime}(p .210)$, thereby inhibiting the transmission of nociceptive pain. 
Organic, psychosocial, and functional processes combine to form the pain experience. Each is an element of the whole patient and needs to be evaluated accordingly. The impact on pain perception also includes how a patient physically expresses pain (pain behavior) and the level of distress (suffering) that accompanies pain. Organic evaluations (physical exam and lab work) approximate but do not directly measure symptoms or function. For example, $85 \%$ of patients complaining of low back pain have no organic explanation for the pain. "By contrast, measures to assess a patient's functional status can quantify symptoms, function, and behavior more directly" (Turk \& Okifuji, 1999, p. 1786).

Pain behavior is the outward body language of pain. Initially, behaviors such as limping or grimacing serve as warnings and protect a person from further injury. If that body language is reinforced by the environment (e.g., more attention, avoidance of unpleasant activity), then its adoption as a habitual pattern may elicit positive reinforcement, with or without the pain. Unlike malingering, which is the "conscious and purposeful faking of a symptom to achieve some benefit, usually financial," (p. 1786), pain behaviors are unconscious and unintended but influence pain and evoke positive social support. Interestingly, pain behavior is the most predictive factor in whether an Administrative Law judge grants disability under the Social Security Act. If applicants look like they are in pain, then they must be in pain (Turk, 1999).

Suffering is the degree of distress accompanying events because of the threat or perception of a threat to one's identity and purpose. "Patients with pain are at risk of suffering because the effect of pain on functional ability puts their physical, psychological, 
occupational, and social integrity in jeopardy" (Turk, et. al., 1999, p. 1785). Once recognized and addressed, usually through a cognitive-behavioral approach, a patient may learn to lessen suffering, therefore reducing the perception of pain.

\section{The Physician's Role}

Organized medicine in the United States may also be called scientific medicine. This form of treatment revolves around "the established body of conventional, orthodox or mainstream knowledge . . based on standard methods of prevention, diagnosis and treatment. New treatments undergo extensive review involving medical schools, research centers, professional organizations and their journals, and regulatory offices of the government" (Mayo Foundation, 1998, p. 2). Medical providers assess and treat their patients using established medical techniques and therapies. The antithesis of scientific medicine is quackery, or the selling of treatments proven to be worthless.

Often, those with chronic pain disorders are labeled difficult patients. When standard medical interventions prove ineffective, the practitioner may blame the patient. At these times, the patient is described as noncompliant, complaining about fees, coverage, outcomes, or the access to specialty physicians or treatment programs. Often, the medical chart notes these patients as angry, cranky, too independent (or too submissive). Talarico (1998) explains that the difficulty probably lies in the communication between the doctor and the patient. When health care providers are aware of their own emotional triggers, then those providers will not be "misled by their own idiosyncratic responses to people who "push their buttons"' (p. 168). 
Lowenhaupt (1998) suggests that a "more effective management of difficult patients comes from identifying and dealing with . . . the underlying drivers of difficult behaviors" (p. 29). Instead of focusing solely on the biological aspect of pain, physicians need to understand the social, financial, and personal characteristics of their patients. In building a trusting relationship with patients, the emphasis of a partnership approach (physician-patient) gives the individual personal responsibility for and direct involvement in one's own care. Another important factor is discovering the patients' expectations and developing mutually acceptable and reasonable goals.

Suggested methods of care must take into account medical insurance coverage and uninsured/uncovered treatments. This does not to suggest that treatment should be withheld for lack of insurance, but rather that compliance to a treatment regimen also relies on the affordability of that plan. Writing prescriptions is no assurance of compliance when a patient simply cannot afford to buy the medications. "Reassure patients that whatever the financial model of their plan ... (they will receive) good care and that cost will never be the primary driver of care" (Lowenhaupt, 1998, p. 30).

The physician must also assume the roles of educator and cheerleader, giving patients the tools and confidence needed to manage their own disorder successfully. If difficult behavior lies in psychological, social, or financial problems, the physician can provide an important service by directing and encouraging patients to seek assistance within a variety of programs. 


\section{Primary Care}

Also known as family practice, general practice, internal medicine, and sometimes gynecology, primary care physicians act as the gatekeepers of a patient's overall care. As generalists, primary care providers view their patients as whole systems, seeking out patterns of symptoms to identify specific disease processes. Common disorders are diagnosed and treated completely under the purview of primary care services.

\section{Secondary Care}

When diseases and disorders become complex enough to require extensive specialized medical training, the primary care provider refers the patient to others who have concentrated their studies and practice to specific biological and/or psychological processes. For patients with chronic pain, these secondary care providers may include the following disciplines: Anesthesiology, rheumatology, physical medicine, neurology, psychology/psychiatry, orthopaedics, oncology, occupational medicine, and physical therapy.

The outcomes of secondary care referrals are twofold: first to diagnose the disease or disorder, and second to put effective treatment into place. Often, when patients are stabilized on a treatment regimen, they then return to the primary care provider for the routine care of that disorder. Return to specialists may be limited to annual visits and unforseen complications between follow-ups.

\section{Pain Treatment Facilities}

Shortly after World War II, anesthesiologists recognized the need for specialized clinics to deliver anesthesia block therapies to those with pain. This method of treatment, 
while effective for specific disorders or patients, did not serve the general pain population adequately (Turk \& Okifuji, 1998). Soon, other specialty pain programs arose offering a variety of single modalities or a combination of therapies.

In 1973, the International Association for the Study of Pain (IASP) was founded. One of IASP's tasks was creating a definition of pain that would gain universal acceptance for scientific research (Morris, 1991). Also, IASP sets the standards for the delivery of multidisciplinary pain treatment.

The IASP defines a pain treatment facility as "A generic term used to describe all forms of pain treatment facilities without regard to personnel involved or types of patients served" (IASP, 1999, p. 1). Using this definition, a variety of pain services could qualify as a pain treatment facility.

\section{Modality-oriented Clinic}

In pain management's infancy, as well as today, modality-oriented clinics offer services based on a particular theory of treatment. Often a sole practitioner or a singlediscipline group, this type of facility offers a regimen based on one discipline (e.g., anesthesia, physical medicine, chiropractic, or cognitive-behavioral) rather than a comprehensive assessment and/or management of pain patients.

\section{Pain Clinic}

Some pain centers concentrate their practice to the treatment of a specific diagnosis or to a certain part of the body. Called pain clinics, they may specialize in any one of many common disorders (e.g., headaches, back pain). A pain clinic employs a group of specially trained individuals, not just one practitioner. While assessment in a pain 
clinic is not interdisciplinary, at least three different specialities or disciplines of providers interact with each other to provide diagnostic and therapeutic treatment. One of the providers present must be either a psychiatrist or clinical psychologist. Patients are typically treated for a specific length of time depending upon the disorder and pain severity, but all are eventually discharged back to the primary care physician for management with periodic follow-up (IASP, 1999).

\section{Multidisciplinary Pain Clinic}

Because pain is a complex phenomenon, evaluation and treatment must stem from a variety of medical disciplines. A multidisciplinary pain clinic is "staffed by physicians of different specialties and other non-physician health care providers who specialize in the diagnosis and management of patients with chronic pain" (IASP, 1999, p. 2). Enough specialties need to be incorporated, including a psychiatrist or clinical psychologist, to ensure a thorough evaluation of the physical and psychosocial components of chronic pain.

Joined in one setting, with both inpatient and outpatient clienteles, multidisciplinary pain clinics enjoy the most success in controlling pain. "Although no official statistics exist, physicians' associations count as many as 1,200 pain care clinics or centers in the United States, some 3,000 physicians who focus their practices on pain management, and more than 6,000 pain management specialists and administrators" (Valigra, 1998, p.33). Here, heterogeneous populations of pain patients are treated using the multidisciplinary approach, which may include specialty physicians, education, physical and/or occupational therapy, psychologists, anaesthetic pain blocks, and surgery. 
"There is no standard treatment protocol or specified set of clinicians who make up the treatment team" (Turk \& Okifuji, 1998, p. 185). As such, the efficacy and efficiency of multidisciplinary pain clinics are difficult to assess. In the end, the one common goal is that patients are capable of self-managing their pain.

\section{$\underline{\text { Multidisciplinary Pain Center }}$}

Multidisciplinary pain centers provide all of the services offered in multidisciplinary pain clinics. In addition, these centers incorporate research, employ basic scientists, and provide educational opportunities to teach the latest skills and theories to health professionals, and advance the understanding of pain to pain specialists and other health care providers. Multidisciplinary pain centers are usually associated with major health institutions, medical schools, and research universities.

The cost of multidisciplinary treatment is expensive, an estimated $\$ 8,100$ per patient (Turk \& Okifuji, 1998). Yet so are standard treatments, including surgery. Interestingly, third party payers are more likely to spend an average of $\$ 15,000$ per surgery to treat low back pain than to refer a patient for multidisclipinary treatment. Over time, "only $17 \%$ of surgical patients viewed themselves as improved compared with $38 \%$ of the nonsurgically-treated patients" (p. 189) with low back pain.

\section{Cognitive-Behavioral Pain Management}

Because this study focuses on patients referred to a cognitive-behavioral pain management program, further exploration of this type of modality-oriented clinic warrants a closer look. First, I will review the cognitive-behavioral therapy model and why cognition and behavior are important components of pain relief. Then, a review of the 
paradigm for the Pain Management Program should reveal similarities and differences in this model of therapy.

\section{Cognitive-Behavioral Model}

Cognitive therapy is "a treatment method that focuses on revising a person's maladaptive processes of thinking, perceptions, attitudes and beliefs." Behavioral therapy is "a form of psychotherapy that focuses on modifying observable problematic behaviors by systematic manipulation of the environment" (Depression Guideline Panel, 1993, p. 149). In psychotherapy, cognitive-behavioral approaches are characterized by active leader involvement (i.e., a therapist) in teaching and directing preset topics and activities. Participants must also be active and are charged with applying the information and techniques to their own lives.

Cognitive-behavioral formats are also known as behavior therapy (see above), rational-emotive therapy (RET), and reality therapy. RET is characterized by a leader who points out faulty thinking, while participants challenge self-deprecating thoughts. How one thinks is the primary concern, more important than how one may feel (Corey, 1990).

Reality therapy focuses on the idea that human behavior is purposeful, where individuals choose how to react, dispelling the notion that behavior originates in the external environment. Also, total behavior consists of: 1) doing; 2) thinking; 3) feeling, and 4) physiology. Keeping with the here-and-now, total behovior is examined, rather than looking at the individual components as if they were separate from total behavior. As such, the leader emphasizes that participants must be responsible for how they live their lives. Also, the participants decide which changes they should make (Corey, 1990). 
Traditional cognitive-behavioral programs meet on a regular basis, (i.e., once or twice a week) and for a specific length of time (i.e., six to twelve weeks). Cognitivebehavioral therapy is often provided in a small group setting (i.e., ten to thirteen people), usually reducing the cost of participation and administration when compared with individual therapy. The same group size and duration applies to pain management programs as well.

To see how the cognitive-behavioral model meshes with pain management, we must understand how thought and behavior affect pain. Brand and Yancey, (1993), uses the term orphan sense when describing one's experience of pain. With other senses (e.g., smell, sight), we may gauge our own thoughts with what others observe. As an example, one's idea of a beautiful sunset may be shared, even enhanced, through communication and by living the experience with others. However, the pain one may feel with a broken arm is unique and will not be felt in the same way as someone else with a broken arm. "What takes place in a person's mind is the most important aspect of pain - and the most difficult to treat or even comprehend" (p. 203). Hence, cognitive-behavioral approaches look at the conversation in one's own head as a means of treating and understanding pain.

"The cognitive component of pain perception can have a powerful influence on the effectiveness of interventions" (Laskin, 1998, p. 214). How a patient thinks about pain dramatically affects the way one feels about pain. "Cognitive therapy helps patients identify negative thoughts and beliefs that may contribute to their perception of pain or ability to cope. Learning how to gain control over these thoughts and beliefs helps them reduce their pain and distress" (Robischon, 1998, p. 21). 
As much as pain sensation and cognition influence pain perception, how a patient behaves around pain is equally important. "Behavioral therapy helps modify their pain with new ways of behaving, identifying dysfunctional reactions to pain and stress in their everyday lives" (p. 21).

Coping skills are paramount in successfully managing chronic pain. Here, "coping refers to cognitive and behavioral responses to stressful events that strain a person's capacity to adjust" (Barkin, Lubenow, Bruehl, Husfeldt, Ivonkovich, \& Barkin, 1996b, p. 474). By learning and adapting to a new set of behaviors, patients may avoid or alter previously painful events. Also, those who positively cope with pain experience less depression, greater life satisfaction, more activity, and less disability than other patients. Cognitive-behavioral pain management programs, using the cognitive-behavior counseling model, consider the significant adjustments one must negotiate to function successfully in society. While most patients desire a return to their lives before chronic pain, the essential element in cognitive-behavioral pain management is developing new tools and life skills to negotiate life with chronic pain (Arbuthnott, 1994). Similar to cognitive-behavioral programs focusing on other psychological or counseling issues, pain management participants learn techniques to lessen pain sensation, including meditation, imaging, relaxation, and biofeedback. Emphasis is placed upon patients' assuming the responsibility for their own treatment with emphasis on developing a full, fulfilling, and functional life. Classes are usually taught by therapists, counselors, and health educators. 


\section{Pain Management Program}

The pain management program under study follows the basic components of cognitive-behavioral therapy:

- An intake questionnaire was completed by participants before being scheduled for a group.

- Meets once a week for two hours for eight weeks.

- Topics and activities follow a preplanned schedule.

- Presentations are leader-driven; participants must apply the information to their own situations.

- Participants commit to attending all sessions.

When looking at the fundamental purposes and presentation of the pain management program, one sees how these classes are patterned off a cognitive-behavioral model. However, some important differences exist in this study's pain management program that deviate from the traditional model:

- The program is funded and staffed by primary care without the involvement of psychiatrists, psychologists, or therapists.

- Classes are free of charge.

- All program participants have a comprehensive review of their medical chart summarized by program staff.

- Participants have phone access to and receive a phone consultation with the program physician/pain specialist.

- Class size varies from 20-35 participants. 
- Ongoing monthly support group meetings for program completers are facilitated by the director/physician and/or the coordinator/masters-level educator.

- Director/physician may prescribe pain-related medications to referred patients.

\section{Medications used in Chronic Pain Management}

Prescription and over-the-counter (OTC) analgesics are the most commonly used method to control chronic pain today. While pain medications are routinely dispensed, it is the very lack of understanding or knowledge about these analgesics that primarily causes the undertreatment of all types of pain.

Many factors determine how one responds to analgesic medications. Age, for example, influences how fast one metabolizes opioids; faster in young adulthood, slower as one gets older. One's response to various medications differs from another, especially in experiencing side effects.

As the body metabolizes medications, some analgesics become less effective over time. This progressive reduction in effectiveness is known as a tolerance and increased dosages are required to achieve the same level of relief. When the withdrawal of medication produces its own side effects, requiring one to taper the dose to discontinue (as opposed to stopping all at once), the term physical dependence is used. At some point, many drugs have a ceiling effect, or a point at which any increased dose will not produce a corresponding increase in pain relief.

Three classes of analgesic medications affect or interfere with different components of pain impulses. Categorized as nonsteroidals, opioids, and analgesic 
adjuvants, each group offers benefits, and side effects, when used alone or with other pain medications (Laskin, 1998).

\section{Nonsteroidals}

Nonsteroidals are analgesic medications used in treating mild to moderate pain. They work at the pain site by blocking the production of prostaglandin. Prostaglandin sensitizes the pain receptors in the peripheral nervous system, aiding in the transmission of pain messages to the spine. Without prostaglandin, sensory neurons are less likely to receive and transmit pain impulses.

Three types of nonsteroidal medications, mostly sold OTC, are used by millions of people each day for acute and chronic pain. The first group, salicylates (including aspirin), have both analgesic and anti-inflammatory agents. Acetaminophen (e.g., Tylenol®), has similar analgesic properties, but lacks the anti-inflammatory effect. The last group, nonsteroidal anti-inflammatory drugs (NSAIDs), vary in strength and effectiveness across the spectrum. Some (e.g., ibuprofen) are comparable to aspirin and acetaminophen, while other NSADs are much stronger and require a prescription.

The advantage of nonsteroidal medications is that the body does not build up a tolerance to or physical dependence upon the medication. Conversely, nonsteroidals have a ceiling effect. At some given dosage, additional pain relief is not achieved.

\section{Opioids}

Opioid medications (e.g., morphine derivatives) have been used routinely to treat severe acute pain and chronic cancer pain. Their use for severe chronic non-cancer (nonmalignant) pain, however, remains controversial. 
Opioids work throughout the central nervous system, particularly in the spine, and share a similar chemical shape as substance $P$. When opioids are introduced into the body, they bind to the pain receptor sites in the dorsal horn of the spine and prevent substance $\mathrm{P}$ from stimulating the spinothalamic nerve fibers, thereby blocking pain messages from the spine to the brain.

\section{Analgesic Adjuvants}

Adjuvants, while not true analgesic drugs, show analgesic properties when used alone or with other medications. For example, some anticonvulsants, anesthetics, and tricyclic antidepressants belp reduce neuropathic pain. While some adjuvants alter mood, others appear to potentiate opioids.

\section{Addiction and Physical Dependence}

Fear of addiction is the largest concern among medical practitioners, and it causes the prolonged undertreatment of both malignant and nonmalignant pain. The undertreatment of pain is conceivably a major factor to suicides, attempts of suicide, and the movement for physician-assisted suicides (Brookoff, 1999a). Although the incidence of addiction to opioid pain medications is extremely low in chronic pain patients, societal pressures for a War on Drugs, zero tolerance to drugs, FDA regulations, and the threat of litigation all contribute to physicians choosing to err on the side of caution (e.g., undertreating pain).

Often, the terms addiction and physical dependence are used interchangeably. Again, physical dependence will cause withdrawal symptoms when those medications are stopped. Hypertensive, thyroid, insulin, and corticoid medications, to name a few, cause 
the body to build up a physical dependence; to discontinue using them without discomfort, one must taper or wean off these drugs. But these drugs are hardly considered as having addictive potential.

"Addiction is defined as an overwhelming preoccupation with obtaining and using a drug for its psychic effects" (Laskin, 1998, p. 217). Addiction is a behavior, not a physical dependence or state of being. With addiction, one has lost control over drug use, is a compulsive drug user, and continues to use drugs despite knowledge of additional harm.

Brookoff (1999a) proposes behaviors commonly seen in a medical practice that may predict addictive behavior:

- Selling prescription drugs

- Stealing or borrowing drugs from others

- Injecting medications intended for oral use

- Obtaining prescription drugs from a non medical source

- Concurrent abuse of alcohol or use of illicit drugs

- Multiple dose escalations or other noncompliance with treatment despite warnings

- Seeking prescriptions from other physicians, urgent care, or emergency rooms without informing the prescriber or after warnings to stop

- Evidence of deterioration of function related to drug use

- Repeated resistance to changes in treatment despite adverse effects from the medication.

To the contrary, the following behaviors may be related to the undertreatment of pain: 
- $\quad$ Aggressive complaining about the need for more medicine

- Drug hoarding during periods of reduced symptoms

- $\quad$ Requesting specific medications

- Unsanctioned dose escalation or noncompliance on one or two occasions

- Unapproved use of the medication to treat another symptom

- $\quad$ Reporting psychic effects not intended by the physician

- Resistance to a change in treatment despite some side effects with anxiety about return of symptoms.

\section{Intractable Pain Treatment}

Up through the 1980s, physicians were (and still are) reluctant to prescribe opioid medication for severe chronic pain, being fearful of discipline, loss of license, and/or criminal prosecution. While the need to relieve cancer pain has received attention in the form of research dollars and compassion for its terminal prognosis, nonmalignant pain treatment with opioid medications strikes up images of addiction and secondary gain.

The conduct of physicians and other health care providers is regulated at the state level. No one law covers how and when to use opioid medications in all the United States. In 1990, the State of California enacted the Intractable Pain Treatment Act (similar laws have been enacted in other, but not all states). In Section 2241.5 of California's Business and Professions Code, this Act recognizes that "a physician and surgeon may prescribe or administer controlled substances to a person in the course of the physician's and surgeon's treatment of that person for a diagnosed condition causing intractable pain." Further, it 
defines intractable pain as "a pain state in which the cause of the pain cannot be removed or otherwise treated and which ... no relief or cure of the cause of the pain is possible ..."

Corresponding to the rights of physicians to prescribe opioid medications without fear of prosecution, California established a Pain Patient's Bill of Rights in October 1997 (Part 4.5, Section 124960, Division 106, Health and Safety Code). This act recognizes that the undertreatment of chronic pain poses a significant health problem and pain management may be the only source of relief. As such, "A patient who suffers from severe chronic intractable pain has the option to choose opiate medications to relieve (that) pain without first having to submit to an invasive medical procedure."

The Pain Patient's Bill of Rights does not require that physicians prescribe opioid medication. However, if he or she refuses, the physician must inform the patient that there are physicians and specialists who will.

\section{Euthanasia and Physician-Assisted Suicide (PAS)}

The debate surrounding euthanasia and PAS is nothing new. Twenty-four hundred years ago, Hippocrates incorporated into The Oath, "I will give no deadly medicine to any one if asked, nor suggest any such counsel." Then and now (at least in all states but Oregon), merely suggesting this course of action can be a cause for sanction (Lema \& Lema, 1998). The difference now is that medical technology is capable of artificially prolonging life. Unfortunately, the lag time between when that technology is introduced and when the ethical and moral values are debated and developed are years apart. 
What standard of care must physicians offer their patients, especially those who are terminal or in intractable pain? First is the generally undisputed theme that a patient has the right to reject unwanted treatments and interventions. Second, the patient has the right to relief from suffering. Neither of these tenets, however, supports an automatic rationale supporting PAS or euthanasia (Emanuel, L, 1998).

To address a patient's request for PAS, the underlying cause of the request must be investigated. Unfortunately, today's practitioners are not routinely trained in how to respond to these probes. Depression plays a large role in patient requests for PAS, however, it is essential to treat the depression rather than focus on hastening death. Also, PAS requests may point to treatment failure, beyond the scope of the practitioner's ability. Again, hastening death is no answer; patients must be referred to those with more specialized training.

Emanuel, Daniels, Fairclough, \& Clarridge (1998), propose that the following requirements exist, called primary safeguards, if PAS is legalized:

- The patient must be terminal (life expectancy of less than six months),

- The patient must be competent; must initiate, and repeatedly request PAS or euthanasia,

- The patient must have intractable pain and/or suffering, and

- The patient must be evaluated by another physician (preferably a psychiatrist). In the 1980s, public opinion in the United States favored zero tolerance with respect to drug use. Physicians prescribing too many pain medications faced formal disciplinary action and/or loss of medical licenses. In the 1990s, the pendulum began 
swinging in the opposite direction. For the first time in this nation's history, one state's medical board has taken disciplinary action against a physician for undertreating pain. The message being sent to the medical community is that, not only are sanctions in place when a practitioner causes death by over treating pain, but one must also not under treat that pain (Barnett, 1999).

Still, what is the difference between euthanasia and PAS? In looking at a patient who dies of a drug overdose (be it narcotics, barbiturates, or benzodiazepines), if the physician injected, or ordered an injection constituting a lethal dose, then euthanasia has taken place. On the other hand, if the patient dies of taking an overdose of prescribed medication, and the physician was aware of the patient's intent to overdose but prescribed them anyway, PAS has occurred. In euthanasia, the physician plays an active role in ending a patient's life. For PAS, the means of hastening death are provided (passively), but the action must be that of the patient.

A more important point, what is not euthanasia or PAS? Withholding lifesustaining measures such as food, antibiotics, or blood transfusions is neither euthanasia nor PAS. Nor is administering increased doses of opioids for pain control, even if doing so may shorten one's life (Emanuel, et. al., 1998).

By 1997, the United States Supreme Court ruled against sanctioning PAS. That same year, the Supreme Court also unanimously upheld the right for states to decide whether to prohibit or permit PAS. In 1998, the State of Oregon became the first and only state to legalize PAS, and only under certain circumstances. 


\section{Placebo effect}

Placebo is a Latin word meaning I shall please. Long associated in medical science as a pejorative term, placebos are considered medications or treatments given to patients even though those regimens possess no known, scientific explanation or documented activity causally related to cure. As opposed to quackery, the placebo does no harm, but possesses little or no explainable value.

Returning to Kleinman's (1988) definition of illness (i.e., disease, disorder) and sickness (i.e., suffering), we may understand how the placebo effect contributes to health and wellness. A health care provider in the western model of medicine concentrates on the biochemical and structural disease process while patients experience the biopsychosocial and spiritual aspects of sickness.

Lifestyle choices have a profound effect on the state of one's health. (Harvey \& Hoffmann, 1997). Not only do biochemical and structural changes influence health and wellness, but also how one reacts to the disorder, one's adherence to treatment regimens, and one's sense of control over the limiting effects of that disorder. However, one's subjective treatment experience, sometimes called the placebo effect, is as real as objective diagnostics, surgeries, and drug therapies.

"People seek medical consultation because they want symptom relief. But almost as important they want a label, an explanation for their symptoms" (Brown, June 1998, p 50). Responding to the complaint, if the patient feels a thorough examination is performed, that an understanding of the likely prognosis is achieved, and believes that something is being done, then a healing ritual has occurred. 
One research study after another has clearly demonstrated the power of a positive treatment experience. In a British study of 200 patients with nonspecific complaints, 100 were told that they should feel better in two weeks while the other 100 were told by doctors that they did not know what was wrong with them. After two weeks, $64 \%$ of the first group was better. Only $39 \%$ of the second group reported improvement (Brown, July 1998).

In a study of patients with nonspecific chest pain, 176 patients received an ECG and serum creatinine phosphokinase test. Outcomes were compared with similar patients where no tests were performed. Of those receiving testing, $80 \%$ of patients reported improvement. In patients who did not undergo testing, only $54 \%$ reported improvement (Brown, July 1998).

Of course, not all disorders respond equally well to a placebo, or positive healing ritual. Brown (June 1998) suggests that disorders that are both subjective and distress related (including mild hypertension, depression, anxiety, panic disorder, insomnia, allergies, and moderate pain) can benefit by the hopefulness and attention given in the therapeutic office visit. Chronic pain disorders also see improvement with a positive response to treatment (placebo effect): conditions such as arthritis, low back pain, and headaches.

Alternative medicine "offers the healing ingredients of the treatment situation: healing rituals and symbols, thorough evaluation, a healer's enthusiasm and commitment, encouragement, attention, positive regard, and high expectation for improvement" (Brown, June 1998, p 48). Before the arrival of managed care, most physicians had the 
time to listen to patients and provide these fundamental rituals. But today, in the name of efficiency, when the third, fourth, or fifth patient comes in with the same virus, the physician can recognize the cough upon entering the room, and dismisses any need for a physical exam. He or she then pronounces that nothing can be done, no medicine is given because it is a virus, and the patients should go home and rest (and the physician may forget to tell them that they should be better in four days). Fast visit, money saved, and more patients seen. However two days later, these same patients tend to show up in the more costly urgent care and emergency settings with the same complaints and demand an antibiotic (which can cause harm and does not provide any healing benefit for viruses). Patients then take their medicine and are better in two days. One wonders what would have happened if, in the first visit, the health care provider had taken a few minutes to listen to the patient, performed a healing ritual, and written down on a prescription pad some OTC medication with dosages to help relieve the symptoms? Perhaps those patients would have healed on their own in four days with less suffering, taking no unnecessary medications, and not returning for additional visits.

The opposite of the placebo effect is the nocebo effect. The placebo response is the optimistic reaction to a treatment situation. In the nocebo response, pessimism prevails. There are "three ways in which the nocebo effect is activated: (1) negative messages from the healthcare environment, (2) negative messages from the patient's social and psychological milieu, and (3) secondary gain" (Harvey \& Hoffman, 1997, p 34).

In both placebo and nocebo, the patient responds to his or her own belief or assessment of the presenting condition. The practitioner also has overt and covert 
expectations of the treatment outcome. In addition, the interaction or relationship between the person and the provider affects one's own perception.

From reviewing the literature, the placebo and nocebo may not be fakery, as some in medicine may believe. The effects of the psychosocial and spiritual components of healing are not easily measured. The value of one's sense of control, proactive rituals, and optimism is not understood. A ritual which does not fit the mold of a positivist ontology, one without a direct cause-and-effect outcome, that is not predictable or replicable, is nonetheless very real.

\section{Measurements to Assess Chronic Pain Patients}

At the dawn of any new scientific field, previously standardized testing for general use is tried on specific populations. Even today, the Minnesota Multiphasic Personality Inventory (MMPI), the Beck Depression Inventory, and the State-Trait Anxiety Inventory are popular instruments used and misused to assess the level of psychological distress in those with chronic pain. One problem is that, in spite of high internal and external validity, reliability, and extensive research justifying standardization, these tests were designed to diagnose potential psychological problems in normal, medically healthy populations. Targeting this assessment to the medically unhealthy violates the established external validity. For example, the MMPI, developed specifically for assessing psychopathology in psychiatric populations, fails to discriminate between "organic (and) psychogenic etiology of chronic pain (Etscheidt, Steger, \& Braverman, 1995, p 30). The 566 true/false personality questions are inordinately long and of questionable value, especially when compared with the 61-question MPI. 
Chronic pain, by itself, causes increased stress, uncertainty about the future, and even depression. Many feelings and symptoms shared by those with chronic pain are also indicators of major depression and mood disorders. Populations with higher incidences of major depression include those who earn less than $\$ 20,000$ per year, those who are single/divorced/ widowed, women (more so than men), and those with insomnia, guilt, and low self esteem (Cassem, 1998).

The two-question PRIME-MD test used in primary care settings, touted a 96 percent sensitivity in screening for major depression. According to Brody, Hahn, Spitzer, Kroenke, Linzer, deGruy \& Williams (1998, p 2469), the physician asks the patient if, in the last month he or she has often been bothered by:

- little interest or pleasure in doing things (anhedonia) and

- feeling down, depressed or hopeless (depressed mood).

The question then comes to mind, are these standardized tests really uncovering mental illness or merely confirming symptoms and feelings shared by chronic pain patients?

Some measurement scales and inventories have been specifically adapted or developed for use in assessing pain in a clinical setting. Those listed below were completed by and analyzed for the pain patients incorporated into this study. What makes these inventories different is that they are specifically targeted to compare one chronic pain patient with another chronic pain patient, not to the general population. At the time these inventories were completed for this study, between 1991 and 1996, these three test instruments represented the most common, reliable and valid surveys in the study of chronic pain. 


\section{The Multidimensional Pain Inventory (MPI)}

${ }^{\circ C}$ Chronic pain is a complex, subjective phenomenon that is uniquely experienced by each patient" (Kerns, Turk, \& Rudy, 1985, pg. 345). The chronic pain experience is not the same within similar age groups, diagnostic conditions, or treatment methods. In other words, one cannot predict a pain course, foretell treatment outcomes, or measure levels of pain by using a mechanical, biological approach. As such, the assessment of chronic pain patients must encompass more, including an evaluation of the psychosocial aspects to pain. If one appreciates the behavior, affect, and cognition variables of the pain experience, then one may set up treatment options compatible with the patients' perception, environment, and motivation. By grounding a written assessment in a cognitive-behavioral model, one may "broadly define, clarify, and synthesize a diversity of variables hypothesized to measure the impact of chronic pain on the patient's physical, psychological, social, and behavioral functioning” (Turk \& Rudy, 1988, p. 233).

The MPI (formerly known as The West Haven-Yale Multidimensional Pain Inventory, or WHYMPI) was designed to fill the gap between empirical, biological data and patients' pain perception by developing some "comprehensive assessment protocols that are designed specifically for use with chronic pain patients" (Kerns, et al, 1985, p. 346). While the MPI is comprehensive, it also has the advantage of being brief and selfadministered.

The 61-question MPI is ordered into three sections. Using Likert scales, "all items are responded to on a seven-point scale anchored by 'never' and 'very often"' (Bernstein, Jaremko, \& Hinkley, 1995, p. 956). Twelve unique scales develop within these sections 
and rate various aspects of the pain experience. $\mathrm{A} 13^{\text {th }}$ scale, known as the General Activity Level, is a combination of the four Activity Level scales. According to D. C. Turk (personal communication, October 5, 1998) and Kerns, et. al. (1985), the components and scales of the MPI are shown in the following table.

Table 2

The Breakdown of MPI Parts and Scales

\begin{tabular}{l|l} 
Part I & $\begin{array}{l}\text { Perceived pain intensity and impact on } \\
\text { patients' lives }\end{array}$ \\
\hline Scale 1 & Pain Severity \\
\hline Scale 2 & Interference \\
\hline Scale 3 & Life Control \\
\hline Scale 4 & Affective Distress \\
\hline Scale 5 & Support \\
\hline Part II & $\begin{array}{l}\text { Responses of others as perceived by the } \\
\text { patient }\end{array}$ \\
\hline Scale 6 & Punishing responses \\
\hline Scale 7 & Solicitous responses \\
\hline Scale 8 & Distracting responses \\
\hline Part III & Activity level \\
\hline Scale 9 & Household chores \\
\hline Scale 10 & Outdoor work \\
\hline Scale 11 & Activities away from home \\
\hline Scale 12 & Social activities \\
\hline Scale 13 & General activity level \\
\hline
\end{tabular}


"Assets of the (MPD) inventory are its brevity and clarity, its foundation in contemporary psychological theory, its multidimensional focus, and its strong psychometric properties" (Kerns, et al, 1985, p. 345). The value of a subjective measurement is justified because pain is a personal and individual experience; perceived areas of control directly correlate to one's motivation for adhering to treatment regimens. Also, how one perceives the pain experience carries over into how one projects pain affect and intensity to others, including loved ones and health care providers.

Using the multivariate statistical procedure of cluster analysis in two different studies, one on a group of heterogeneous pain patients (Turk \& Rudy, 1988) and one on a group experiencing temporomandibular disorder (Rudy, Turk, Zaki, \& Curtin, 1989), three statistically significant clusters appeared. Three emergent groups identified categories of coping styles, namely dysfunctional, interpersonally distressed, and adaptive copers. Those results suggest that the MPI may possess high external validity in assessing both heterogeneous and some homogeneous groups of pain patients.

The 61 questions on the MPI calculate into 13 scales. Nine of those scales are used to cluster coping styles: 'Pain Severity, Interference, Life Control, Affective Distress, Support, Punishing Responses, Solicitous Responses, Distracting Responses and General Activity Level" (Walter \& Brannon, 1991, p. 476). Each cluster displays unique, patterned responses in these nine scales.

In the article, $A$ cluster analysis of the Multidimensional Pain Inventory (Walter \& Brannon, 1991), a Houston headache clinic administered the MPI to 79 volunteers to see if a cluster analysis of the MPI on headache sufferers would yield similar results. Of the 
three calculated headache clusters, Cluster III and Cluster II closely resembled the categories of dysfunctional and adaptive coper respectively. Cluster I $(n=8)$ displayed unique characteristics when compared with Clusters $I I$ and $\Pi 1 I$, but was too small statistically to correlate with interpersonally distressed copers.

In the table below, information about the MPI cluster characteristics and a comparison of those characteristics with the cluster groups developed in the headache study are extracted from the article's discussion of results:

Table 3

MPI Cluster Comparison

\begin{tabular}{|c|c|c|c|c|c|c|}
\hline \multirow[b]{2}{*}{$\begin{array}{l}\text { Pain Scales } \\
\Downarrow\end{array}$} & \multicolumn{3}{|c|}{ Turk \& Rudy's Characteristics } & \multicolumn{3}{|c|}{ Compared with Walter \& Brannon } \\
\hline & Dysfunctional & $\begin{array}{l}\text { Interpersonally } \\
\text { Distressed }\end{array}$ & $\begin{array}{l}\text { Adaptive } \\
\text { Coper }\end{array}$ & $\begin{array}{c}\text { Cluster III } \\
\text { Dysfunctional }\end{array}$ & $\begin{array}{c}\text { Cluster I } \\
\text { Unclassified }\end{array}$ & $\begin{array}{l}\text { Cluster II } \\
\text { Adaptive } \\
\text { Coper }\end{array}$ \\
\hline Pain severity & High & & Lower & High & High & Lower \\
\hline Interference & High & & Lower & High & Low & Lower \\
\hline $\begin{array}{l}\text { Affect } \\
\text { Distress }\end{array}$ & High & & Lower & High & Low & Lower \\
\hline Life control & Low & & Higher & Low & High & Average \\
\hline Activity level & Low & & Average & & Low & Average \\
\hline Social support & High & Not supportive & Average & High & Average & $\begin{array}{l}\text { Below } \\
\text { average }\end{array}$ \\
\hline $\begin{array}{l}\text { Others punish } \\
\text { responses }\end{array}$ & & High & Low & Low & High & Low \\
\hline $\begin{array}{l}\text { Distracting by } \\
\text { others }\end{array}$ & High & $\begin{array}{l}\text { Below } \\
\text { average }\end{array}$ & High & High & $\begin{array}{l}\text { Below } \\
\text { average }\end{array}$ & Fewer \\
\hline
\end{tabular}

Bold type above indicates agreement.

With another homogeneous pain population verifying the cluster analysis of the MPI, this study "suggests that the MPI is a valid measure of the cognitive, behavioral and affective aspects of pain" (Walter \& Brannon, p. 476). Since pain experiences correlate to 
coping style more than to diagnosis, researchers and medical professionals may design more effective pain management programs and treatment strategies addressing the issues of each cluster, in addition to each disorder.

"The reliability (internal consistency) estimates for all MPI scales appear to be quite satisfactory, ranging from 0.70 to $0.90^{\prime \prime}$ (Kerns, et al., 1985, p. 351). However, the inter-correlations between scales remain low (from 0.00 to 0.58 ), demonstrating that each scale encompasses its own unique measurement.

The MPI shows good convergent validity in all three parts, suggesting that the model relates to observable data. Also, construct validity rates high when compared with several well-established questionnaires.

“(S)everal of the scales (e.g., Interference, Self-Control, Negative Mood, Pain Severity, and the Activity Scales) might be important dependent measures in the evaluation of cognitive-behavioral and other comprehensive pain treatment approaches" (Kerns, et al., 1985, p. 355). Because these scales stood on their own, selected scales may be used in an abbreviated, follow-up survey with confidence in the accuracy of the particular scale measurement.

\section{$\underline{\text { Pain Discomfort Scale }}$}

The Pain Discomfort Scale (PDS), is a ten-item instrument intended to measure pain affect (Jensen, Karoly, \& Harris, 1991). Pain affect differs from pain intensity in that intensity describes the level of the physical sensation of pain and pain affect measures unpleasantness, upset, or suffering (what one does cognitively with pain). In testing for reliability, Jensen, et al. (1991) found that the PDS, with a coefficient alpha reliability of 
0.77 , has good internal consistency. An interesting note: when the authors tested construct validity, they found that the PDS correlated highly to depression as measured on the Beck Depression Inventory $(r=0.58, p<0.001$, two-tailed test).

\section{Eleven Point Box Scale}

For the measurement of pain intensity, the 11 Point Box Scale is included in both pre- and post-treatment questionnaires. The 11 Point Box Scale simply asks patients to rate their level of pain from zero (no pain) to 10 (pain as bad as it can be). This method of rating pain is a standard practice in Western medicine today.

\section{Individual Factors that Influence Chronic Pain}

Included in an overall review of medicinal responses to chronic pain problems, review of individual characteristics or factors may aiso influence the self-management of chronic pain. Factors include one's locus of control, coping style, socioeconomic status, and family support system. By using the MPI, I will explore the importance of depression, pain intensity or affect, suffering, interference, dissatisfaction with function, support, perceived life control, affective distress, and activity levels (Kerns, et al, 1985) to one's continued commitment to workshop attendance and effective pain self-management over time.

\section{Measuring Effectiveness of Pain Treatment}

Another difficulty in assessing the efficacy of any treatment program is an agreement of how to measure outcomes. Evaluated by multiple stakeholders, success through one lens may not be seen as success by another. 
Table 4

Review of Stakeholders

\begin{tabular}{|l|l|}
\hline \multicolumn{1}{|c|}{ Stakeholder } & \multicolumn{1}{c|}{ Measurement of success } \\
\hline Patient & $\begin{array}{l}\text { Elimination or reduction of pain } \\
\text { Reduction in emotional distress }\end{array}$ \\
\hline $\begin{array}{l}\text { Worker's compensation and/or disability } \\
\text { insurance company }\end{array}$ & $\begin{array}{l}\text { Return to gainful employment } \\
\text { Claim closed }\end{array}$ \\
\hline Managed care organization & Decrease in use of health care system \\
\hline Referring physician & Reduction in opioid use \\
\hline
\end{tabular}

Adapted from Turk \& Okifuji, 1998.

For the purposes of this study, I will be looking at effectiveness from the standpoint of the patient and the managed care organization. Effectiveness from the patient perspective will look at differences pre- and post-treatment in pain severity, dysfunction, and dependence upon and satisfaction with the health care system. From the HMO's perspective, medical utilization pre- and post-treatment will be compared to program attendance, demographic information, satisfaction and coping style. Comparing coping styles with the other variables may help us understand the economic effectiveness of chronic pain management for all program participants. If medical utilization and customer satisfaction are affected by any of these factors or variables, we may see a need for tailored services, matching referrals to individual needs for more efficient and effective treatment.

\section{Size and Scope of Typical Research Projects in Chronic Pain}

Throughout this chapter, I have described various research projects delving into the issues surrounding chronic pain. To appreciate the size and scope of this study and the 
Chronic Pain 55

magnitude and character of other (nonmalignant) chronic pain research, a summary of various other studies is shown in Table 5. Sixteen study populations, all since 1988, range in size from 56 to 875 participants. The gender mix ranges from 50-percent male to 96.6percent female. Average (mean) age, for the most part, centers in the 40 s and early 50 s, with a wide array of ages, from a three-year-old to an 86-year-old.

Since the most liberal definition of chronic pain starts at three months, we see that the reported time with pain ranges from three months to 56 years. Average (mean) years in pain for these studies report participants experience from 1.5 years to 11.58 years with pain.

Finally, the subject and purpose of these chronic pain studies, while varied, reflect the nature of research within today's medical community. These studies focus on a better understanding of chronic pain disorders, looking beyond the Western medical (biologycentered) model, and call for more investigation of the biopsychosocial aspects of chronic pain. 
Table 5

\section{Profiles of Populations in Chronic Pain Research}

\begin{tabular}{|c|c|c|c|c|c|c|}
\hline Author(s) & $\begin{array}{c}\text { Year } \\
\text { published }\end{array}$ & $\begin{array}{c}\text { Sine } \\
(n)\end{array}$ & $\begin{array}{l}\text { Percent } \\
\text { Male vs. } \\
\text { Female }\end{array}$ & $\begin{array}{c}\text { Age }(\bar{x}) \& \\
\text { Range } \\
\text { (yrs) }\end{array}$ & $\begin{array}{c}\text { Years in } \\
\text { Pain }(\bar{x}) \& \\
\text { Range (yrs) }\end{array}$ & Subject of Study \\
\hline $\begin{array}{l}\text { Etscheidt, Steger \& } \\
\text { Braverman }\end{array}$ & 1995 & 86 & $\begin{array}{c}45.3 \% \mathrm{M} \\
54.7 \% \mathrm{~F}\end{array}$ & $\begin{array}{c}43.2 \\
(19-75)\end{array}$ & $\begin{array}{c}5.2 \\
(.25-25 y \mathrm{Ts})\end{array}$ & MPI profiles \\
\hline Flor \& Birbaumer & 1993 & 78 & $\begin{array}{c}40 \% \mathrm{M} \\
60 \% \mathrm{~F}\end{array}$ & $\begin{array}{c}42.43 \\
(20-65)\end{array}$ & $\begin{array}{c}9.4 \\
(.5-40 \text { yrs })\end{array}$ & $\begin{array}{l}\text { Musculoskeletal } \\
\text { pain }\end{array}$ \\
\hline $\begin{array}{l}\text { Hadjistavropoulos \& } \\
\text { Craig }\end{array}$ & 1994 & 90 & $\begin{array}{c}50 \% \mathrm{M} \\
50 \% \mathrm{~F}\end{array}$ & $\begin{array}{c}44.11 \\
(20-70)\end{array}$ & 4.36 & Low back pain \\
\hline $\begin{array}{l}\text { Ledingham, Doherty } \\
\text { \& Doherty }\end{array}$ & 1993 & 72 & $\begin{array}{l}9.7 \% \mathrm{M} \\
90.3 \mathrm{~F}\end{array}$ & $\begin{array}{c}53 \\
(18-81)\end{array}$ & $\begin{array}{c}4 \\
(1.5-6 \mathrm{yrs})\end{array}$ & Fibromyalgia \\
\hline $\begin{array}{l}\text { McCarberg \& Wolf; } \\
\text { Ershoff }\end{array}$ & $\begin{array}{l}1999 \\
1995\end{array}$ & 353 & $\begin{array}{l}25.2 \% \mathrm{M} \\
74.8 \% \mathrm{~F}\end{array}$ & $(18+)$ & 9 & $\begin{array}{l}\text { Evaluate a chronic } \\
\text { pain program }\end{array}$ \\
\hline $\begin{array}{l}\text { Nicassioo, Radojevic, } \\
\text { Weisman et. al. }\end{array}$ & 1997 & 71 & $\begin{array}{l}11.3 \% \mathrm{M} \\
88.7 \% \mathrm{~F}\end{array}$ & $\begin{array}{c}53.1 \\
(24-78)\end{array}$ & $\begin{array}{c}11.1 \\
(.33-52 \mathrm{yrs})\end{array}$ & $\begin{array}{l}\text { Fibromyalgia } \\
\text { interventions }\end{array}$ \\
\hline $\begin{array}{l}\text { O'Malley, Jackson, } \\
\text { Kroenke, et. al. }\end{array}$ & 1998 & 185 & $\begin{array}{c}36 \% \mathrm{M} \\
64 \% \mathrm{~F}\end{array}$ & 46 & 2 & $\begin{array}{l}\text { Rheumatology vs. } \\
\text { psychiatric pain }\end{array}$ \\
\hline Rothschild \& Vu & 1994 & 100 & $\begin{array}{l}19 \% \mathrm{M} \\
81 \% \mathrm{~F}\end{array}$ & $\begin{array}{c}50 \\
(14-81)\end{array}$ & $(.25-30 \mathrm{yrs})$ & Fibromyalgia \\
\hline $\begin{array}{l}\text { Stirling, Reid, Pollard } \\
\text { \& Ondrack }\end{array}$ & 1996 & 875 & $\begin{array}{l}18.3 \% \mathrm{M} \\
80.7 \% \mathrm{~F}\end{array}$ & $\begin{array}{c}43.6 \\
(3-86)\end{array}$ & 6.48 & $\begin{array}{l}\text { Chronic Fatigue } \\
\text { symptoms survey }\end{array}$ \\
\hline Turk \& Okifuji & 1997 & 63 & $\begin{array}{l}4.8 \% \mathrm{M} \\
95.2 \% \mathrm{~F}\end{array}$ & 46.84 & 9.4 & $\begin{array}{l}\text { Pain behaviors } \\
\text { (fibromyalgia) }\end{array}$ \\
\hline Turk \& Okifuji & 1996 & 158 & $\begin{array}{c}43.7 \% \mathrm{M} \\
56.3 \% \mathrm{~F}\end{array}$ & $\begin{array}{c}43.01 \\
(20-78)\end{array}$ & $\begin{array}{c}5.0 \\
(.25-56 \mathrm{yrs}) \\
\end{array}$ & $\begin{array}{l}\text { Trauma vs. insidious } \\
\text { pain }\end{array}$ \\
\hline $\begin{array}{l}\text { Turk, Okifuji, Sinclair } \\
\text { \& Starz }\end{array}$ & 1996 & 117 & $\begin{array}{l}3.4 \% \mathrm{M} \\
96.6 \mathrm{~F}\end{array}$ & 46.75 & 10.5 & Fibromyalgia \\
\hline Turk \& Rudy & 1988 & 122 & $\begin{array}{l}79.5 \% \mathrm{M} \\
20.5 \% \mathrm{~F}\end{array}$ & 49.2 & 10.6 & $\begin{array}{l}\text { Taxonomy of pain } \\
\text { patients }\end{array}$ \\
\hline $\begin{array}{l}\text { Wade, Dougherty, } \\
\text { Hart \& Cook }\end{array}$ & 1992 & 88 & $\begin{array}{r}40.9 \% \mathrm{M} \\
59.1 \% \mathrm{~F}\end{array}$ & 41.8 & 1.5 & $\begin{array}{l}\text { Personality \& } \\
\text { chronic pain }\end{array}$ \\
\hline Walter \& Brannon & 1991 & 79 & $\begin{array}{l}29 \% \mathrm{M} \\
71 \% \mathrm{~F}\end{array}$ & $\begin{array}{c}39 \\
(18-71) \\
\end{array}$ & 11.58 & $\begin{array}{l}\text { MPI clusters } \\
\text { (headache) }\end{array}$ \\
\hline Waylonis \& Perkins & 1994 & 56 & $\begin{array}{l}12.5 \% \mathrm{M} \\
87.5 \% \mathrm{~F}\end{array}$ & 46 & 10.8 & $\begin{array}{l}\text { Post-trauma } \\
\text { Fibromyalgia }\end{array}$ \\
\hline
\end{tabular}


Size and Scope of Past Research at the Pain Management Program

A research project funded by the HMO looked into the effectiveness of this study's pain program (McCarberg \& Wolf, 1999; Ershoff, 1995). In 1992 and 1993, 353 physician-referred patients completed the pre-treatment questionnaires. In that study, the pain program staff randomly assigned patients to one of two groups. The first group (initially considered the control group) received a program workbook for home study and was told that if they had any questions or problems, they could call the pain physician or his staff. The second group (the treatment group) received the workbook materials, could call the pain physician or his staff, and attended the workshop.

At six and twelve months post-treatment, the program's staff mailed the same questionnaire to both groups for completion. Also, they collected data on medical utilization via individual chart review on all subjects to learn the total pain related and non pain related costs one year prior and one year post assignment to a workshop group.

Ershoff (1995) performed several parametric and nonparametric tests to analyze the data (including Kruskal-Wallis ANOVA by Rank Test, Wilcoxon Signed Rank Test, paired $t$-tests, ANCOVA, and Chi Square). In the preliminary findings, the statistics detected only a few areas where significant differences arose between the two groups. Interestingly, both groups experienced significantly less pain-related medical utilization post-treatment. Overall, most patients got better. However, only those patients completing the workshop expressed satisfaction with the program. 


\section{Validity and Reliability}

Because chronic pain is such a complex and subjective issue, valid and reliable measurements for pain patient populations have been difficult to establish. The widespread use of psychological testing, designed to identify and select psychiatric disorder in otherwise healthy populations, has been adopted by psychologists and psychiatrists also involved with chronic pain patients. The fallacy, however, is that validity and reliability testing was normed by comparing medically healthy patients to those with mental illness. Because there are various biopsychosocial issues in patients with chronic pain, truly reliable and valid testing must be normed by comparing one set of chronic pain patients with other sets of chronic pain patients.

Three measurement instruments discussed previously and designed specifically for chronic pain patients were also used in the Pain Management Program pre-treatment questionnaire. They were: a) the Multidimensional Pain Inventory (MPI), b) the Pain Discomfort Scale (PDS), and c) the 11 Point Box Scale. At the time these assessments were administered to the study's population, these three surveys represented a comprehensive array of topics thought important in understanding the various aspects of chronic pain, how pain influences one's quality of life, and the need for medical services or interventions.

\section{Leadership Issues in Chronic Pain}

When reviewing the importance of leadership in the treatment of chronic pain, I will be using Rost's (1991) definition as a foundation: 'Leadership is an influence relationship among leaders and (collaborators) who intend real changes that reflect their 
mutual purposes" (p. 102). This view of leadership as a process contains the same essential elements as does the relationship between healing professionals and chronic pain patients: (a) an influence relationship, between the practitioner and patient; that (b) intend(s) real changes, where the patient may learn to accept chronic pain and adopt pain management strategies and techniques; and that (c) reflect(s) their mutual purposes, the advancement of a healing process through increased activity, appropriate opioid medication use, and less demand for medical intervention, to name a few.

Of interest to educators and leadership scholars, I propose that the study of chronic pain patients may. reveal essential elements necessary for individuals and their supporters to negotiate a change process. Serving as facilitators, those who conduct pain programs (e.g., cognitive-behavioral pain management training) collaborate with patients to find solutions and adaptations, thereby actively participating in the leadership process. 
Chronic Pain 60

Outcome measures will be the currency of health care in the new millennium.

Steven D Waldman, MD

Director, Pain Consortium of Greater Kansas 


\section{CHAPTER 3}

\section{Methodology}

Introduction

In this chapter I will discuss abstract notions of effectiveness, efficiency, and predictability, and explore ways to measure them, using readily obtainable data. This chapter will review information about one pain management program, available data on program participants, and information needing to be gathered to quantify success and explore improvement possibilities.

\section{Methodological Overview}

The justification for offering any pain management program must be weighed against many variables. Primarily, is the treatment effective? If it does not benefit those referred to the program, then who does benefit, and are any patients harmed by the treatment? Are these patients satisfied with the treatment they receive from their health care provider?

Second, is the proposed pain management program efficient? In vying for limited resources, does this program offer an anticipated standard of effective care at a reasonable cost?

Third, is there a predictive quality in the information gathered from a patient at the time of referral that may foretell successful pain management or suggest the need to 
modify treatment modalities? If an aspect about certain types of patients hinders their selfmanagement process, can an intervention be designed to address those areas of concern?

The pain management program under study was an eight-week cognitivebehavioral workshop at a Southern California HMO. For two hours each week, groups of twenty to thirty-five patients learned various techniques to help manage chronic pain. The discussions were lead by a primary care physician/pain specialist and a program coordinator/master's level educator. Homework assignments were given each week so that participants could practice techniques introduced in the program. Referrals to the program came from a variety of treating physicians and health care professionals. The program was offered free of charge and is outlined as follows: 
Table 6

Pain Management Program Outline

\begin{tabular}{|c|c|c|}
\hline WEEK & TOPIC & HOMEWORK \\
\hline 1 & $\begin{array}{l}\text { Event - Thought } \\
\text { Where pain comes from } \\
\text { Concept of pain gate } \\
\text { Morning logs }\end{array}$ & $\begin{array}{l}\text { Record one event - thought each day. List } \\
\text { automatic thought(s) and automatic } \\
\text { response(s). Then suggest alternate } \\
\text { thoughts and responses. }\end{array}$ \\
\hline 2 & $\begin{array}{l}\text { Review Event - Thought } \\
\text { Establish phone partners } \\
\text { Relaxation \& focusing }\end{array}$ & $\begin{array}{l}\text { Contact phone partner at least once per } \\
\text { week (ongoing). } \\
\text { Practice relaxation techniques (ongoing). }\end{array}$ \\
\hline 3 & $\begin{array}{l}\text { Doctors and expectations } \\
\text { The health care system } \\
\text { Requests and promises }\end{array}$ & $\begin{array}{l}\text { Requests and promises - practice saying } \\
\text { no. }\end{array}$ \\
\hline 4 & $\begin{array}{l}\text { Review saying no } \\
\text { Anger, acceptance, and loss } \\
\text { Problem solving }\end{array}$ & $\begin{array}{l}\text { List one problem, brainstorm alternatives, } \\
\text { select best option(s). }\end{array}$ \\
\hline 5 & $\begin{array}{l}\text { Medications used to treat pain } \\
\text { Addiction vs. tolerance } \\
\text { Exercise }\end{array}$ & $\begin{array}{l}\text { Design \& execute an appropriate exercise } \\
\text { program (ongoing). }\end{array}$ \\
\hline 6 & $\begin{array}{l}\text { Review exercise program } \\
\text { Depression and chronic pain } \\
\text { Fact vs. opinion }\end{array}$ & $\begin{array}{l}\text { Record statements and determine if they } \\
\text { are facts (cannot be changed) or opinions } \\
\text { (open to interpretation). }\end{array}$ \\
\hline 7 & $\begin{array}{l}\text { Review facts and opinions } \\
\text { Life evaluation }\end{array}$ & $\begin{array}{l}\text { Set up a one month goal and a one year } \\
\text { goal. }\end{array}$ \\
\hline 8 & $\begin{array}{l}\text { Review goals } \\
\text { Biofeedback } \\
\text { Dealing with families and } \\
\text { significant others }\end{array}$ & $\begin{array}{l}\text { Attend two follow-up support group } \\
\text { sessions. }\end{array}$ \\
\hline
\end{tabular}

After an initial chart review and phone consultation with the program's physician, patients received an invitation to participate. Admission, however, could only occur until after the completion of an eight-page pre-treatment questionnaire (Appendix A). 


\section{$\underline{\text { Research Design }}$}

This study reviewed data on all 2,561 patients referred to a Southern California HMO's pain management program from August 1, 1991 to May 15, 1996, including 353 patients in the McCarberg \& Wolf (1999) and Ershoff (1995) studies. Of this population, 1,832 patients were listed as having completed the pre-treatment assessment, but 103 questionnaires could not be located. I entered 1,729 pre-treatment assessment questionnaire responses into a database for statistical analysis.

Pre-treatment questionnaires asked for demographic information, including marital status, current employment, and level of education. In addition, attendance records for each patient's workshop participation were entered into the database, including those who successfully completed the program, those who dropped, those who signed up for class but did not attend any session, and those who never signed up to participate.

A one-page (two sided), post-treatment survey was also mailed to the 1,832 people listed as having completed pre-treatment questionnaires (see Appendix B). This survey was the screening version of the MPI (eight questions), the 11 Point Box Scale, three quantitative and two qualitative questions related to patient satisfaction and continuous quality improvement. A 4" $x 7^{\prime \prime}$ refrigerator-type mood magnet was sent along with the follow-up questionnaire as an incentive to respond. A second post-treatment survey was sent to non responders six months after the initial mailing. Seven hundred thirty-one replies were received (39.8\% response rate), of which 15 were incomplete. Eleven point Box scores and MPI responses were compared with the pre-treatment survey. 
Computer records listing each patient's medical utilization were available on 2,430 subjects from January 1994 through August 1997. One hundred thirty-one patients did not visit the HMO during that time, I assume because they expired, changed medical insurance coverage, sought treatment outside of the HMO, or gave up on traditional Western medicine. The utilization records included both the number and type of doctor visits and any prescription opioid medicines purchased through the HMO. Unfortunately, these records did not distinguish between pain related treatments and other types of medical maladies. Because the goals in the Pain Management Program included self-efficacy, a review of total medical utilization pre- and post-treatment could detect changes in patient perceptions centered around using and misusing the medical system.

This research project incorporated a total patient population. Because of the size of the group and the vast amount of available data, the first purpose of this study was to construct and present descriptive statistics about a large group of chronic pain patients.

As is common in a study with human subjects, a true experimental design was not possible. This study looked retrospectively at referred patients, their participation in the pain workshop, and medical utilization information. The strongest statistical model available for the pre- and post-treatment questionnaires was found in the quasiexperimental set of statistical designs. More specifically, this project utilized the selfselected experimental group design, part of the nonequivalent control group designs. According to Huck, Cormier, \& Bounds (1974), "The nonequivalent control group design has two groups that are compared to observations before and after the exposure of one group to the treatment" (p. 302). While similar to pretest-posttest control group designs 
(both true experimental and pseudoexperimental), the nonequivalent control group differs in that there is no random assignment to groups. The self-selected experimental group design, "consists of subjects who volunteer, are self-selected, or seek to be exposed to the treatment, whereas the control group subjects do not seek exposure" (p. 302).

Quasi-experimental designs, when compared to true experimental designs, have better control over external threats to validity, making the results more generalizable. However, increased threats to internal validity include uncertainty about whether group self-selection is equivalent, and if so, whether history and maturation play a part in that selection. Also, Huck, et al (1974) point out that regression to the mean and mortality can threaten validity, especially if groups were selected based on extreme scores.

Because this study was enormous in size, I could test these threats to internal validity. By comparing various descriptive statistics in each group, using either twosample case of the mean or ANOVA, minute differences in groups could be detected. In the case of the number of years in pain, the assumption of a normal distribution was violated, requiring the nonparametric test, Kruskal-Wallis One-way ANOVA, to detect differences among the groups.

Utilization data, both DOVs and opioid medications, followed another quasiexperimental design, namely a multiple-group time-series. Here, "the multiple-group timeseries design includes a series of observations or measurements before and after treatment, while the nonequivalent group design includes only one observation before and after treatment for the groups" (Huck, et. al., 1974, p. 319). Utilization information was calculated into the number of days pre- and/or post-treatment. Sixty-three pain 
management workshops were conducted from October 1991 through May 1996. For the purpose of determining number of years pre- and post-treatment, those patients who did not sign up for class were assigned to workshops with similar referral dates. Whole years of utilization information were then calculated. The eight weeks of the pain management program were eliminated from the study, so that one year pre-treatment included the 365 days before the first day of class and one year post-treatment contained the 365 days after the last day of class. Because outcome data spanned three years and eight months, approximately one-half of the group could be banded into two complete years while the other one-half incorporated three complete years of medical utilization. The total range extended from two years pre-treatment to five years post-treatment.

Once statistical significance was found, linear models were employed to see if associations existed among various sets of data. I was most interested in uncovering correlations between pre- and post-treatment questionnaire responses, participation in the program, and outcome data.

One important aspect considered was the comparison of the stereotypical chronic pain patient versus the actual demographic information on these study participants. The pervasive societal model of chronic pain patients paints them as unemployed, seeking disability benefits, and abusing their prescription drugs. They are excuse makers determined to make society pay so they will not have to work. Psychologically, they suffer from a variety of mental illnesses and social maladaptations that, if treated, would make their pain go away. 
Chronic Pain 68

These observations are still supported by many physicians who believe in pre-1990 models of chronic pain. "Most clinicians and managers (share) a paradigm composed of misconceptions rather than the latest scientific findings" (Donovan, et al., 1999, p 41). In 1991 and again in 1995, the American Pain Society (APS) published standards for understanding the mechanisms behind and effectively treating chronic pain, revolutionizing the world view of pain patients. By looking at the profiles of patients in this study, outcome measurements, and questionnaire responses, we can see how this population differs from pre-1990 beliefs.

The pre-treatment questionnaire responses aided in statistical analysis as follow in Table 7 (full version in Appendix A): 
Table 7

Available Variables (Factors) and Their Attributes

\begin{tabular}{|c|c|c|}
\hline Variables & Type of Statistic & Purpose or Sample Question \\
\hline $\begin{array}{l}\text { Medical Record } \\
\text { Number }\end{array}$ & $\begin{array}{l}\text { Continuous, } \\
\text { Nominal }\end{array}$ & $\begin{array}{l}\text { Identification control; to be converted to } \\
\text { case number for privacy purposes. }\end{array}$ \\
\hline Age & Continuous, Ratio & Is age a factor? \\
\hline Sex & Discrete, Nominal & $\begin{array}{l}\text { Do men experience or report pain } \\
\text { differently than women? }\end{array}$ \\
\hline $\begin{array}{l}\text { Marital Status or } \\
\text { Significant Other }\end{array}$ & $\begin{array}{l}\text { Continuous, } \\
\text { Nominal }\end{array}$ & Does marital status influence outcomes? \\
\hline Who living with & $\begin{array}{l}\text { Continuous, } \\
\text { Nominal }\end{array}$ & Importance of social support. \\
\hline Education & $\begin{array}{l}\text { Continuous, } \\
\text { Ordinal }\end{array}$ & $\begin{array}{l}\text { Does level of education affect } \\
\text { outcomes? }\end{array}$ \\
\hline Work & $\begin{array}{l}\text { Continuous, } \\
\text { Nominal }\end{array}$ & Indicates level of disability. \\
\hline $\begin{array}{l}\text { Number of Years } \\
\text { with Chronic Pain }\end{array}$ & $\begin{array}{l}\text { Continuous, } \\
\text { Ordinal }\end{array}$ & $\begin{array}{l}\text { Does length of time with pain affect } \\
\text { outcomes? }\end{array}$ \\
\hline Location of Pain & $\begin{array}{l}\text { Continuous, } \\
\text { Nominal }\end{array}$ & Any relationship to other variables? \\
\hline MPI & $\begin{array}{l}\text { Continuous, } \\
\text { Interval }\end{array}$ & $\begin{array}{l}\text { Evaluates perceived pain and its impact } \\
\text { on self, perception of others, and activity }\end{array}$ \\
\hline 11 Point Box Scale & Continuous, Ratio & $\begin{array}{l}\text { Does intensity of pain affect outcomes? } \\
\text { What is change in pain over time? }\end{array}$ \\
\hline PDS & $\begin{array}{l}\text { Continuous, } \\
\text { Interval }\end{array}$ & $\begin{array}{l}\text { Shows pain affect. Also, correlates } \\
\text { highty to depression. }\end{array}$ \\
\hline $\begin{array}{l}\text { Taxonomy of Pain } \\
\text { Patient (Calculated } \\
\text { from the MPI) }\end{array}$ & $\begin{array}{l}\text { Continuous, } \\
\text { Nominal }\end{array}$ & $\begin{array}{l}\text { Does being an active coper, } \\
\text { interpersonally distressed, or } \\
\text { dysfunctional affect outcomes? }\end{array}$ \\
\hline
\end{tabular}


Included in this analysis were various profiles of typical patients referred to the pain management program. By obtaining additional demographic information from the medical provider (e.g., age, gender), variations could be seen between pain patients and the general population as a whole. Other attributes inferred from the questionnaires, including location of pain and disorder or cause of pain to see if other associations existed.

With patients analyzed by number of years post-treatment, I evaluated the medical utilization and costs to see if any trends appeared. For example, in Ershoff's (1995) study, the cost of medical care one year post-treatment on average was approximately one-third of the medical costs for the year before referral. Because the long-term effects of pain management programs are not understood, reviewing patients' records over time could demonstrate whether these cost savings continued. If there was a point in time when the effects of this treatment strategy appeared to wear off, then interventions could be designed to reinforce the self-management tools presented in the workshop.

\section{Data Collection}

The HMO providing this pain management program graciously awarded a $\$ 4,800$ grant to cover the data gathering expenses. In exchange, I proposed and received approval for this study from the HMO's Internal Review Board (IRB) and promised to deliver a copy of this dissertation to the IRB when completed. Predating the proposal, I secured a paid, part-time position with the pain management program because of my volunteer efforts and interest of study in this field (April 1997). There were no monetary incentives, job guarantees, or other benefits expressed or implied based upon the results of this study. Because I am an employee of the HMO, this project served as an inexpensive, in-house, 
secondary analysis of the efficiency and effectiveness of the Pain Management Program to the health care organization. As a former participant and present employee, I recognize that I have biases toward the program as I have seen it work for many people. However, as a researcher, I adhered to strict rules of impartiality and think that is represented in the data analysis and conclusions.

With the grant money, I mailed follow-up questionnaires, including the cost of printing and postage, and paid for the computer time and programming needed to capture utilization information. The Pain Management Program made the eight-page pre-treatment questionnaires available to me for input into a data base.

Using the talents of the Information Systems people at the HMO, I received a comprehensive list of utilization data on each participant. This information included outpatient doctor visits, emergency room visits and urgent clinic appointments. Diagnostic codes were not available. Also, opioid medications purchased at one of many HMO pharmacies were included. Not all benefits, including drug coverage, were consistent over the entire population.

\section{Entry to the Population}

In 1992, I participated in this pain management program as a chronic pain patient. Since then, I have observed six additional workshops and, until 1997, participated regularly in semimonthly support group meetings. At times, I have served as a volunteer phone partner and resource for chronic pain patients diagnosed with Reflex Sympathetic Dystrophy. Over the years, I have come to know both the Director and Coordinator of the program. 
Since April 1997, I have been employed by the HMO as a Staff Specialist in the Pain Management Program. My duties include reviewing medical charts for program participants. Also, I regularly interact with patients, encouraging them to participate, helping reinforce program techniques, and serving as a liaison among the patients, Coordinator, and Program Physician.

Due to the vast amount of data already collected by the HMO for this program (but not analyzed), my personal interest in the study of chronic pain self-management, the Director's interest in further research, and the support I have received from the HMO, I feel secure in developing this topic and in using this site for my dissertation study.

\section{$\underline{\text { Site Selection }}$}

The medical facility housing the Pain Management Program is a Southern California HMO. However, it is also part of a large, national HMO. Due to its size, treatment methods and patient populations are stable. All medical services are provided within the HMO, except certain captured costs for workers' compensation. Another benefit of this site is that an HMO setting serves as a standard of care model as our society shifts to managed care.

The pain management program under study offers one type of low-cost treatment for chronic pain patients. Currently, HMO administrators are replicating this program at other sites throughout the nationwide system because they perceive it as having some success in managing this difficult patient population. 


\section{Selection of Subjects}

The Pain Management Program is a cognitive-behavioral workshop designed for patients who have undergone most or all known standard medical treatments and are having trouble self-managing chronic pain. To participate, one of the patient's health care providers (e.g., physician, social worker, physical therapist) sends a referral to the pain program. According to the procedures at the time, staff members completed a chart review and patients received a phone consultation with the program physician. Afterward, participants received a questionnaire for completion. The questionnaire served as an entry ticket to the program, as it had to be completed and returned before a class space was reserved for the patient. At the time I requested this information, 4,511 referrals had been sent to the program (from the March 1987 program inception through May 1997). Two thousand twenty questionnaires were completed. Available attendance records existed for 2,684 participants. I focused this study on a narrower time span because attendance records did not begin until October 1991, and I wanted to have at least one complete year of post-treatment information available. Also, the HMO did not record medical utilization records for all patients until January 1994.

\section{Protection of Subjects}

Before collecting any data, I received human subjects research approval from two different sources. First, the University of San Diego Human Subjects Committee approved my proposal design, pending approval by the HMO. Next, I petitioned the HMO's Internal Review Board, both for funding and permission to obtain the outlined information. In both cases authorization was given without incident. 
This study was a post hoc examination of data already in existence for clinical and administrative purposes. I eliminated any individual identifiers, such as name and patient record number, and substituted random case numbers in their place. In its final form, the HMO cannot identify any patients included in the study nor will my data files contain any information that will enable me to go back and update my records with additional patient information. Once this study is accepted in its final form, I will destroy those files showing any connection between the HMO's identifiers and case number assignment. I will neither release nor publish any information on individual participants. The data analysis is for identifying possible links that enhance or detract from one group's ability to self-manage chronic pain and to help evaluate program effectiveness in those areas.

The follow-up survey also serves as part of a routine, secondary analysis of the program's effectiveness and efficiency (Appendix B). Included with the survey was a letter, signed by both the director and the researcher, briefly explaining the study (Appendix C). This letter included an informed consent. Patients wanting to participate in the study chose to do so by returning the questionnaire.

If the results of this analysis showed a relation between workshop attendance, individual characteristics, and/or utilization, then assurances needed to be made that individuals would not be denied treatment merely because they did not fit a certain profile. The purpose of this study was to identify potential problem areas and address those issues in concurrent, pre-workshop, and follow-up interventions. 


\section{Data Analysis}

This study proposed to be a quantitative analysis employing general statistical models and sound research designs to assess the effectiveness and efficiency of one pain management program. Also, I looked at statistical relationships of individually reported factors or characteristics with program completion, utilization, and the ability to selfmanage chronic pain over time.

My ability to conduct this analysis related to my own interest in statistics (I tutor and lecture doctoral students in quantitative methods) and in research (I taught introductory research classes to graduate counseling students and counsel doctoral students in quantitative research design). Also, I have surrounded myself with a committee expert in statistical and economic modeling. This promised to give new and varied contexts into the research of chronic pain.

\section{Background of the Researcher}

In 1986 I was diagnosed with Carpal Tunnel Syndrome (CTS), a painful compression of the median nerve. Carpal tunnel release surgery followed to remedy the problem. After two years, the symptoms returned and a second surgery was scheduled. The latter surgery proved unsuccessful.

Gradually, the CTS-type symptoms became more intense. Again, conservative treatment failed to produce results, but the symptomology took on new characteristics. Fortunately, I had two caring physicians who, instead of insisting that it was all in my head, took my complaints and symptoms seriously. 
After a year of testing and treatments, I was diagnosed with Reflex Sympathetic Dystrophy (viz., Complex Regional Pain Syndrome, Type 1). 'Reflex Sympathetic Dystrophy (RSD) is characterized by severe burning pain, swelling, and vasomotor, sudomotor, dystrophic, and atrophic changes in the affected body parts" (Schwartzman \& Kerrigan, 1990, p. 57).

The Pain Management Program helped me to reframe and self-manage this painful condition. I also witnessed others making remarkable progress, assuming control of their medical care. Still, some did not seem to get the message; somehow they were stuck and unable or unwilling to change or progress.

Eventually, I had a successful surgery, a cervical sympathectomy disconnecting portions of the sympathetic nervous system from the spinal column. Some research suggests that this method of treatment, if successful, stops pain an average of two or three years. In some managed care settings, this procedure is discouraged or not covered. It seems that the anticipated benefit of being pain-free for two or three years does not justify the cost.

I firmly believe that education-based programs, such as a cognitive-behavioral pain management program, can help people live well with chronic conditions. By understanding more about chronic pain and treatment options, by regaining a sense of self efficacy, patients are better able to become true partners in managing their own health and wellness. I recognize these biases and have tried to compensate with strict adherence to research doctrine. 
I would like to pursue a career in health care and/or education. Teaching research methods and statistics, as well as delving more into chronic pain research should yield a

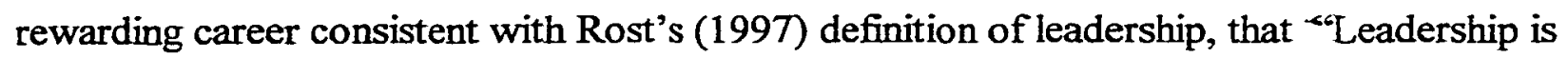
an influence relationship among leaders and (collaborators) who intend real changes that reflect their mutual purposes" (p. 102).

\section{Summary}

My purpose in investigating the effects of chronic pain management satisfied both personal and professional interests. This project considered potential explanations about why some people succeed and others fail to self-manage chronic pain. Particalarly, a better understanding of chronic pain may help patients accept their condition, reform their identities, and create new meaning for their lives. Also, updating physicians and other health care providers in chronic pain standards of care, breaking down barriers to effective treatment, and helping to reframe societal views in expectations and efficacy, should improve the quality of life for those experiencing chronic pain.

This study set up a framework to analyze chronic pain patients and uncover possible improvements to patients' and providers' training and treatment. By looking at the problem from both the patient's and the provider's perspective, a clearer appreciation of the need to educate ourselves and others will be realized. By understanding today's stumbling blocks, lower health care costs, reduce frustration, and more effective treatment regimens may be uncovered. 
Chronic Pain 78

Half of what we learn in medical school is out of date in five years, but our patients always tell us the truth.

Daniel Brookoff $M D, P h D$ 


\section{CHAPTER 4}

Data Analysis

\section{Introduction}

The information used to compile this study originated from three sources. First, the Pain Management Program's database identified all patients referred to the program. Preset parameters included all participants enrolled in one of 63 classes beginning October 3, 1991, and ending May 9, 1996. The beginning date reflects the time at which weekly attendance records became available. Because my initial request for utilization information was in August 1997, and, wanting to have at least one year's post-treatment utilization, I limited the data gathering to those classes ending by May 1996.

Completing the questionnaire was a necessary step in registering for class, but not all questionnaire completers enrolled in the Pain Management Program. This study included those patients referred to the program between August 1, 1991, and May 15, 1996, who did not sign up for class. Of the non-participant group, $55.4 \%$ did not complete the pre-treatment questionnaire and were not invited to attend. The remaining $44.6 \%$ of nonparticipants completed questionnaires, were invited, but chose not to attend.

Data from the pain program included a patient's identifying number, referral date, and the eight-page pre-treatment questionnaire. A total of 2,561 patients (viz. Total Group) was referred during this period. The program's database indicated 1,832 patients (viz. MPI Group) completed the pre-treatment questionnaire, which included the full 
version of the MPI. Questionnaires were lost for 103 patients, therefore the size of the pre-treatment questionnaire group was 1,729. Pain Management Program data was supplied primarily in paper form and required extensive manual entry to capture the data.

Next, the Information Technology (IT) department of the HMO, with limited access to the pain program's database, captured attendance records, pain sites (if available), and class start dates. From the systemwide database, IT supplied updated names, addresses, age (as of 12/97), and most medical utilization information. On December 17, 1997, IT gathered data as shown in Table 8 below. The outpatient visits were called the Utilization Group, while pharmacy prescriptions (viz. Pharmacy Rss) represented the Opioid Group.

Table 8

Utilization Data from January 1, 1994 to August 31, 1997

\begin{tabular}{|l|r|r|l|}
\hline \multicolumn{1}{|c|}{ Subject } & $\begin{array}{c}\text { Number of } \\
\text { participants } \\
(\boldsymbol{n})\end{array}$ & $\begin{array}{c}\text { Number of } \\
\text { cases }\end{array}$ & \multicolumn{1}{c|}{ Comments } \\
\hline $\begin{array}{l}\text { Outpatient visits } \\
\text { (Utilization Group) }\end{array}$ & 2,430 & 131,280 & Included Urgent Care, ER \\
\hline $\begin{array}{l}\text { Pharmacy Rs } \\
\text { (Opioid Group) }\end{array}$ & 1,860 & 38,913 & Opioids only \\
\hline
\end{tabular}

One assumption of this study was that all chronic pain patients had at least one Doctor Office Visit (DOV) each year that they had medical coverage. Erring on the side of caution, those patients who had coverage but did not see at least one health care provider during the time in question were excluded in utilization analysis. Using this assumption, 131 patients either changed health care providers, lost their insurance 
coverage, expired, or for some other reason were not seen during the dates for which utilization information were gathered.

To see graphically how these groups interrelate, Figure 1 shows the relationship among the four groups in which information was gathered. To review, the Total Group was all patients referred to the Pain Management Program from August 1, 1991 and May 9, 1996 ( $n=2,561)$. The Utilization Group included all outpatient services rendered from January 1, 1994 to August 31, $1997(n=2,430)$. The difference between the Total Group and the Utilization Group were 131 pain patients with no detectible DOVs.

Patients in the MPI Group came from the pool of Total Group participants, but included only those specifically marked in the pain program's database as having completed the pre-treatment questionnaire. Post-treatment questionnaires were sent to all those identified as the MPI group. In the MPI Group $(n=1,832), 103$ questionnaires could not be found.

The Opioid Group represented those patients in the Utilization Group who filled opioid prescriptions at one of the HMO's pharmacies. Some employer groups offered drug coverage outside of the HMO pharmacy. Some patients did not have any drug coverage and were free to choose their own pharmacies, including those outside of the HMO. Still, other patients did not receive any opioid prescriptions. Out of the Utilization Group, 1,860 patients received opioid medications through the HMO's pharmacies. 
Figure 1

\section{Study Population}

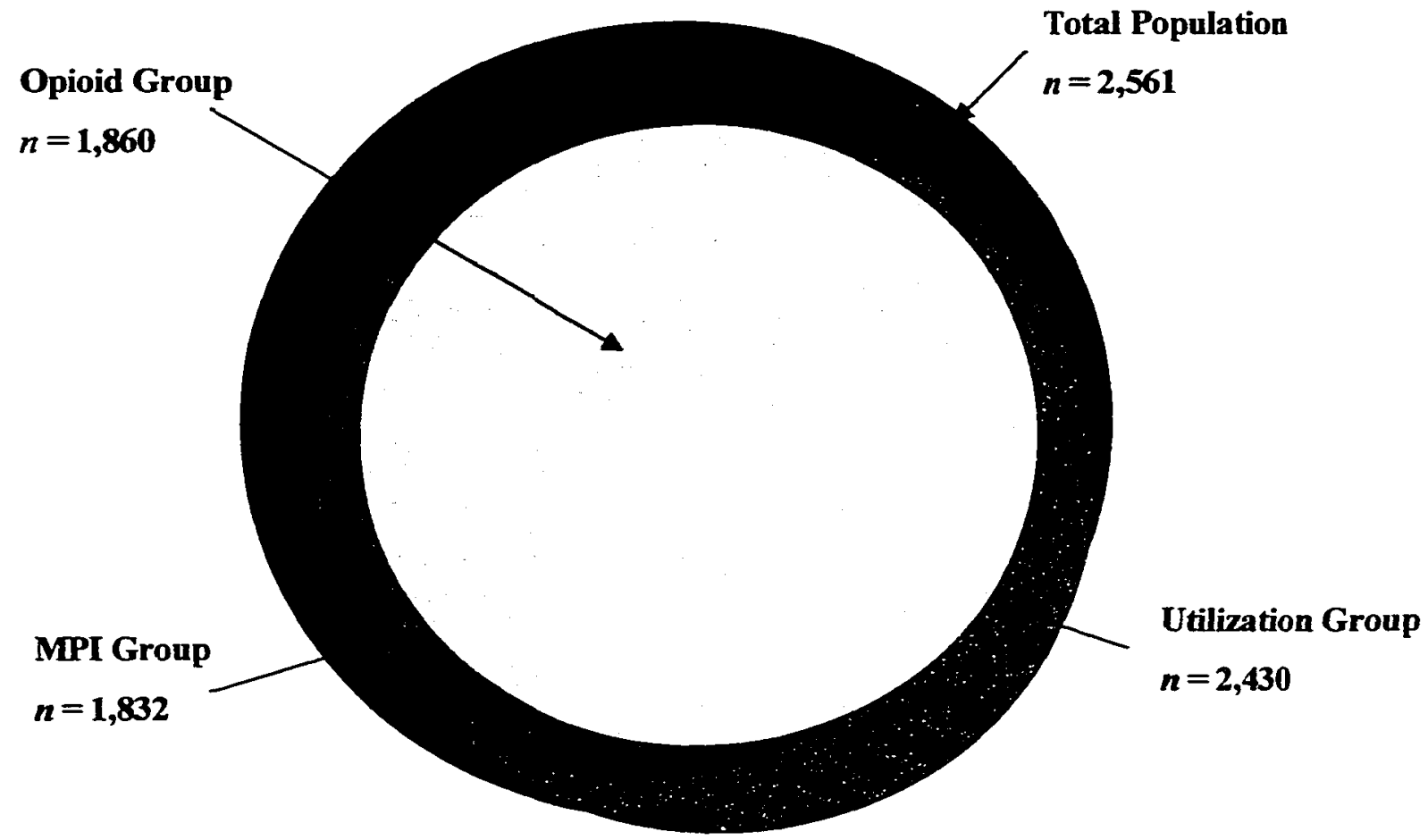

\section{Systemwide Demographics}

The third source of data came from a mandatory governmental filing published by the HMO's Underwriting Department. According to the 1997 Membership Utilization Data (1998), this Southern California HMO offered care to 2,300,231 patients. Of those patients, 774,676 were children (under the age of 20), and their systemwide demographic and utilization information was eliminated because the study population was almost exclusively adult ( $n=7$ under the age of 20 ). What remained were data on adults: $1,508,766$ patients between the ages of 20 and 64 , and 16,789 patients age 65 or older. Patients obtained coverage through employer groups, from individual plans, or by 
accessing health care through Medicare or MediCal. Of the entire HMO population, $48.6 \%$ were male and $51.4 \%$ female. Removing children from these figures, the adult HMO population consisted of $47.5 \%$ male and $52.5 \%$ female (median age found in the grouping between $40-44$ years old).

The average adult was seen 1.338 times per year by a primary care physician (family practice, general practice, or internal medicine). Patients saw speciality group physicians an average of .874 times per year. Emergency room encounters added another .143 visits per patient per year. Non-physician encounters (mental health, chemical dependency, optometry, podiatry, physicians assistants and nurse practitioners added another 1.535 visits per year. Excluding pediatric visits, adult members had an average of 3.89 DOVs per year.

\section{Information Technology Demographics}

While a wealth of information on utilization was made available through Information Technology (IT), demographic information on pain patients was limited to gender and age.

\section{$\underline{\text { Gender }}$}

As in other examples of chronic pain research (see Table 5), the total pain population of this study was dominated by women. The percentage of men and women for the Total Group is shown in Figure 2. The percentage of women participants in each group (Total, Utilization, MPI, and Opioid) varied from 74.4\% (Utilization Group) to $76.6 \%$ (MPI Group), but this variation was not statistically significant $(p=.218)$. 
Figure 2

\section{Gender Distribution of Total Group}

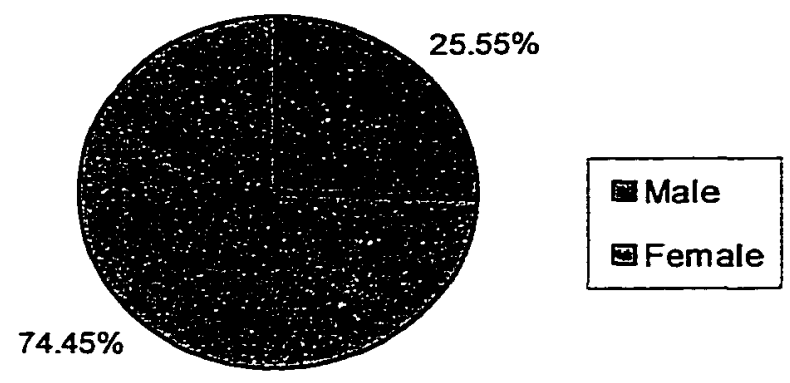

Using a one-sample case of proportion, the percentage of women in the pain group was compared to that of the HMO's general population. The proportion of women to men in the pain population far exceeded that of the general population $(z=2965, p<.001)$.

\section{Age of the Total Group}

Age was another demographic factor considered when checking consistency among the groups. The ages ranged from one participant as young as 14 to another as old as 102 . Figure 3 shows the range and frequency of ages in the Total group. 
Figure 3

Age

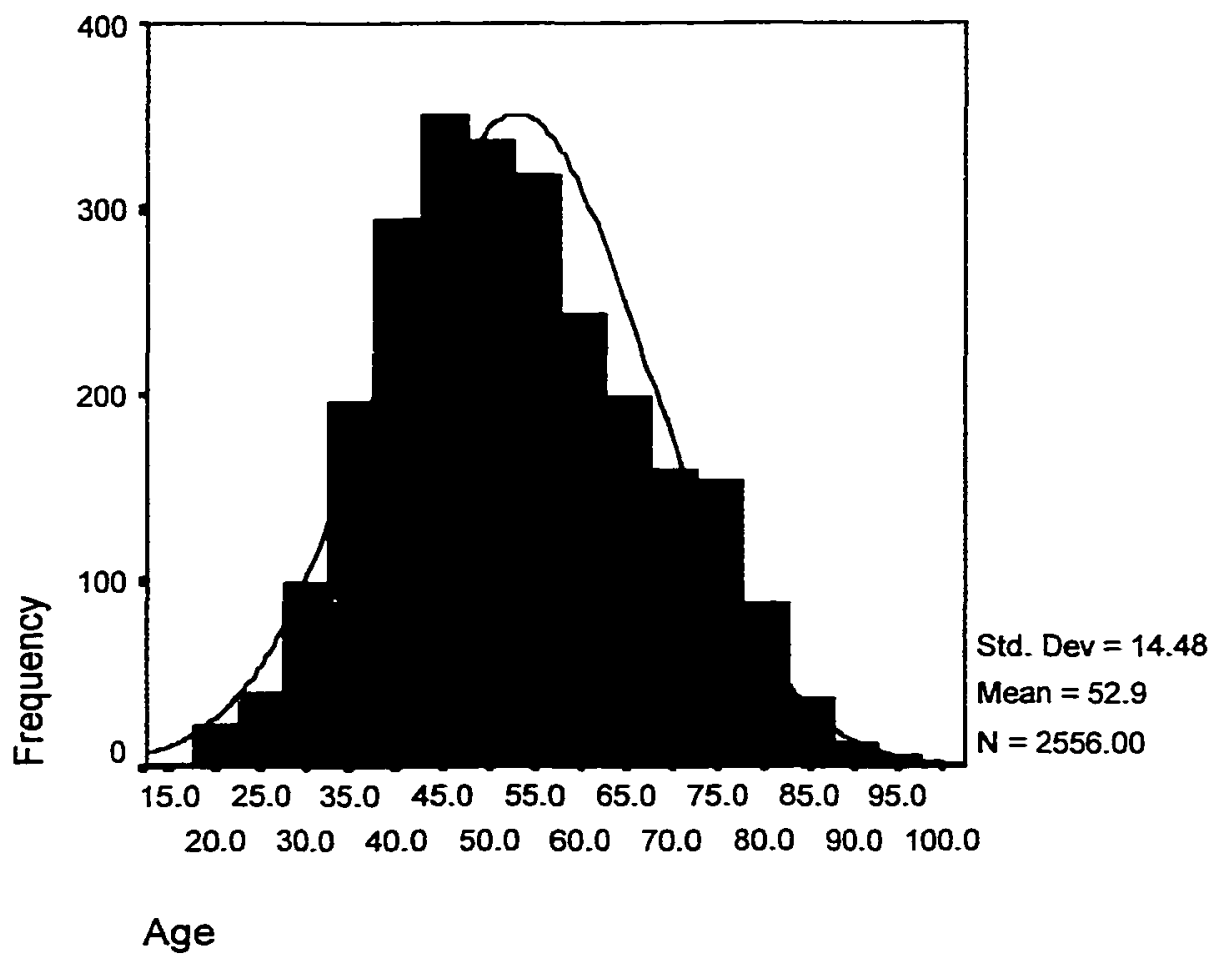

The mean age for men was 53.64 years, while women averaged 52.56 years.

However, these differences were not significant $(t=1.546, d f=1070.201, p=.122)$. In other words, there was no difference in age between men and women referred to the pain management program.

The mean age for each group in the study population (see Figure 1) ranged from 52.86 years (Total) to 53.40 years (MPI). The difference in mean ages among all groups was not significant. As portrayed above, the arrangement of ages approximated a normal distribution. 
However, the pain patients under study were considerably older when compared to the HMO adult population. The 1997 Membership Utilization Data (1998) listed frequency of ages in banded groups with the median age for the HMO population in the interval of 40-44 years old. Due to the large size of the HMO population, one would expect the frequency distribution to approximate a normal distribution, signifying that the mean and the median were similar if not the same. Using 44 years as a conservative mean age, the pain population mean of 52.86 years was significantly older $(t=30.924, p<$ $.001)$

\section{Questionnaire Demographics}

The Pain Management Program, as part of a screening process, required the completion of an eight-page questionnaire if referred patients were to attend the class (Appendix A). Pages one and two incorporated various demographic information as summarized in the following sections. I created a database of responses on 1,729 questionnaires, as these forms were kept by the program but had not been compiled or evaluated. Not every person completed every question on the form, so the number of responses to each question varied. Also, responses were self-reported and not verified with any other source. Some information provided insight, while other data were merely anecdotal.

\section{Marital Status}

As seen in Figure 4, almost $66 \%$ of 1,719 responses were married at the time the questionnaire was completed. The importance of marriage could be viewed from several aspects, from social and psychological support to financial relief. As for health insurance, 
if the spouse were employed or retired, the pain patient may have access to health care through the spouse's employer or retirement plan. Not to discount the importance of friends and family, but one-third of this population may not have had this access to financial, social, or psychological support as one might if married or legally obligated to provide for basic needs. Because pain may effect one's ability to work and can impact one's admission into a health care plan, the ability to secure medical coverage as a legal dependent can offer greater access to affordable health insurance.

Figure 4

\section{Marital Status}

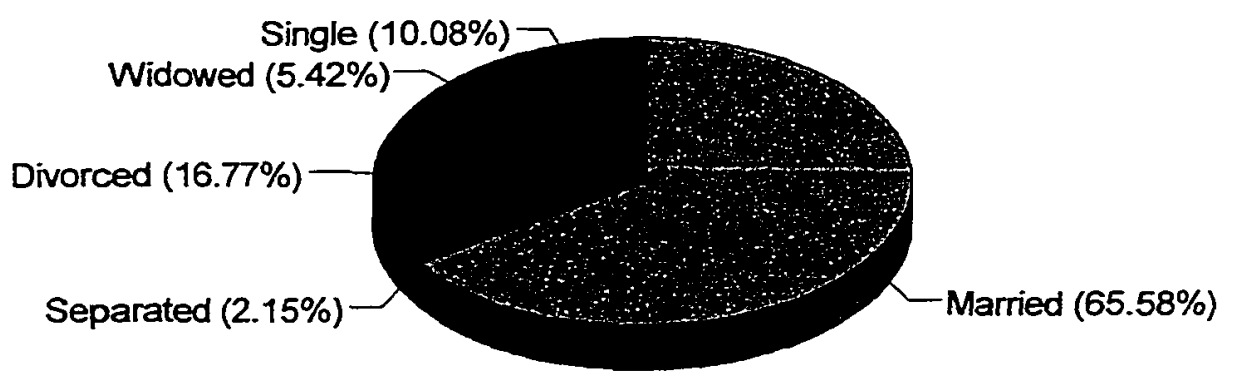

More telling of one's support system to help manage chronic pain would be the question shown in Figure 5, With whom are you currently living? Of 1,715 respondents, $85.13 \%$ mentioned living with someone else. Only 255 patients reported living alone. In 
further analysis, marital status and living arrangements could surface as a factor to one's ability to manage chronic pain.

Similarly, another question asked patients to identify their significant other. In 1,677 responses, $88.2 \%$ marked spouse or someone else as their significant other (friend, child, parent, other relative). Still, 198 responses hinted that no support system was in place.

Figure 5

With Whom Are You Currently Living?

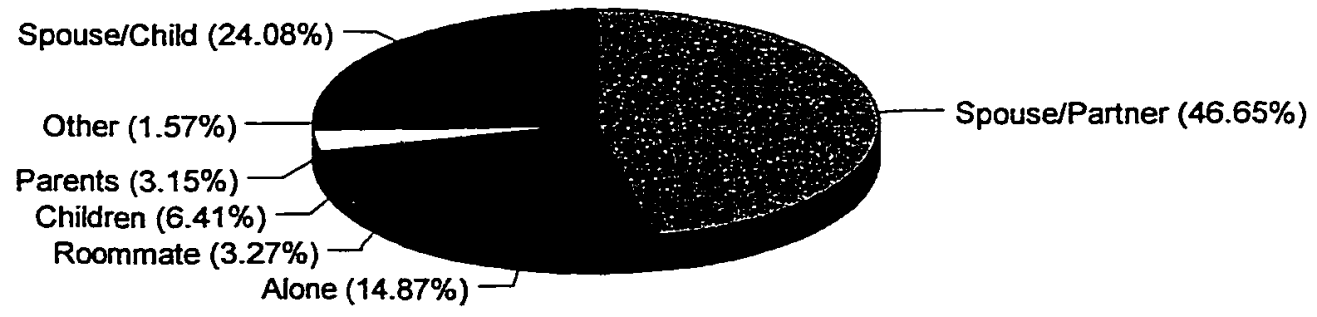

\section{Education}

The educational level of patients could also play a factor in how well the concepts presented in the Pain Management Program were understood, practiced, and integrated into daily life. In Figure 6 below, almost one-half of the respondents (831 of 1722) marked that they had experienced some college or vocational school and another one-quarter were college graduates or beyond. Superficially, this population appears highly educated. However, in a world of exploding technology and increasing job changes during the 
average worker's life, lifelong learning may be an increasingly necessary part of peoples' lives. If society demands lifelong leaming to keep up with daily activities, we will have a population that accesses learning beyond high school. When analyzing utilization information later in this chapter, an association between education and pain management may develop.

Figure 6

Educational Level

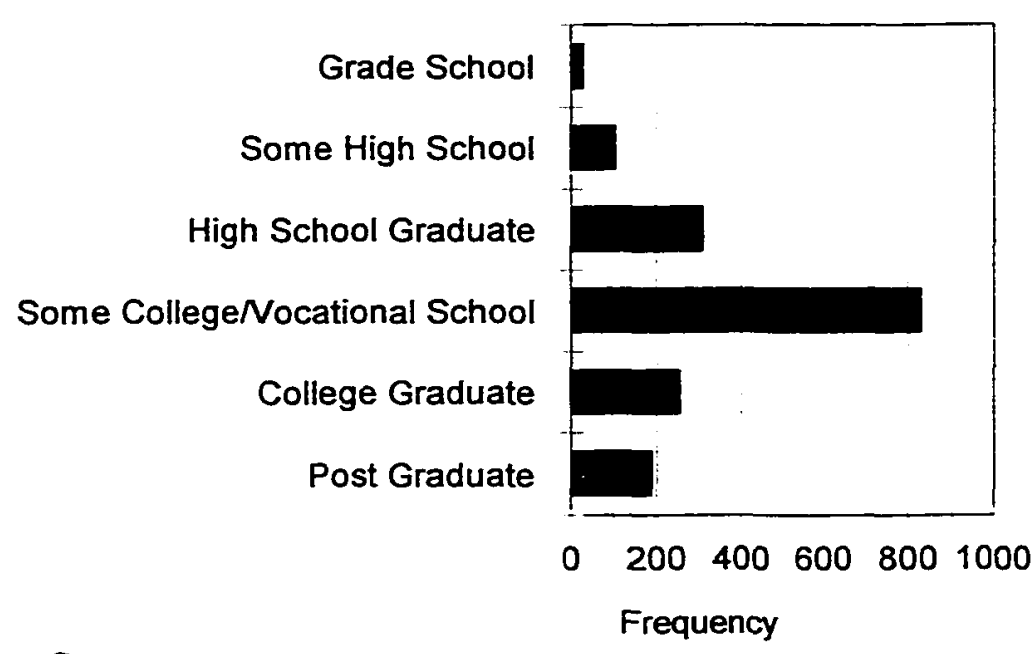

\section{Employment Status}

The image of a chronic pain patient is often characterized as someone who seeks or is already on disability. When reviewing the demographic information on employment, however, only 412 out of 1716 responders marked disabled under the question, "Which best describes your work situation now?' In Figure 7, the largest group of patients, $30.71 \%$, was employed full time $(n=527)$, with $43.06 \%(n=739)$ employed in some capacity (part or full time). Given the widespread distribution of employment situations, 
we can investigate the role of employment on outcome measures and see if someone's level of functioning affects pain.

Figure 7

\section{Employment Status}

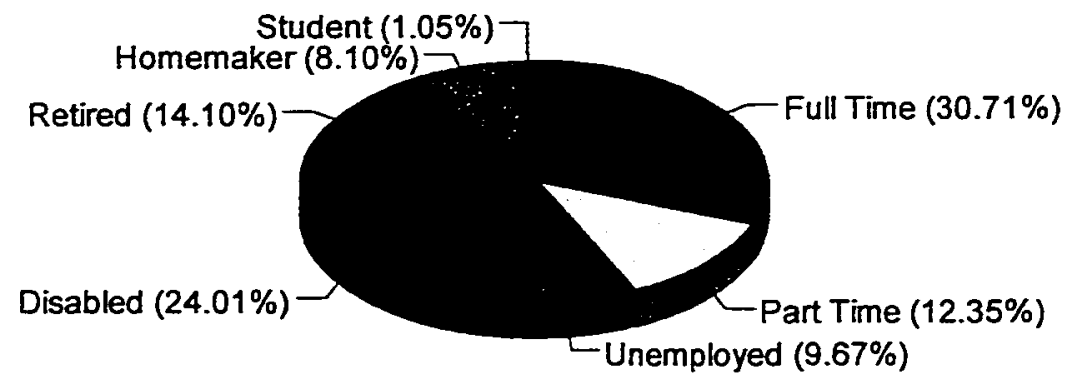

\section{Years in Pain}

In Figure 8, the report of pain years was not a normal distribution, therefore violating the basic core of parametric statistics. While the mean number of years with pain was 8.33 years, extreme scores affected the validity of using the mean as an appropriate measurement. Therefore, the median ( 4.00 years) and the mode ( 1.00 year) become more important measures as they are usually unaffected by extreme values.

Also, the first and third quartiles (2.00 years and 10.00 years respectively), were more meaningful in understanding this group. These quartiles show that one-half of all patients were referred to the program between their second and tenth year in pain. 
Figure 8

\section{Years in Pain}

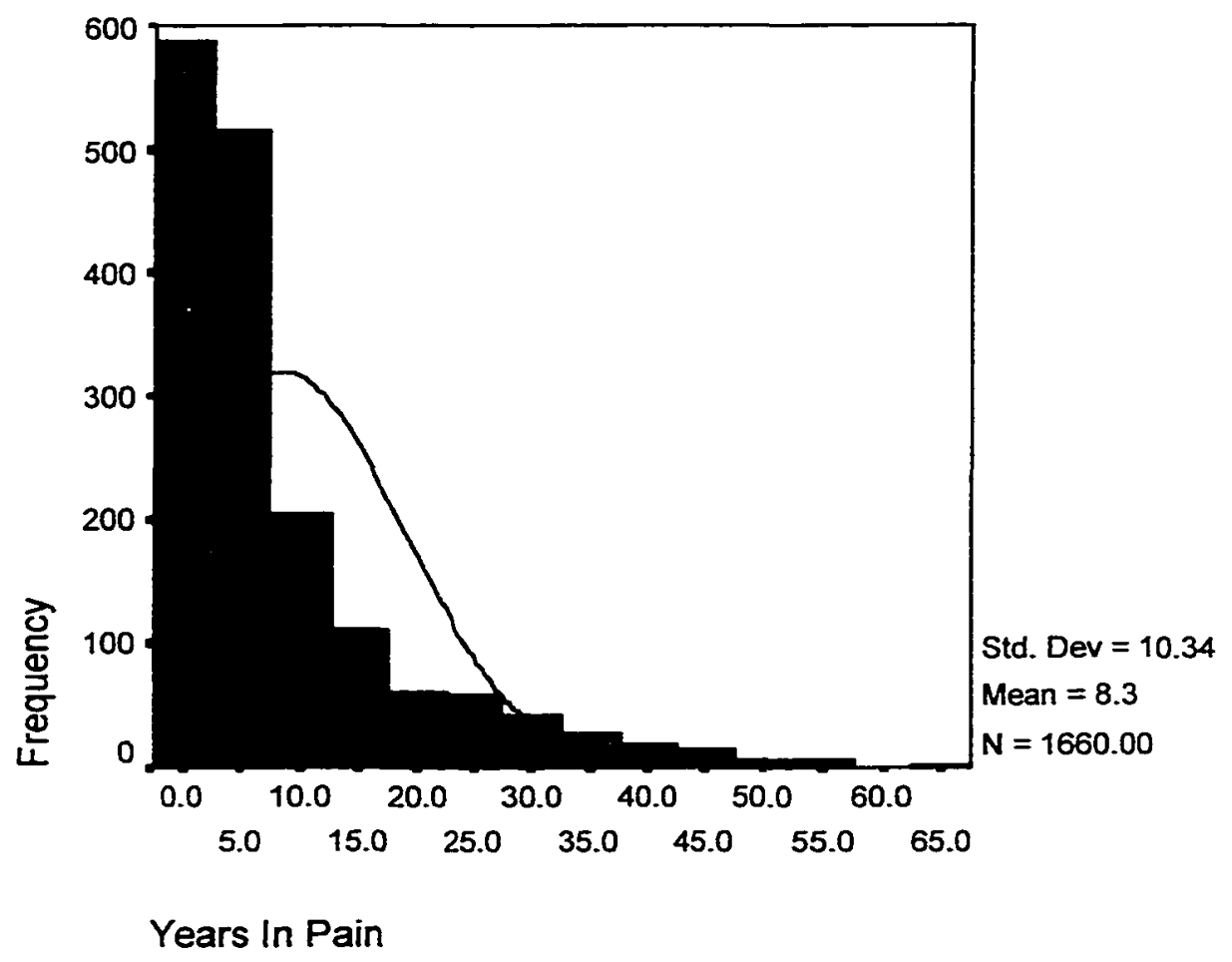

One assumption commonly used when comparing utilization information pre- and post-treatment is that patients seek medical treatment within the year before referral. When all the tests and evaluations are completed and medicine offers no cure, referral to a pain management program is the logical next step. Here, because the mode indicates that more patients were referred in their first year with pain, the one and two-year pretreatment data could confirm or deny this assumption. Not only was available pretreatment utilization analyzed, but a comparison linking the number of years with pain to annual utilization was needed. 


\section{$\underline{\text { Pain Site and Cause }}$}

Qualitatively, the questionnaire asks patients to write, "Briefly describe your pain when did it start, where is the pain, etc." To quantify this question, I read the responses and categorized them into two areas, the part of the body affected with pain $(n=1679)$ and the perceived cause of the pain $(n=593)$.

With the pain site, I was interested to see if pain was found in a specific area, or if patients experienced pain at multiple sites. In Table 9 below, pain sites reported by at least than $7 \%$ of respondents are listed.

Table 9

\section{$\underline{\text { Pain Site }}$}

\begin{tabular}{|l|c|c|}
\hline \multicolumn{1}{|c|}{ Site } & Frequency & $\begin{array}{c}\text { Percent of Total } \\
\text { Responses }\end{array}$ \\
\hline Multiple, upper and lower body & 588 & 35.0 \\
\hline Multiple, lower body only & 265 & 15.8 \\
\hline Back & 215 & 12.8 \\
\hline Multiple, upper body only & 204 & 12.2 \\
\hline Head & 123 & 7.3 \\
\hline
\end{tabular}

These five categories formed $83.1 \%$ of all responses. The next categories were legs, with 53 responses (3.2\%) and abdomen/pelvis with 44 responses (2.6\%). Other sites, each at less than $2 \%$ of respondents, included in order: neck, hand/wrist, feet/ankle, shoulder, arm, chest/breast, hips, genitalia, emotional pain, and kidney/bladder.

Fewer responses $(n=593)$ included either a diagnosis or cause for pain. Table 10 represents the eight most commonly listed causes. 
Table 10

Condition Causing Pain

\begin{tabular}{|l|c|c|}
\hline \multicolumn{1}{|c|}{ Diagnosis or Cause } & Frequency & Percentage \\
\hline Motor Vehicle Accident & 99 & 16.7 \\
\hline Headaches/Migraines & 90 & 15.2 \\
\hline Neurological & 71 & 12.0 \\
\hline Work related & 57 & 9.6 \\
\hline Herniated disc (back) & 49 & 8.3 \\
\hline Fibromyalgia & 49 & 8.3 \\
\hline Post Surgery & 49 & 8.3 \\
\hline Arthritis (osteo and rheumatoid) & 34 & 5.7 \\
\hline
\end{tabular}

The remaining causes of pain comprising at least $1 \%$ of those reporting included, in order: fracture, degenerative disc/joint disease, carpel tunnel syndrome, cancer, chronic fatigue syndrome, spasms, and reflex sympathetic dystrophy. Again, since this information was voluntary and self-reported, causes remain anecdotal and should not be construed as representative or complete.

\section{Pre-Treatment Inventories}

The three inventories incorporated into the pre-treatment questionnaire provided more information about how patients perceived pain. Included were the 11 Point Box Scale, the PDS and the MPI. All subjects who signed up for the program completed the questionnaire. All of those who did not complete questionnaires fell into the category of no participation. Of 1,310 patients who did not sign up for the program, $729(55.6 \%)$ also 
did not complete questionnaires. The other 581 patients (44.4\%) completed questionnaires but did not enroll in the pain management classes.

Eleven Point Box Scale

On pre-treatment questionnaires, 1,595 patients rated their level of pain as shown in Figure 9 below:

Figure 9

\section{Eleven Point Box Scale}

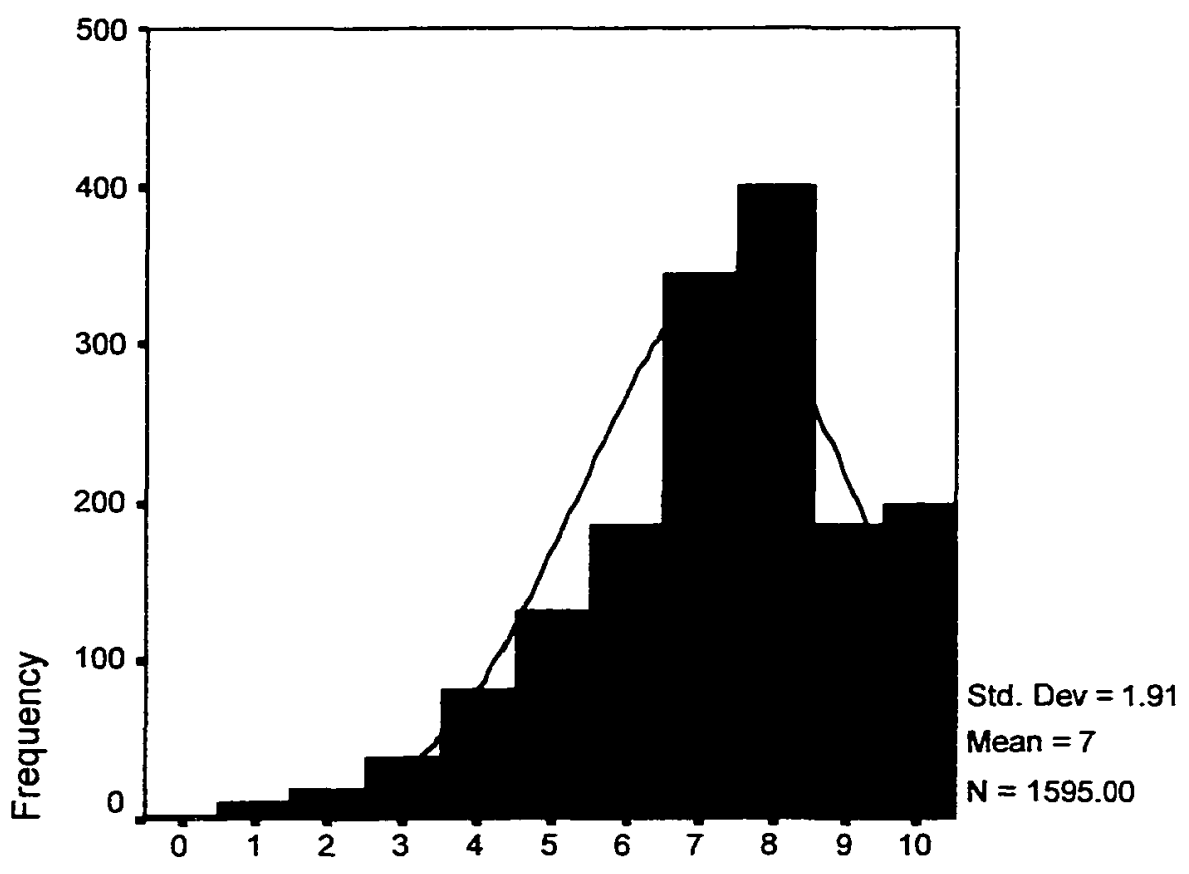

11 Point Box Scale

Although negatively skewed (-0.68), the spread of scores still adequately represents a normal distribution. The mean $(\bar{x}=7.23)$ is close to the median of 7.0 , with the mode clearly at 8.0. Quartiles are at $6.0\left(25^{\text {th }}\right.$ percentile $), 7.0\left(50^{\text {th }}\right.$ percentile $)$, and 8.0 $\left(75^{\text {th }}\right.$ percentile). 


\section{Pain Discomfort Scale (PDS)}

The Pain Discomfort Scale measures pain affect, or the suffering component of chronic pain (see Appendix A, questionnaire page 8). Here, patients were asked to read 10 statements and rank how accurately each statement reflected their own experience. Values were set between zero (very untrue) to four (very true). In five of the questions, a rating of zero would represent low pain affect (less suffering), while in the other five questions, a rating of zero would indicate high pain affect.

For the 1,582 responses, I recoded the statements so that an overall score of zero would represent low-to-no pain affect and a score of four would show high pain affect. Figure 10 below demonstrates the average scores for all respondents.

Figure 10

\section{Pain Affect as Measured by the PDS}

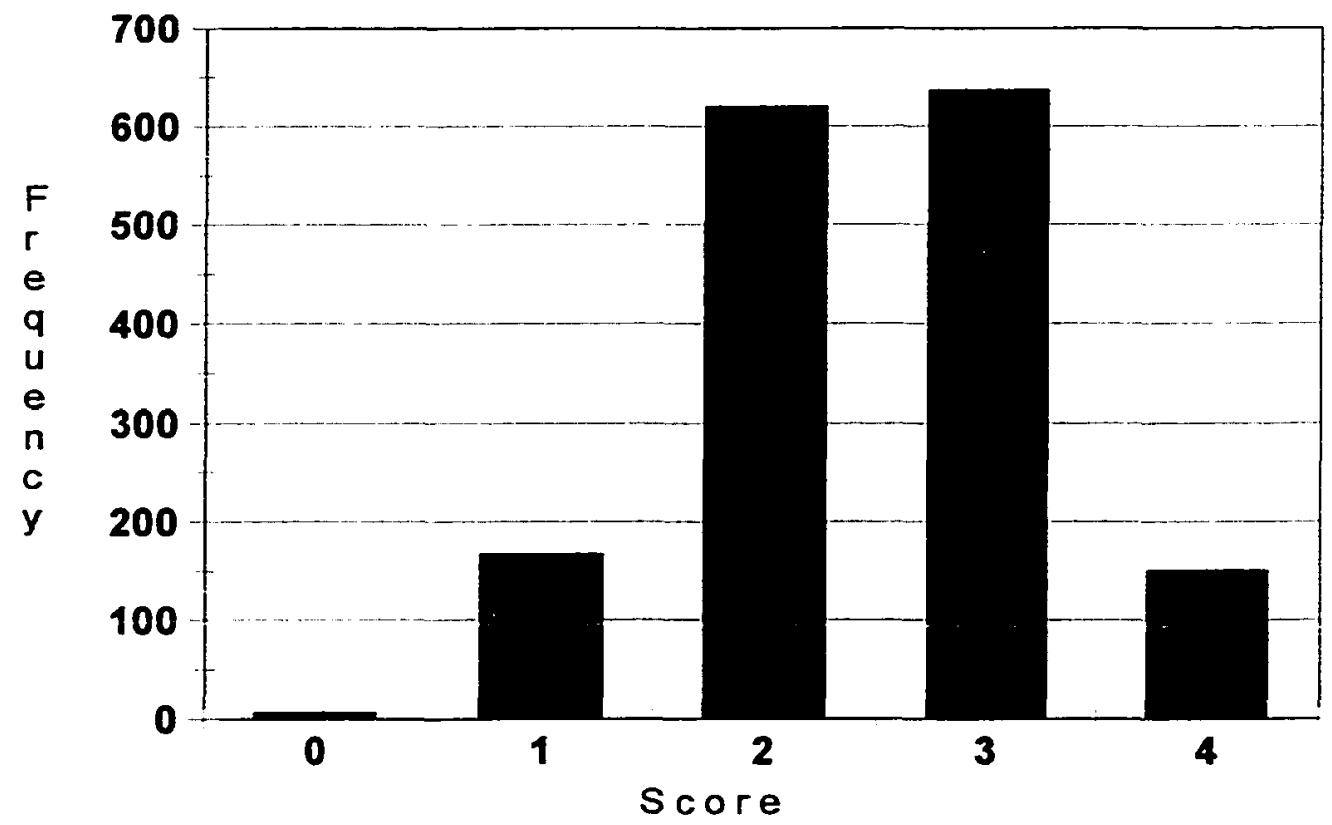


Almost $80 \%$ of patients responding indicated that their pain affect fell in the moderate-to-high range, while $9.5 \%$ rated pain affect as very high and $11.0 \%$ felt low-tono pain affect. Because a high pain affect is correlated to depression, scores in the threeto-four range warrant a closer look to see how this may effect outcome measures. Multidimensional Pain Inventory (MPI)

As previously discussed, the MPI was a valuable instrument designed for pain patients and measured the unique factors effecting them. Before calculating the various scales from respondents, I looked at seven questions that some were not able to answer within the parameters given.

Per the pre-treatment questionnaire in Appendix A, the following questions were directed at finding how much pain influences one's life and daily activities. Included were the total number of respondents and the number of patients who could not respond on a scale from zero (not at all) to six (extreme):

- Since the time your pain began, how much has your pain changed your ability to work? $(n=1,678)$. Those who retired for reasons other than pain - $132(7.9 \%)$.

- How much has your pain changed the amount of satisfaction or enjoyment you get from work? $(n=1,712)$. Those presently not working - $671(39.2 \%)$.

How often do you do each of these activities?

- $\quad$ Mow the lawn? $(n=1,712)$. Do not have a lawn - $608(35.5 \%)$.

- Work in the garden? $(n=1,715)$. Do not have a garden - $550(32.1 \%)$.

- Work on the car? $(n=1,700)$. Do not have a car - $69(4.1 \%)$.

- Wash the car? $(n=1,709)$. Do not have a car $-61(3.6 \%)$. 
- Visit relatives? $(n=1,714)$. Do not have relatives within 100 miles $-321(18.7 \%)$.

Because the 13 scales were completed only if all the questions were answered, each of the exception responses was revised to a score of three, the neutral response on a scale from zero to six. All other responses remained unchanged.

Another question asked on the MPI but not included in any of the 13 scales was the frequency with which chronic pain patients engaged in sexual activities. Using an array from zero (never) to six (very often), Figure 11 below summarizes the 1,684 responses: Figure 11

\section{Sexual Activity}

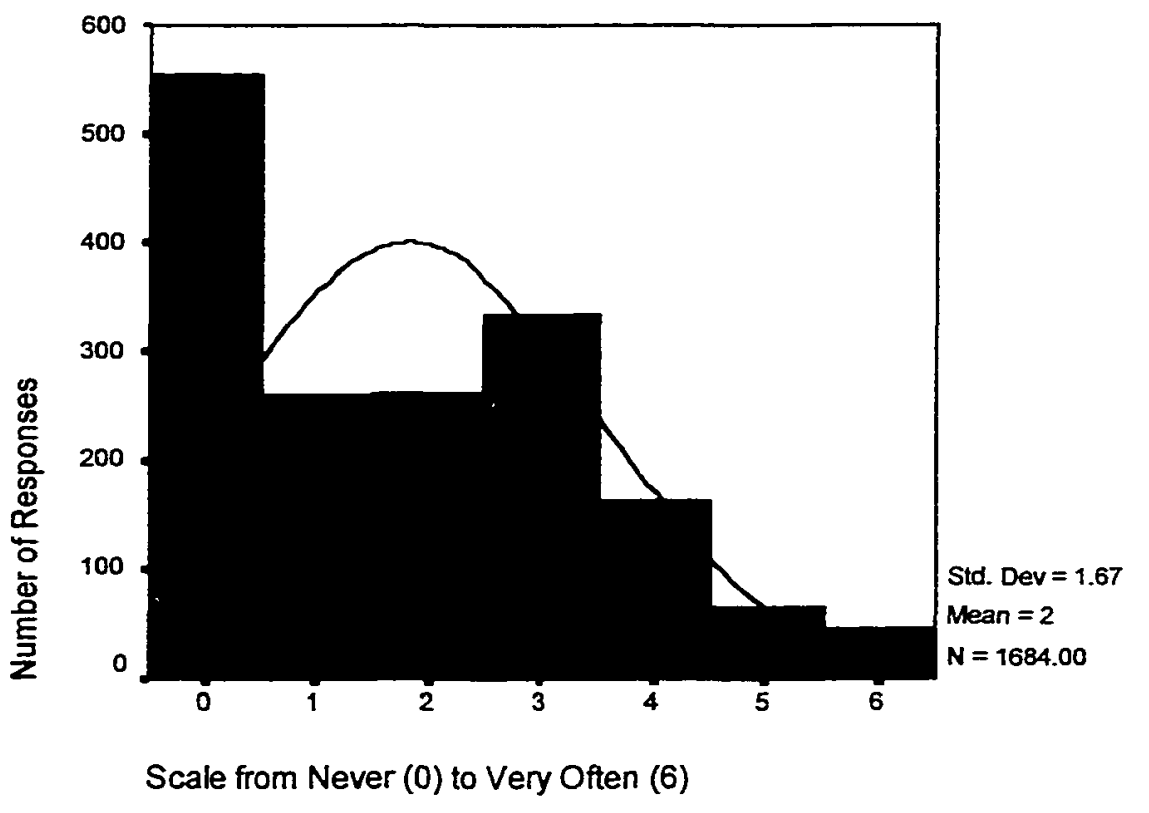

This figure is merely anecdotal and no other research data was used for comparison purposes. All the same, gender, age, and pain level were not associated with how participants rated sexual activity $(p>.05)$. 
The 13 scales of the MPI are summarized below in Table 11. Calculations

necessary to detect coping styles (adaptive, interpersonally distressed, and dysfunctional) were not available as these formulas are in the copyright process. Responses for Part I ranged from zero (no pain effect) to six (extreme). For Parts II and III, zero represented never and six is very often. Each of these scales was calculated by using between three and 11 questionnaire responses.

Table 11

MPI Scores from Pre-Treatment Questionnaires

\begin{tabular}{|c|c|c|c|c|}
\hline Scale & Identifies & $\begin{array}{c}\text { Total } \\
\text { responses }(n)\end{array}$ & $\operatorname{Mean}(\bar{x})$ & $\begin{array}{c}\text { Standard } \\
\text { Deviation }(s)\end{array}$ \\
\hline \multicolumn{5}{|c|}{ Part I - Perceived pain intensity and impact on patients' lives } \\
\hline 1 & Pain Severity & 1687 & 4.31 & 1.04 \\
\hline 2 & Interference & 1520 & 4.25 & 1.10 \\
\hline 3 & Life Control & 1673 & 2.92 & 1.20 \\
\hline 4 & Affective Distress & 1680 & 3.43 & 1.24 \\
\hline 5 & Support & 1467 & 4.22 & 1.51 \\
\hline \multicolumn{5}{|c|}{$\begin{array}{l}\text { Part } \mathbf{I} \text { - Responses of others as perceived by the patient } \\
\text { (This section is completed only by those with a significant other) }\end{array}$} \\
\hline 6 & Punishing responses & 1413 & 1.90 & 1.58 \\
\hline 7 & Solicitous responses & 1344 & 3.48 & 1.25 \\
\hline 8 & Distraction responses & 1384 & 2.16 & 1.40 \\
\hline \multicolumn{5}{|c|}{ Part III - Activity level } \\
\hline 9 & Household chores & 1657 & 3.46 & 1.57 \\
\hline 10 & Outdoor work & 1673 & 1.48 & 1.15 \\
\hline 11 & Activities away from the home & 1668 & 2.45 & 1.18 \\
\hline 12 & Social activities & 1685 & 2.03 & 1.10 \\
\hline 13 & General activity level & 1568 & 2.37 & .87 \\
\hline
\end{tabular}




\section{How Gender Related to the MPI}

In Part I, one's pain perception and its impact on life, only the Support scale showed significant differences along gender lines. Men, on average, reported feeling higher levels of support from their spouses/significant others than did women, $\bar{x}_{m}=4.65$ vs. $\bar{x}_{w}=4.07, F(1,1452)=40.30, p<.001$. There was no difference detected by gender in reported scores for Pain Severity $(F=.89, p=.35)$, Interference $(F=.57, p=.45)$, Life Control $(F=.02, p=.89)$, or Affective Distress $(F=.02, p=.90)$.

When tallying the role of one's significant other (Part II), all three scales were statistically different by gender, with men reporting more extreme values. While both genders conveyed relatively low levels, males reported more Punishing responses than did females, $\bar{x}_{m}=2.05$ vs. $\bar{x}_{w}=1.84, F(1,1398)=4.80, p=.029$. Conversely, males also revealed that significant others gave higher Solicitous responses, $\bar{x}_{m}=3.62$ vs. $\bar{x}_{w}=3.43$, $\mathrm{F}(1,1329)=5.79, p=.016$, and higher Distracting responses, $\bar{x}_{m}=2.45$ vs. $\bar{x}_{w}=2.08, F$ $(1,1369)=17.23, p<.001$.

Under Activity levels (Part III), women reported doing more household chores, $\bar{x}_{w}=3.73$ vs. $\bar{x}_{m}=2.63, F(1,1641)=162.21, p<.001$, while men disclosed more outdoor work, $\bar{x}_{\mathrm{m}}=1.95$ vs. $\overline{\mathrm{x}}_{\mathrm{w}}=1.33, \mathrm{~F}(1,1656)=94.69, p<.001$. Activities away from home $(F=.74, p=.39)$ and Social activities $(F=.97, p=.33)$ displayed no significant difference between genders. However, the General activities level was higher for women than for men, $\bar{x}_{w}=2.40$ vs. $\bar{x}_{m}=2.25, F(1,1549)=9.40, p=.002$. 
How Age Associated with the MPI

Each patient's age was assigned to a decade so that post hoc studies could be done. Because only two teenagers completed pre-treatment questionnaires, they were omitted from this part of the study. Nine of the 13 MPI scales were associated with age. Three of the nine scales exhibited significant differences between patients in their twenties and those in their eighties. All other age groups, while following a natural progression with age, remained too close to observe any significance. The remaining six scales verified differences between young aduits and the elderly, as well as middle-aged and the elderly. Table 12 shows the significantly different ages and possible conclusions. 
Table 12

How Age Associated with the MPI

\begin{tabular}{|c|c|c|c|c|}
\hline Scale & $\begin{array}{l}\text { Group } 1 \\
(\bar{x})\end{array}$ & $\begin{array}{l}\text { Group } 2 \\
(\bar{x})\end{array}$ & Statistics & $\begin{array}{l}\text { Reported Results } \\
\text { Demonstrate }\end{array}$ \\
\hline $\begin{array}{l}\text { Life } \\
\text { Control }\end{array}$ & $20 \mathrm{~s}(2.41)$ & $\begin{array}{l}60 \mathrm{~s}(3.10) \\
70 \mathrm{~s}(3.21) \\
80 \mathrm{~s}(3.05)\end{array}$ & $\begin{array}{l}\mathrm{F}(6,1500)=5.08 \\
p<.001\end{array}$ & $\begin{array}{l}\text { Semse of life control is } \\
\text { significantly higher in over 59- } \\
\text { year-olds than in twenties }\end{array}$ \\
\hline $\begin{array}{l}\text { Affective } \\
\text { Distress }\end{array}$ & $20 \mathrm{~s}(3.63)$ & $80 \mathrm{~s}(2.80)$ & $\begin{array}{l}\mathrm{F}(6,1502)=8.41 \\
p<.001\end{array}$ & $\begin{array}{l}\text { Distress is less in over } 79 \text {-year- } \\
\text { olds than those in twenties }\end{array}$ \\
\hline Support & $40 \mathrm{~s}(4.06)$ & $80 \mathrm{~s}(4.89)$ & $\begin{array}{l}\mathrm{F}(6,1315)=4.42 \\
p<.001\end{array}$ & $\begin{array}{l}\text { Pazients in forties have less } \\
\text { support than older than } 79 .\end{array}$ \\
\hline $\begin{array}{l}\text { Punishing } \\
\text { Responses }\end{array}$ & $20 \mathrm{~s}(2.47)$ & 80 s (1.29) & $\begin{array}{l}\mathrm{F}(6,1265)=4.86 \\
p<.001\end{array}$ & $\begin{array}{l}\text { Sprouses punish more in } \\
\text { twenties than in eighties. }\end{array}$ \\
\hline $\begin{array}{l}\text { Solicitous } \\
\text { Responses }\end{array}$ & $\begin{array}{l}30 \mathrm{~s}(3.39) \\
40 \mathrm{~s}(3.35) \\
50 \mathrm{~s}(3.40)\end{array}$ & $80 \mathrm{~s}(4.11)$ & $\begin{array}{l}\mathrm{F}(6,1204)=3.89 \\
p=.001\end{array}$ & $\begin{array}{l}\text { Olader spouses ( }>79 \text { years) are } \\
\text { more solicitous than in thirties, } \\
\text { forties, and fifties. }\end{array}$ \\
\hline $\begin{array}{l}\text { Distracting } \\
\text { Responses }\end{array}$ & $\begin{array}{l}40 \mathrm{~s}(2.11) \\
50 \mathrm{~s}(2.09) \\
70 \mathrm{~s}(2.06)\end{array}$ & $80 \mathrm{~s}(2.90)$ & $\begin{array}{l}\mathrm{F}(6,1235)=2.16 \\
p=.044\end{array}$ & $\begin{array}{l}\text { People over } 79 \text { years reported } \\
\text { more spouse distraction than in } \\
\text { forrties, fifties, and seventies. }\end{array}$ \\
\hline $\begin{array}{l}\text { Household } \\
\text { Chores }\end{array}$ & $\begin{array}{l}20 \mathrm{~s} \text { to } 60 \mathrm{~s} \\
(3.4 \text { to } 3.7)\end{array}$ & $80 \mathrm{~s}(2.72)$ & $\begin{array}{l}\mathrm{F}(6,1482)=3.94 \\
p=.001\end{array}$ & $\begin{array}{l}\text { Peoople eighty and older report } \\
\text { do-ing less chores than those } \\
\text { untder seventy. }\end{array}$ \\
\hline $\begin{array}{l}\text { Social } \\
\text { Activities }\end{array}$ & $20 \mathrm{~s}(2.47)$ & $\begin{array}{l}70 s(1.92) \\
80 s(1.80)\end{array}$ & $\begin{array}{l}\mathrm{F}(6,1506)=3.39 \\
p=.003\end{array}$ & $\begin{array}{l}\text { Perople in their twenties have } \\
\text { more social activities than those } \\
\text { over sixty-nine. }\end{array}$ \\
\hline $\begin{array}{l}\text { General } \\
\text { Activity } \\
\text { Scale }\end{array}$ & $20 \mathrm{~s}(2.58)$ & $80 \mathrm{~s}(2.07)$ & $\begin{array}{l}\mathrm{F}(6,1400)=3.48 \\
p=.002\end{array}$ & $\begin{array}{l}\text { General activity level is less in } \\
\text { those over } 79 \text { than those in their } \\
\text { twrenties. }\end{array}$ \\
\hline
\end{tabular}

\section{PDS and the 11 Point Box Scale}

The Pain Discomfort Scale, as previously discussed, wras designed to measure pain affect, also called suffering, as opposed to the 11 Point Box scale measuring perceived pain (the physical sensation of pain). 
The PDS inventory (see p. 8, Appendix A) incorporated ten questions requesting responses from zero (very untrue) to four (very true). Questions were posed so that someone with severe pain affect would answer five of the questions with a four and five with a zero. Recoding the database, I arranged the scales so that the lowest average score (zero) would represent no pain affect, and the highest average score (four) would indicate severe pain affect on all measures. Respondents with average PDS scores of zero were deleted from this study due to their small number $(n=6)$. Table 13 below displays the post hoc testing results.

Table 13

Comparison of the PDS with the 11 Point Box Scale (Schefféa, $)$

\begin{tabular}{|l|l|c|c|c|c|}
\hline \multirow{2}{*}{\begin{tabular}{c}
\multirow{2}{*}{$\begin{array}{c}\text { PDS } \\
\text { Revised) }\end{array}$} \\
\cline { 3 - 6 }
\end{tabular}} & & \multicolumn{4}{|c|}{$\begin{array}{c}\text { 11 Point Box Scale } \\
\text { Subset for alpha =.05 }\end{array}$} \\
\cline { 2 - 6 } & & $\mathbf{1}$ & $\mathbf{2}$ & $\mathbf{3}$ & 4 \\
\hline 2 & 154 & 5.85 & & & \\
\hline 3 & 570 & & 6.84 & & \\
\hline 4 & 605 & & & 7.63 & \\
\hline Sig. & 144 & & & & 8.56 \\
\hline
\end{tabular}

Means for groups in homogeneous subsets are displayed.

a. Uses Harmonic Mean Sample Size $=237.456$.

b. The group sizes are unequal. The harmonic mean of the group sizes is used. Type I error levels are not guaranteed.

Clearly and understandably, pain and suffering were closely linked. Since this was not a causal mode, it was not clear if pain effected suffering, or vice versa. An evaluation of patients' pain issues needs to encompass both influences on pain. 


\section{MPI and the 11 Point Box Scale}

The most dramatic correlations were seen when comparing the MPI scales with the pre-treatment 11 Point Box scale. In other words, the higher the level of perceived pain, the more pain influenced quality of life. Listed below are tables and narrative describing the six MPI scales associated with one's level of pain.

\section{Pain Severity}

As one might expect, the MPI pain severity scale had a positive, moderate-to-high correlation with the 11 Point Box scale. This one variable alone demonstrated a more associative quality that any other combination of the thirteen MPI scales (adjusted $R^{2}=$ $.451, \mathrm{~F}(1,1555)=1278.75, p<.001)$. Since the MPI scales were ranked from zero to six, and the 11 Point Box Scale asked the participant to select a number between zero and ten, some adaptation was needed to correlate the 11 Point Box Scale to the MPI pain severity scale. To show the relationship with the 11 Point Box score, the linear regression equation calculated as $\hat{\mathbf{Y}}=1.234$ (Pain Severity scale) +1.893 .

\section{Interference}

Using a One-way ANOVA, the Interference scale correlated well to the 11 Point Box score, $\mathrm{F}(9,1393)=26.775, p<.001$. Using Scheffé for post hoc testing, Table 14 illustrates how increases in the severity of pain directly impacted the Interference scale. 
Table 14

Interference Scale and the 11 Point Box Scale (Scheffé ${ }^{2 b}$ )

\begin{tabular}{|c|c|c|c|c|c|c|}
\hline \multirow{2}{*}{$\begin{array}{l}11 \text { Point } \\
\text { Scale }\end{array}$} & \multirow{2}{*}{$\mathbf{N}$} & \multicolumn{5}{|c|}{$\begin{array}{c}\text { Interference Scale } \\
\text { Subset for alpha }=.05\end{array}$} \\
\hline & & 1 & 2 & 3 & 4 & 5 \\
\hline 1 & 7 & 2.9740 & & & & \\
\hline 3 & 31 & 3.1349 & 3.1349 & & & \\
\hline 2 & 15 & 3.4152 & 3.4152 & 3.4152 & & \\
\hline 4 & 73 & 3.5392 & 3.5392 & 3.5392 & & \\
\hline 5 & 113 & 3.6227 & 3.6227 & 3.6227 & 3.6227 & \\
\hline 6 & 168 & & 3.9959 & 3.9959 & 3.9959 & 3.9959 \\
\hline 7 & 315 & & & 4.2465 & 4.2465 & 4.2465 \\
\hline 8 & 352 & & & & 4.5276 & 4.5276 \\
\hline 9 & 163 & & & & & 4.6263 \\
\hline 10 & 166 & & & & & 4.7234 \\
\hline Sig. & & .603 & .168 & .213 & .115 & .418 \\
\hline
\end{tabular}

Means for groups in homogeneous subsets are displayed.

a. Uses Harmonic Mean Sample Size $=34.667$.

b. The group sizes are tinequal. The harmonic mean of the group sizes is used. Type I error levels are not guaranteed.

\section{$\underline{\text { Life Control }}$}

One's sense of control over one's life was also directly related to the reported levels of physical pain. The higher the life control scale, the more one would feel in control. As expected, the higher the level of pain, the lower the sense of control.

Significant differences were seen with pain scores of nine and ten $\left(\bar{x}_{9}=2.52, \bar{x}_{10}=2.48\right)$ and pain scores of two or three $\left(\bar{x}_{2}=3.67, \bar{x}_{3}=3.63\right), F(9,1393)=11.95, p<.001$. 


\section{Affective Distress}

For affective distress, scales increased when self-reported pain levels were higher. Those disclosing level three pain were the least affected, $\bar{x}_{3}=2.39$, significantly lower than those reporting pain levels more than six $[(\bar{x}$ from 3.44 to 3.88$), F(9,1539)=12.89$, $p<.001]$.

\section{Activity Level}

The Outdoor Work scale showed significant differences between the genders, with men reporting more outdoor work than women $(t=8.736, p<.001)$. However, outdoor work appeared unrelated to the level of pain. Patients reporting pain at levels two, six, eight, nine, and ten ( $\bar{x}$ scores from 1.48 to 1.33$)$ participated less in outdoor activities than those who reported pain at level one, $\bar{x}_{1}=2.46, \mathrm{~F}(9,1535)=3.82, p<.001$. No significant difference appeared among the other reported levels of pain.

General activity scales appeared to have some relationship to pain levels. Understandably, patients with level one pain scored a higher overall activity level, $\bar{x}_{1}=$ 3.09 , than those with pain levels more than seven $[\bar{x}$ scores from 2.25 to $2.13 ; F(9,1437)$ $=5.06, p<.001]$.

\section{Attendance}

Of the 2,561 patients referred to the Pain Management program, four possible outcomes occurred. First, a patient did not commit to attending the program, whether by not returning the questionnaire, returning the questionnaire but not responding to at least two follow-up phone requests to schedule a class, or by refusing to register. Another 
scenario was that a patient signed up for class, but never attended. Those who attended between one and four classes were labeled as having dropped out of the program. When patients attended five or more classes, they were identified as program completers. Figure 12 below shows this breakdown of outcomes:

Figure 12

\section{$\underline{\text { Referred Patient Outcomes }}$}

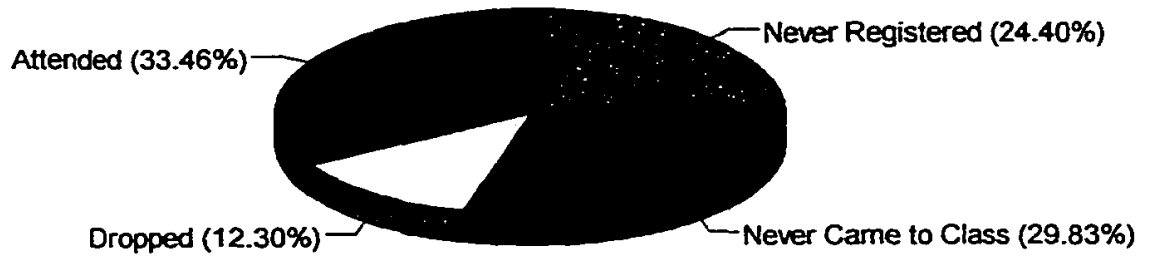

Approximately one-third of referred patients completed the program. To understand the almost $46 \%$ of patients who attended at least one session, Figure 13 demonstrates the attendance pattern. 
Figure 13

Number of Classes Attended

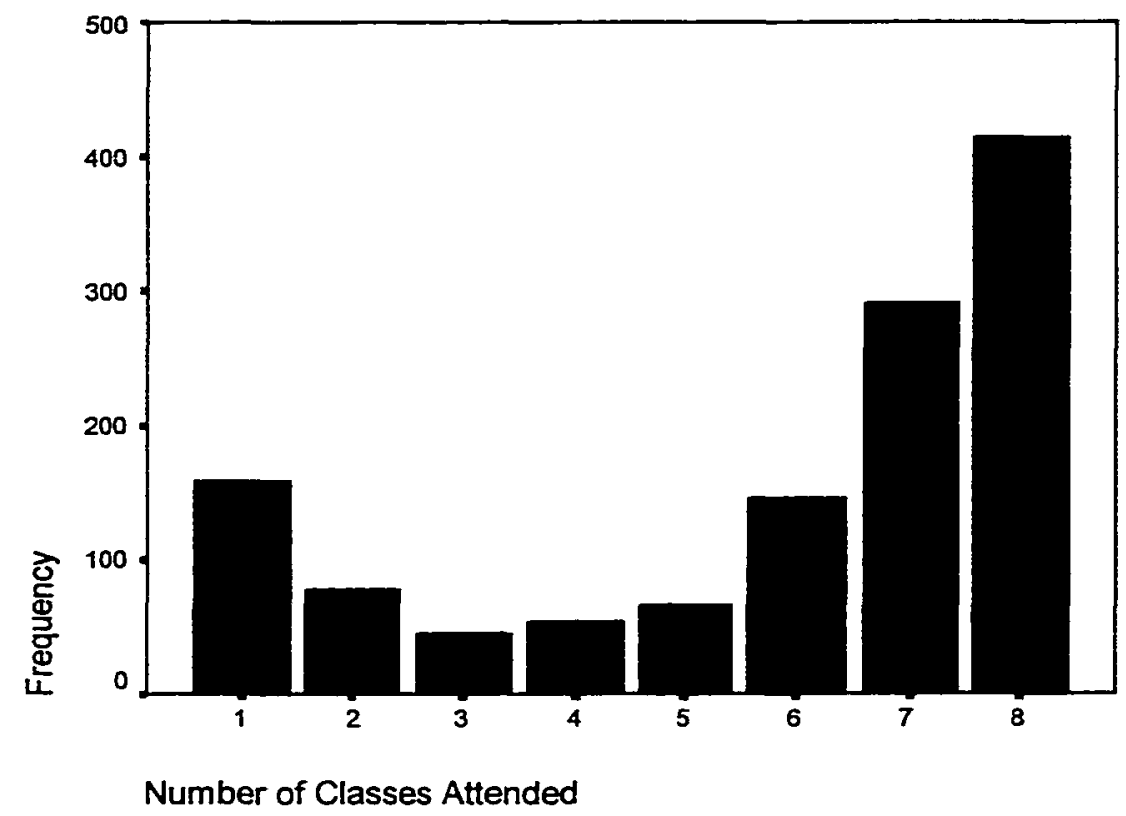

Of the 1,250 patients who attended at least one session, $12.7 \%$ did not return (including those who rescheduled for a later session). However, clearly one-third (33.1\%) attended each and every session and approximately two-thirds those who came class $(68.0 \%)$ completed the program.

\section{Follow-up Survey}

The follow-up survey was mailed to the 1,832 patients recorded as having completed the pre-treatment questionnaire, including those patients whose questionnaires were lost. This survey repeated the 11 Point Box Scale and eight MPI questions out of 61 in the original version (viz. The Screening Version of the MPI). 


\section{Eleven Point Box Scale - Post-Treatment}

As shown in Figure 14 below, the mean pain score for 700 respondents was 5.61 , an overall average decrease of 1.62 points. In percentages, a decrease in the pre-treatment mean of 7.23 to a 5.61 represents a $22.4 \%$ decline in pain scores.

When observing Figure 14, notice the more platykurtic arch (kurtosis of -.835 vs. pre-treatment kurtosis of .201 ). While the $75^{\text {th }}$ percentile remained at 8.0 , the $25^{\text {th }}$ and $50^{\text {th }}$ percentiles shifted down to 4.0 and 6.0 respectively.

Figure 14

\section{Eleven Point Box Scale (Post-Treatment)}

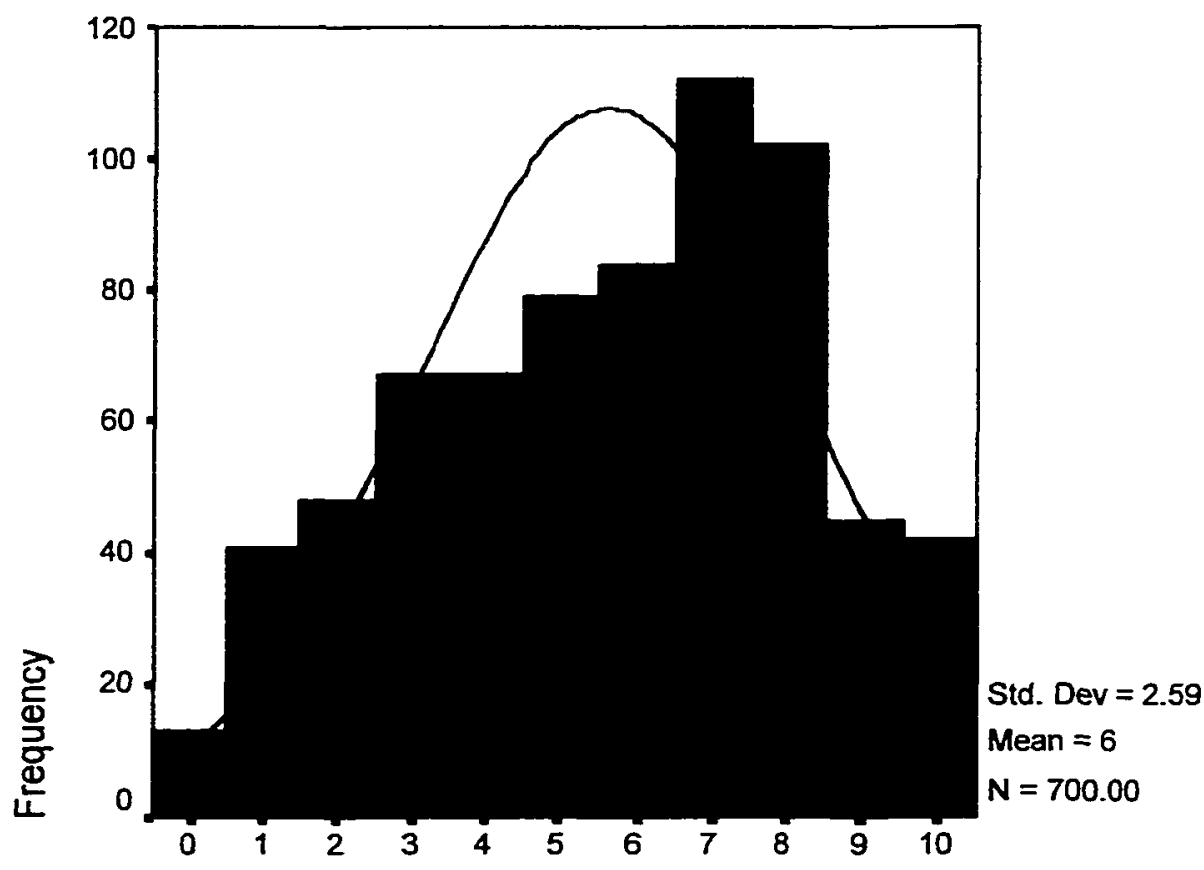

11Point Box Scale

Comparing the responses of 1,595 pre-treatment and 700 post-treatment questionnaires, 604 patients answered both 11 Point Box Scales. Using a paired-sample 
Chronic Pain 109

$t$ test, these 604 patients reported significant decreases in pain $(t=13.518, p<.001)$. To get a clearer picture of how patients' reported levels of pain changed over time, Figure 15 below compares the pre- and post-treatment responses, side-by-side:

Figure 15

\section{Comparison of Pre-Treatment and Post-Treatment 11 Point Box Scale}

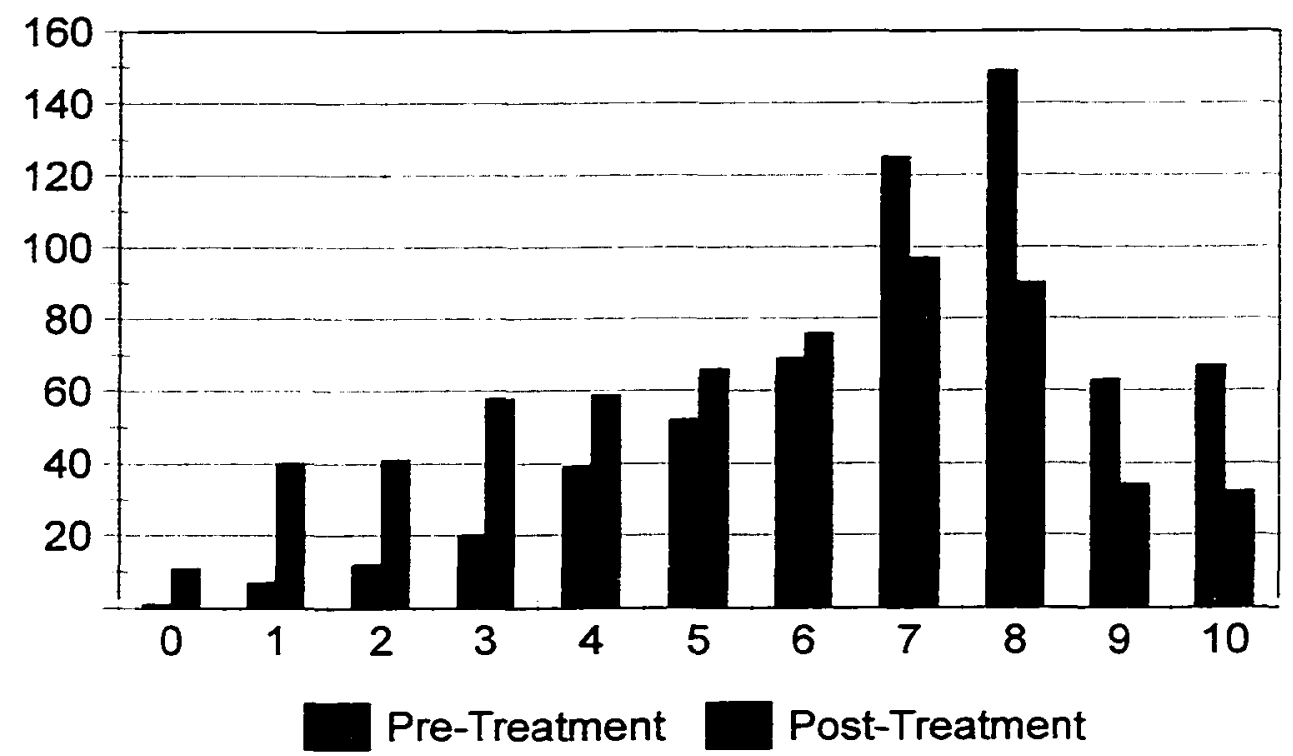

Graphically, more patients reported lower pain levels between one and five years after the initial questionnaire. Patients who attended classes reported lower pre- and posttreatment pain levels $\left(\bar{x}_{\text {pre }}=6.81\right.$ and $\left.\bar{x}_{\text {post }}=5.31\right)$. Those who did not attend reported the highest level of pre-treatment pain $\left(\bar{x}_{\text {pre }}=7.37\right.$ and $\left.\bar{x}_{\text {post }}=5.87\right)$. Patients who dropped out reported the highest level of post-treatment pain $\left(\bar{x}_{\text {pre }}=7.25\right.$ and $\left.\bar{x}_{\text {post }}=6.01\right)$. None of these differences, however, achieved statistical significance $(p>.05)$. 


\section{MPI - Post-Treatment}

The screening version of the MPI, included in the post-treatment survey, consisted of eight questions. Two questions each came from four of the MPI scale indicators: Pain Severity, Interference, Life Control, and Affective Distress.

Before comparing pre- and post-treatment scales for those who answered both questionnaires, I wanted to know the difference between the full scale scores, all pretreatment responses on the two-question set for each screening scale, the pre-treatment scales for those answering the post-treatment surveys, and the post-treatment scales. Table 15 below summarizes these groups and their ratings.

Table 15

Comparison for Scales on the MPI

\begin{tabular}{|l|c|c|c|c|c|}
\hline & $\begin{array}{c}\text { Full Scale - } \\
\text { pre-treat } \\
\text { MPI Group } \\
(n)\end{array}$ & $\begin{array}{c}2 \text { Question } \\
\text { Scale } \\
\text { MPI Group } \\
(n)\end{array}$ & $\begin{array}{c}2 \text { Question } \\
\text { Scale - pre- } \\
\text { treat - } \\
\text { paired }(n)\end{array}$ & $\begin{array}{c}2 \text { Question } \\
\text { Scale - } \\
\text { post-treat - } \\
\text { paired }(n)\end{array}$ & $\begin{array}{c}\text { Comments - } \\
\text { Pre/Post } \\
\text { significance }\end{array}$ \\
\hline $\begin{array}{l}\text { Pain } \\
\text { Severity }\end{array}$ & $\begin{array}{c}4.31 \\
(1,687)\end{array}$ & $\begin{array}{c}4.13 \\
(1,699)\end{array}$ & $\begin{array}{c}4.00 \\
(643)\end{array}$ & $\begin{array}{c}3.52 \\
(643)\end{array}$ & $\begin{array}{c}\text { Decreased } \\
t=8.42, p<.001\end{array}$ \\
\hline Interference & $\begin{array}{c}4.25 \\
(1,520)\end{array}$ & $\begin{array}{c}4.85 \\
(1,706)\end{array}$ & $\begin{array}{c}4.74 \\
(645)\end{array}$ & $\begin{array}{c}4.08 \\
(645)\end{array}$ & $\begin{array}{c}\text { Decreased } \\
t=10.43, p<.001\end{array}$ \\
\hline Life Control & $\begin{array}{c}2.92 \\
(1,673)\end{array}$ & $\begin{array}{c}3.30 \\
(1,695)\end{array}$ & $\begin{array}{c}3.44 \\
(645)\end{array}$ & $\begin{array}{c}3.86 \\
(645)\end{array}$ & $\begin{array}{c}\text { Increased } \\
t=6.51, p<.001\end{array}$ \\
\hline Affective & 3.43 & 3.61 & 3.51 & 3.27 & $\begin{array}{c}\text { Decreased } \\
\text { Distress }\end{array}$ \\
\hline
\end{tabular}

The first consideration was the difference between the full rating of these four scales as compared to the two-question screening version. Similarly, did the screening version adequately resemble the full version? Because of the large number of subjects, 
significant differences were easier to detect. In fact, all comparisons demonstrated statistical significance.

Full scale Pain Severity was computed using three questions from the pretreatment questionnaire. As with all the other scales, individual questions were answered on a Likert scale from zero (no pain or suffering) to six (extreme pain and/or suffering). The most severe rating found was for the full version $\left(\bar{x}_{\mathrm{fv}}=4.31\right)$, higher than the pretreatment screening version $\left(\bar{x}_{\mathrm{sv}}=4.13\right)$ in a paired-samples $t$ test $(t=18.78, p<.001)$.

The Interference scale used 11 questions centering around how pain interferes with activities and relationships, where zero indicated no change at all and six measured an extreme change. Here, the full version rating $\left(\bar{x}_{\mathrm{fv}}=4.25\right)$ was much lower than the screening version $\left(\bar{x}_{\mathrm{sv}}=4.85, t=-33.18, p<.001\right)$.

For the Life Control scale, four questions were asked on the pre-treatment questionnaire, but for this measurement the scale was reversed. A score of zero in this set represented no control over pain, problems, planning and stressful situations, while a score of six equated to success. The lowest (most dysfunctional) score came from the full version scale (2.92), significantly lower than the screening score $\left(\bar{x}_{\mathrm{sv}}=3.30, t=-25.65, p\right.$ $<.001)$

Finally, the Affective Distress scale, based on three questions, was lower (less dysfunctional) than using the screening version $(t=-13.62, p<.001)$. These questions asked participants to rate their mood, irritability, and anxiety.

The size of each group on Table 13 represented the total number of participants answering all questions within the four scales. The number of those completing the 
screening version pre-treatment (two questions each) was larger than the number completing the full version (from three to eleven questions). Leaving even one question unanswered in any part resulted in no score for that particular scale.

Next, the question arose, did patients score better post-treatment? For this comparison, the screening version pre-treatment scores were matched to responses on the post-treatment survey. In each scale, patients demonstrated significantly less dysfunction and more control with time. Also, I ran a One-way ANOVA matching the full scale pretreatment and screening version pre-treatment to the screening version post-treatment scores. Once again, each of the four scales was significantly different pre- and posttreatment ( $F$ from 2.428 to $8.404, p \leq .001$ ).

\section{Total Quality Questions on Follow-up Surveys}

Most of the pre- and post-treatment results have already been analyzed during this study. Patient satisfaction, however, remained to be evaluated. Three questions about patient satisfaction were addressed in the post-treatment survey. How useful has the Pain Management Program been in helping you to manage pain?

The focus of this question was to measure patients' perception on the utility of the techniques taught in the Pain Management Program. The survey asked patients to rate their reply on a scale from zero (not at all useful) to six (extremely useful). Computing a One-way ANOVA between usefulness ratings and class attendance, patients who did not come to class $\left(n_{n s}\right)$ and those who dropped out $\left(n_{\mathrm{d}}\right)$ rated the program's usefulness on the negative side of neutral, $\bar{x}_{n s}=2.47, \bar{x}_{d}=2.57$. Patients who completed at least five 
sessions of the program $\left(n_{\mathrm{c}}\right)$ indicated positive usefulness, significantly higher than those who dropped or never came $\left[\bar{x}_{c}=4.01, F(2,673)=46.33, p<.001\right]$.

How satisfied were you with the Pain Management Program?

Patient satisfaction also remained high for program completers $\left(\bar{x}_{c}=4.47\right)$, while those who dropped or never came reported neutral scores $\left(\bar{x}_{d}=3.08, \bar{x}_{n s}=3.17\right.$ respectively). Satisfaction levels for those attending the program were high enough to achieve statistical significance, $F(2,670)=36.93, p<.001$.

Today, how would you rate the cause or condition for your referral to the program?

The parameters of this response ranged from zero (much worse) to six (much better). Even with high satisfaction and usefulness scores for program completers, all groups responded with averaged scores ranging from 3.16 to 3.39 , despite attendance. What this means is that their condition had not changed. In some cases, the condition was even worse with time, confirming the notion that chronic pain was not curable.

\section{Medical Utilization}

Doctor Office Visits (DOVs) and opioid pain prescriptions were included in the HMO's utilization information. The total data set was gathered for three years and eight months (e.g., 44 months). Because annual utilization (in whole years) was important in understanding and comparing these patients, data were further refined into total annual increments. Depending on the start and end dates of each class, counts and costs were divided into complete years, pre- and/or post-treatment. For approximately one-half of the patients, two complete years of utilization data were available. For the remaining patients, three years pre- and/or post-treatment data were gathered ( $\bar{x}=2.54$ years). The 
information captured here was for actual DOVs, and does not reflect the number of referrals to specialty departments which may have been written but not scheduled.

\section{Outpatient DOVs}

A total of 131,256 DOVs for 2,430 patients was recorded between January 1 , 1994 and August 31, 1997. For departments that saw at least $2 \%$ of total DOVs, Table 16 below provides a breakdown of those visits.

Table 16

Summary of DOVs by Department

\begin{tabular}{|l|c|c|}
\hline \multicolumn{1}{|c|}{ Department } & Number of DOVs & $\begin{array}{c}\text { Percent of } \\
\text { Total DoVs }\end{array}$ \\
\hline Family Practice \& Internal Medicine & $* 54,313$ & $41.4 \%$ \\
\hline Physical Therapy \& Occupational Therapy & 12,062 & 9.2 \\
\hline Psychiatry & 7,929 & 6.0 \\
\hline Emergency & 7,260 & 5.5 \\
\hline Orthopedics & 6,577 & 5.0 \\
\hline Ophthalmology \& Optometry & 6,533 & 5.0 \\
\hline Obstetrics \& Gynecology & 4,698 & 3.6 \\
\hline Dermatology & 3,946 & 3.0 \\
\hline Neurology \& Neurosurgery & 3,838 & 2.9 \\
\hline Physical Medicine and Rehabilitation & 3,827 & 2.9 \\
\hline Chemical Dependency and Recovery & 2,783 & 2.1 \\
\hline
\end{tabular}

* Included 5,105 Urgent Care visits (9.4\% of primary care visits, $3.9 \%$ of total visits).

As expected, Primary Care (Family Practice and Internal Medicine) saw the most patients. Because Urgent Care is staffed by primary care physicians, Urgent Care visits were included under the umbrella of Primary Care. Of interest, however, was that chronic 
pain patients visited the Emergency Department 1.41 times more often than Urgent Care (7,260 vs. 5,105 visits). This data did not include a diagnosis or distinguish between acute pain, chronic pain, and non pain visits. With few exceptions, the Emergency Department is not the appropriate place to seek treatment for chronic pain. Learning where to seek appropriate treatment was one of the topics covered in the Pain Management Program.

To further understand utilization patterns, Table 17 looks at how 2,430 chronic pain patients used HMO services in these same departments over the 44-month period from January 1, 1994 to August 31, 1997. Included were the total number of patients using each department's services as well as the respective percentage of all 2,430 chronic pain patients, the average number of visits for those patients using each department (annual and total) and the average number of annual visits for all 2,430 chronic pain patients. In contrast, the annual utilization of the total adult HMO population was 1.338 DOVs for Primary Care, 0.87 for all specialities combined, and 0.14 for the Emergency Department per year. The assumption underlying the calculations below was that each chronic pain patient had coverage for all 44 months. Since some patients changed or lost their health coverage, these figures may be understated. 
Table 17

Analysis of Medical Services Used by Chronic Pain Patients

\begin{tabular}{|c|c|c|c|}
\hline Department & $\begin{array}{l}\text { Number (and \%) } \\
\text { of pain patients } \\
\text { using this dept. }\end{array}$ & $\begin{array}{c}\text { Average }(\bar{x}) \\
\text { Annual (Total) } \\
\text { DOVs for } \\
\text { patients seen }\end{array}$ & $\begin{array}{l}\text { Average }(\bar{x}) \\
\text { Annual DOVs } \\
\text { for all pain } \\
\text { patients }\end{array}$ \\
\hline $\begin{array}{l}\text { Family Practice \& } \\
\text { Internal Medicine }\end{array}$ & $\begin{array}{c}2,398 \\
(98.7 \%)\end{array}$ & $\begin{array}{c}6.17 \\
(22.65)\end{array}$ & $\begin{array}{c}6.10 \\
(22.35)\end{array}$ \\
\hline $\begin{array}{l}\text { Physical Therapy \& } \\
\text { Occupational Therapy }\end{array}$ & $\begin{array}{c}1,265 \\
(52.1 \%)\end{array}$ & $\begin{array}{c}2.60 \\
(9.54)\end{array}$ & $\begin{array}{l}1.35 \\
(4.96)\end{array}$ \\
\hline $\begin{array}{l}\text { Psychiatry and } \\
\text { Social Services }\end{array}$ & $\begin{array}{c}935 \\
(38.5 \%)\end{array}$ & $\begin{array}{l}2.31 \\
(8.40)\end{array}$ & $\begin{array}{c}0.89 \\
(3.26)\end{array}$ \\
\hline Emergency & $\begin{array}{c}1,571 \\
(64.7 \%)\end{array}$ & $\begin{array}{c}1.26 \\
(4.62)\end{array}$ & $\begin{array}{c}0.81 \\
(2.99)\end{array}$ \\
\hline Orthopedics & $\begin{array}{c}1058 \\
(43.5 \%)\end{array}$ & $\begin{array}{c}1.70 \\
(6.22)\end{array}$ & $\begin{array}{c}0.74 \\
(2.71)\end{array}$ \\
\hline $\begin{array}{l}\text { Ophthalmology \& } \\
\text { Optometry }\end{array}$ & $\begin{array}{c}1,619 \\
(66.7 \%)\end{array}$ & $\begin{array}{c}1.10 \\
(4.04)\end{array}$ & $\begin{array}{c}0.73 \\
(2.69)\end{array}$ \\
\hline $\begin{array}{l}\text { Obstetrics \& } \\
\text { Gynecology }\end{array}$ & $\begin{array}{c}925 \\
(38.1 \%)\end{array}$ & $\begin{array}{c}1.39 \\
(5.08)\end{array}$ & $\begin{array}{c}0.53 \\
(1.93)\end{array}$ \\
\hline Dermatology & $\begin{array}{c}905 \\
(37.2 \%)\end{array}$ & $\begin{array}{c}1.19 \\
(4.36)\end{array}$ & $\begin{array}{c}0.44 \\
(1.62)\end{array}$ \\
\hline $\begin{array}{l}\text { Neurology \& } \\
\text { Neurosurgery }\end{array}$ & $\begin{array}{c}1048 \\
(43.1 \%)\end{array}$ & $\begin{array}{c}1.00 \\
(3.66)\end{array}$ & $\begin{array}{c}0.43 \\
(1.58)\end{array}$ \\
\hline $\begin{array}{l}\text { Physical Medicine and } \\
\text { Rehabilitation }\end{array}$ & $\begin{array}{c}977 \\
(40.2 \%)\end{array}$ & $\begin{array}{c}1.07 \\
(3.92)\end{array}$ & $\begin{array}{c}0.43 \\
(1.57)\end{array}$ \\
\hline $\begin{array}{l}\text { Chemical Dependency and } \\
\text { Recovery }\end{array}$ & $\begin{array}{c}186 \\
(7.5 \%)\end{array}$ & $\begin{array}{c}4.08 \\
(15.0)\end{array}$ & $\begin{array}{c}0.31 \\
(1.15)\end{array}$ \\
\hline
\end{tabular}

To examine whether the chronic pain patients seen in each of the above departments differed from all chronic pain patients in this group, each patient's gender and age was calculated and compared to the demographics previously discussed. For Post-Hoc testing purposes, ages were grouped into seven different decades: those less than 30 years 
old (group 2), the five decades between age 30 and 79 (groups 3-7), and all patients more than 79 years of age (group 8). Returning to the analysis of medical utilization by department, Table 18 below shows how close those using each specialty resembled the 2,430 chronic pain patients recorded as having at least one DOV.

Table 18

Gender and Age by Department

\begin{tabular}{|c|c|c|c|c|}
\hline Department & $\begin{array}{l}\text { Breakdown } \\
\text { by Gender }\end{array}$ & $\begin{array}{l}\text { Average Age } \\
\text { (decade) }\end{array}$ & $\begin{array}{l}\text { Difference from } \\
\text { Study Population } \\
\text { (gender/age) }\end{array}$ & $\begin{array}{c}\text { Difference in \# of } \\
\text { DOVs by } \\
\text { gender/age }\end{array}$ \\
\hline $\begin{array}{l}\text { All Chronic Pain Patients } \\
\text { in study }\end{array}$ & $\begin{array}{l}25.3 \% \mathrm{M} \\
74.7 \% \mathrm{~F}\end{array}$ & $\begin{array}{l}52.86 \\
(4.83)\end{array}$ & N/A & N/A \\
\hline $\begin{array}{l}\text { Family Practice \& } \\
\text { Internal Medicine }\end{array}$ & $\begin{array}{l}25.4 \% \mathrm{M} \\
74.6 \% \mathrm{~F}\end{array}$ & $\begin{array}{l}52.94 \\
(4.84)\end{array}$ & $\begin{array}{l}\text { No, } p=.476 \\
\text { No, } t=0.31\end{array}$ & $\begin{array}{l}\text { No, } t=-1.60 \\
\text { Yes, } F=5.55^{* * *}\end{array}$ \\
\hline $\begin{array}{l}\text { Physical Therapy \& } \\
\text { Occupational Therapy }\end{array}$ & $\begin{array}{l}23.3 \% \mathrm{M} \\
76.7 \% \mathrm{~F}\end{array}$ & $\begin{array}{l}53.76 \\
(4.91)\end{array}$ & $\begin{array}{l}\text { No, } p=.056 \\
\text { Yes, } t=2.31^{*}\end{array}$ & $\begin{array}{l}\text { No, } t=-1.06 \\
\text { No, } F=0.74\end{array}$ \\
\hline $\begin{array}{l}\text { Psychiatry and } \\
\text { Social Services }\end{array}$ & $\begin{array}{l}21.4 \% \mathrm{M} \\
78.6 \% \mathrm{~F}\end{array}$ & $\begin{array}{l}49.57 \\
(4.50)\end{array}$ & $\begin{array}{l}\text { Yes, } p=.003^{* *} \\
\text { Yes, } t=-7.89^{* *}\end{array}$ & $\begin{array}{l}\text { Yes, } t=-5.64^{* * *} \\
\text { No, } F=1.71\end{array}$ \\
\hline Emergency & $\begin{array}{l}25.5 \% \mathrm{M} \\
74.5 \% \mathrm{M}\end{array}$ & $\begin{array}{l}52.96 \\
(4.83)\end{array}$ & $\begin{array}{l}\text { No, } p=.444 \\
\text { No, } t=0.26\end{array}$ & $\begin{array}{l}\text { No, } t=-1.19 \\
\text { Yes, } F=4.822^{* * *}\end{array}$ \\
\hline Orthopedics & $\begin{array}{l}24.8 \% \mathrm{M} \\
75.2 \% \mathrm{~F}\end{array}$ & $\begin{array}{l}54.68 \\
(5.00)\end{array}$ & $\begin{array}{l}\text { No, } p=.444 \\
\text { Yes, } t=4.07^{* * *}\end{array}$ & $\begin{array}{l}\text { No, } t=0.74 \\
\text { No, } F=0.55\end{array}$ \\
\hline $\begin{array}{l}\text { Ophthalmology \& } \\
\text { Optometry }\end{array}$ & $\begin{array}{l}23.3 \% \mathrm{M} \\
76.7 \% \mathrm{~F}\end{array}$ & $\begin{array}{l}55.96 \\
(5.13)\end{array}$ & $\begin{array}{l}\text { Yes, } p=.038^{*} \\
\text { Yes, } t=8.70^{* * *}\end{array}$ & $\begin{array}{l}\text { No, } t=-0.46 \\
\text { Yes, } F=36.45^{* * *}\end{array}$ \\
\hline $\begin{array}{l}\text { Obstetrics \& } \\
\text { Gynecology }\end{array}$ & $\begin{array}{c}0.0 \% \mathrm{M} \\
100.0 \% \mathrm{~F}\end{array}$ & $\begin{array}{l}48.81 \\
(4.43)\end{array}$ & $\begin{array}{l}\text { Yes, } p<.00 \mathrm{I}^{* * *} \\
\text { Yes, } t=-9.33^{* * *}\end{array}$ & $\begin{array}{l}\text { Yes**** } \\
\text { Yes, } F=13.02^{* * *}\end{array}$ \\
\hline Dermatology & $\begin{array}{l}22.4 \% \mathrm{M} \\
77.6 \% \mathrm{~F}\end{array}$ & $\begin{array}{l}56.98 \\
(5.24) \\
\end{array}$ & $\begin{array}{l}\text { Yes, } p=.026^{*} \\
\text { Yes, } t=8.37^{* * *}\end{array}$ & $\begin{array}{l}\text { No, } t=-0.40 \\
\text { Yes, } F=2.35^{*}\end{array}$ \\
\hline $\begin{array}{l}\text { Neurology \& } \\
\text { Neurosurgery }\end{array}$ & $\begin{array}{l}25.8 \% \mathrm{M} \\
74.2 \% \mathrm{~F}\end{array}$ & $\begin{array}{l}53.08 \\
(4.84)\end{array}$ & $\begin{array}{l}\text { No, } p=.359 \\
\text { No, } t=0.50\end{array}$ & $\begin{array}{l}\text { No, } t=1.19 \\
\text { No, } F=1.30\end{array}$ \\
\hline $\begin{array}{l}\text { Physical Medicine and } \\
\text { Rehabilitation }\end{array}$ & $\begin{array}{l}25.1 \% \mathrm{M} \\
74.9 \% \mathrm{~F}\end{array}$ & $\begin{array}{l}53.65 \\
(4.90)\end{array}$ & $\begin{array}{l}\text { No, } p=.451 \\
\text { No, } t=1.75\end{array}$ & $\begin{array}{l}\text { No, } t=0.43 \\
\text { No, } F=0.59\end{array}$ \\
\hline $\begin{array}{l}\text { Chemical Dependency } \\
\text { and Recovery }\end{array}$ & $\begin{array}{l}40.9 \% \mathrm{M} \\
59.1 \% \mathrm{~F}\end{array}$ & $\begin{array}{l}44.81 \\
(4.06)\end{array}$ & $\begin{array}{l}\text { Yes, } p<.001^{* * *} \\
\text { Yes, } t=-10.94^{* * *}\end{array}$ & $\begin{array}{l}\text { No, } \hat{i}=0.22 \\
\text { No, } F=0.71\end{array}$ \\
\hline
\end{tabular}

$*-p<.05 \quad * * p<.01 \quad * * *<<.001 \quad * * * t$ value not calculated as $s=0$.




\section{Visits by Specialty}

In the last column of Table 17, the average annual DOVs for the each specialty were calculated based upon the 2,430 chronic pain patients included in the utilization data set. Compared with the total adult HMO population, chronic pain patients saw their Primary Care physicians an average of 6.10 times per year, or 4.56 times more often than the general population. In the Emergency Department, chronic pain patients were seen an average of .81 times per year, or 5.66 times more often than average.

To understand the breakdown of visits to various departments by gender and age, Table 18 compared the 11 most commonly used specialties to see if these patients differed from the 2,430 chronic pain patients (study population) with utilization information.

In determining differences among specialties (column titled Difference from Study Population), the proportion of men-to-women in each group were compared to the study population (a non-parametric binomial test of frequency). Here, a $z$ value is approximated and findings are reported as assumptive significance ( $p$ values). For the age of patients seen, actual years were used to compare ages with those in the study population (one sample case of the means, $\bar{x}=52.86$ ).

In the last column of Table 18, Difference in \# of DOVs (gender/age), differences in the number of DOVs by gender were calculated using the two-sample case of the means, independent samples. In other words, the number of DOVs for men was compared to the number of DOVs for women in the study population to see if gender played a role in utilization. To compare patients by age, decades were used to compare the number of 
DOVs by generation (one-way ANOVA with Scheffé for post hoc testing). Listed below is a summary by department of significant findings.

\section{Family Practice \& Internal Medicine}

Visits to Primary Care most closely resembled the study population as $98.7 \%$ of utilization patients were seen by someone in Family Practice or Internal Medicine. Significant differences were seen in the number of visits by age. Patients in their $30 \mathrm{~s}, 40 \mathrm{~s}$, and 50 s averaged between 20.50 and 21.00 total visits (5.59 to 5.73 annual DOVs), while those more than 79 years of age averaged 32.25 (8.79 annually).

\section{Physical Therapy \& Occupational Therapy}

The pain patients who visited this specialty were slightly, but significantly, older than the study population. The small difference between the mean age of 53.76 years for this group and 52.86 years of age for the utilization group demonstrated how the relatively large sample size $(n=1,265)$ could detect minor differences and indicate that the results were significant.

\section{Psychiatry and Social Services}

Women were more likely to be seen in Psychiatry than men, when compared to the gender proportions of the utilization group. Also this sample was significantly younger that the entire study group ( 49.57 years vs. $52.86, p<.001)$. While there was no difference in the number of DOVs by generation, women visited Psychiatry and Social Services more often than men $\left(\bar{x}_{w}=9.20\right.$ total visits and $\bar{x}_{m}=5.82$ total visits, or $\bar{x}_{w}=$ 2.51 annual visits to $\bar{x}_{m}=1.59$ annual visits respectively). 
Chronic Pain 120

\section{Emergency Department (ED)}

Overall, the number of emergency visits decreased as patients got older. Patients in their 20's were significantly more likely to use ED than those in their 60 s and 80 s $(6.25$ total DOVs vs. 3.44 - 3.52 total DOVs respectively, or annual rates of 1.70 visits and 0.94 -0.96 visits). No other differences were detected.

\section{Orthopedics}

The only significant finding in Orthopedics was that these patients were slightly older than the utilization group (54.68 years vs. 52.86 years). All other comparisons reflected similar proportions to the study group.

\section{Ophthalmology \& Optometry}

While gender was not an issue in eye-related DOVs, age had a tremendous impact on utilization. Patients on average were older for this group than the study group (55.96 years vs. 52.86 years of age). Logically, patients in their 20 s were the least likely to be seen (1.90 DOVs or 0.52 annual visits), significantly less than patients more than 59 . Those in their 60 s were more likely to go to an eye specialist than those in their $20 \mathrm{~s}$, but less likely to be seen than those more than 69 (4.37 DOVs or 1.19 annual visits). Patients in their 70 s and 80 s visited Ophthalmology and Optometry significantly more than any other age (6.83 DOVs and 8.68 DOVs, or 1.86 and 2.37 annual visits respectively, $p<$ $.001)$.

\section{Obstetrics \& Gynecology (OB/GYN)}

All patients visiting this department were women, obviously differing greatly from the gender mix of the study population. With the exception of women more than 79 years 
Chronic Pain 121

of age, the frequency of DOVs had an inverse relationship to age. Women over 39 saw a gynecologist on average between 5.02 and 3.24 total times (annualized at 1.37 to 0.88 DOVs). Women less than 30 , in the traditional childbearing years, visited OB/GYNs the most (10.43 DOVs or 2.84 DOVs annually).

\section{Dermatology}

Similarly, women were more likely to go to Dermatology than men (77.6\% of Dermatology DOVs compared to $74.7 \%$ of DOVs for women in the study population). However, this difference failed to achieve statistical significance between the genders. Nonetheless, as patients aged, they were seen significantly more often (those under 30 were seen 2.48 total times vs. those in their 70 s being seen 6.28 total times, $p=.03$ ), but these differences were not enough to be detected using Scheffé as a post hoc test.

\section{Neurology \& Neurosurgery}

No demographic discrepancies were detected for patients seen in Neurology. However, when comparing age in decades to gender, those more than 79 years of age were more likely to be men than women when measured against those less than 70 years old $(F=3.49, p=.002$.

\section{Physical Medicine and Rehabilitation (PM\&R)}

For the 977 patients seen in Physical Medicine, their age, gender, and number of DOVs were not significantly different from the entire utilization population. Across the board, PM\&R patients, while $40.2 \%$ of the utilization group, adequately represented the utilization population of chronic pain patients. 
Chronic Pain 122

\section{Chemical Dependency and Recovery Program (CDRP)}

While men constituted only $25.3 \%$ of chronic pain patients, they comprised $40.9 \%$ of patients seen in CDRP $(p<.001)$. In other words, male pain patients were 1.62 times more likely than women to be seen in CDRP. Also, $91.3 \%$ of patients seen in CDRP were between 30 and 59 years old. Not one patient above 79 was seen, and only 16 patients were in their 20s, 60s, and 70s. The average number of DOVs was stable between the genders $\left(\bar{x}_{w}=14.56\right.$ vs. $\bar{x}_{m}=15.54$ total visits, or 3.97 and 4.24 annual visits respectively). While $7.5 \%$ of chronic pain patients were seen over the 44 -month period, the annualized rate was only $2.05 \%$ of this group. When investigating the total number of patients receiving opioid medications through the $\mathrm{HMO}, 2.52 \%$ of opioid patients were seen annually in CDRP.

Annualized Doctor Office Visits (DOVs)

Of the total 131,256 DOVs, 97,098 visits could be aggregated into 5,940 complete patient years pre- and/or post-treatment. The total utilization group included 2,430 patients, but 88 patients did not have any complete years of utilization information reported pre- or post-treatment. Therefore, 2,342 patients used HMO services for a total of 5,940 years $(\bar{x}=2.54$ years per patient $)$.

Following Ershoff's (1995) example, DOVs during the eight-week Pain Management Program attendance period were eliminated. Patients attending the program signed a statement promising not to seek new diagnostics or treatments during the eightweek program. Therefore, the range of time spanned from two years pre-treatment to five years post-treatment. The data from IT included costs for $68,484 \mathrm{DOVs}$. The cost of the 
remaining visits was determined by using the most frequent (mode) cost associated with that department. Data on systemwide utilization was limited to age, gender, and annual frequency of DOVs. Table 19 summarizes the spread of values.

Table 19

Summary of Utilization Group DOVs

\begin{tabular}{|c|c|c|c|r|}
\hline $\begin{array}{c}\text { Yrs Pre/Post- } \\
\text { treatment }\end{array}$ & $\begin{array}{c}\text { Number of } \\
\text { DOVs }\end{array}$ & $\begin{array}{c}\text { Number if } \\
\text { Patients }\end{array}$ & $\begin{array}{c}\text { Average }(\bar{x}) \\
\text { Visits }\end{array}$ & $\begin{array}{c}\text { Annual Dov } \\
\text { cost/patient }\end{array}$ \\
\hline-2 & 6,564 & 390 & 16.83 & $\$ 1,648.57$ \\
\hline-1 & 23,349 & 1,067 & 21.88 & $2,113.51$ \\
\hline 1 & 23,742 & 1,456 & 16.31 & $1,552.34$ \\
\hline 2 & 17,851 & 1,234 & 14.47 & $1,342.11$ \\
\hline 3 & 14,564 & 1,024 & 14.19 & $1,335.81$ \\
\hline 4 & 7,957 & 536 & 14.85 & $1,389.32$ \\
\hline 5 & 3,071 & 231 & 13.29 & $1,240.45$ \\
\hline Total & $\sum=97,098$ & $\sum=5,940$ & 16.35 & $\$ 1,551.55$ \\
\hline
\end{tabular}

The range of DOVs per year per patient was between one and 206 visits with an associated annual cost of between $\$ 54.00$ and $\$ 16,199.00$. Because of the extreme spread of values, the outliers were identified, also known as the "unusual score(s) in a distribution that may warrant special consideration" (Hinkle, Wiersma, \& Jurs, 1998, p. 72). To assure outliers would not artificially distort the results, calculations were performed both with and without the outlying values. Outliers were identified as those patients older than 93 years of age, incurring more than 46 annual DOVs, and with a DOV cost of more than $\$ 4,376.00$. 


\section{Opioid Medications}

The number and type of opioid medications filled at the HMO pharmacy served as another indicator of each provider's evaluation and treatment of chronic pain. According to Marcus (2000), “Although NSAIDs and short-acting opioids may be helpful with pain flares, they should not be used chronically on a daily basis in most cases" (p. 1336). A move to long-acting opioid medications, Class II medications, "should be considered in patients who have a clear pain diagnosis, constant pain, pain with significant disability or regular analgesic overuse" (p. 1337).

In the State of California, however, long-acting opioids require a triplicate prescription where the original of the three prescription copies is filed with the Department of Justice (DOJ). These medications are not refillable and may not be called into a pharmacy by phone. By definition, these controlled substances represent, "High abuse potential (and) severe dependence liability" (Tarascon, 2000, p.3). Instead, patients receive Class III medications, ones defined as having "Moderate dependence liability" (p.3), NSAIDs or other analgesic medications.

This study included all opioid prescriptions (Class II and Class III medications) from January 1994 through August 1997. Not all patients referred to the Pain Management Program received opioid medications. Also, not all patients had prescription drug coverage with the HMO. Some patients purchased their prescription medications at outside pharmacies, beyond the record keeping of the HMO. Of the 38,913 opioid prescriptions dispensed by the HMO's pharmacy, drugs given in liquid form were eliminated because the quantity dispensed was reported in milliliters, a misleadingly high 
quantity when compared to the number of pills dispensed. Also, drugs commonly given to treat migraines were omitted as they were often dispensed in a one- or two-dose form, distorting the number of prescriptions per patient. What remained were 35,299 prescriptions for the entire period. When stratified into complete patient years, 26,488 prescription medications were dispensed from the HMO's pharmacies as shown in Table 20 below.

Table 20

Class II and Class III Medications Dispensed through the HMO Pharmacy

\begin{tabular}{|l|l|r|r|c|}
\hline \multicolumn{1}{|c|}{ Generic Name } & Product Name(s) & $\begin{array}{c}\text { Class of } \\
\text { Drug }\end{array}$ & $\begin{array}{c}\text { Number } \\
\text { of R's }\end{array}$ & \multicolumn{1}{c|}{$\begin{array}{c}\text { Percent } \\
\text { of R's }\end{array}$} \\
\hline Acetaminophen w/Codeine & Tylenol \#3 or \#4 & III & 3,470 & $13.1 \%$ \\
\hline $\begin{array}{l}\text { Acetaminophen } \\
\text { w/Hydrocodone }\end{array}$ & $\begin{array}{l}\text { Vicodin } \\
\text { Lortab }\end{array}$ & III & 19,746 & 74.5 \\
\hline Aspirin w/Codeine & Empirin & III & 7 & 0 \\
\hline Fentanyl & Duragesic & II & 120 & 0.5 \\
\hline Hydromorphone HCL & Dilaudid & II & 160 & 0.6 \\
\hline Meperidine HCL & Demerol & II & 138 & 0.5 \\
\hline Methadone HCL & Dolophine & II & 485 & 1.8 \\
\hline & MS Contin & II & 846 & 3.2 \\
\hline Morphine Sulfate & Oramorph & II & 10 & 0 \\
\hline Oxycodone HCL & Roxicodone & II & 1,385 & 5.2 \\
\hline $\begin{array}{l}\text { Oxycodone } \\
\text { w/Acetaminophen }\end{array}$ & $\begin{array}{l}\text { Percocet } \\
\text { Roxicet }\end{array}$ & II & 121 & 0.5 \\
\hline Oxycodone w/Aspirin & Percodan & 26,488 & $100.0 \%$ \\
\hline
\end{tabular}


Class III medications were prescribed $87.7 \%$ of the time. Class II medications accounted for only $12.3 \%$ of all opioid prescriptions.

As part of the Pain Management Program, almost one entire class was devoted to informing patients about their choices in the medications used for chronic pain. The optimal goal would have patients living full lives with or without opioids. In the meantime, one would expect an increase in the trials of long-acting opioid medications after attendance in the program. For some, this shift in long-term opioids should allow increased activity, thereby reversing the amount of pain caused by deconditioning. With new cognitive-behavioral skills, learned techniques would help control pain affect. Even so, others would need access to long-term opioids, as the condition causing pain would not improve or may even worsen. In addition, when conservative modalities fail to help manage chronic pain, one would also expect providers to be more open to this treatment option.

When tabulating the number of years pre- and post-treatment, all data during the eight-week cognitive-behavioral program were eliminated. Therefore, there was no treatment year, or "Year 0." One year pre-treatment (-1 year) included the 365 days prior to the first day of class and one year post-treatment ( 1 year) included the 365 days after the last day of class.

Figure 16 confirms that the proportion of Class II prescriptions, when compared to all opioid prescriptions, did increase in the post-treatment years (except for the second year after referral). At two years pre-treatment, patients received the lowest percentage of Class II prescriptions $(5.3 \%, p<.001)$, while patients at four years post-treatment 
reported the highest percent $(20.2 \%, p<.001)$. In years one, three, and five posttreatment, Class II prescriptions were similarly high (14.3\%, 12.6\%, and $16.1 \%$ respectively, $p=.035$ ). However, no differences were detected among patients who completed, dropped out, or did not attend $(\mathrm{F}=1.032, p=.357)$.

Figure 16

\section{Class II and Class III Drugs Dispensed}

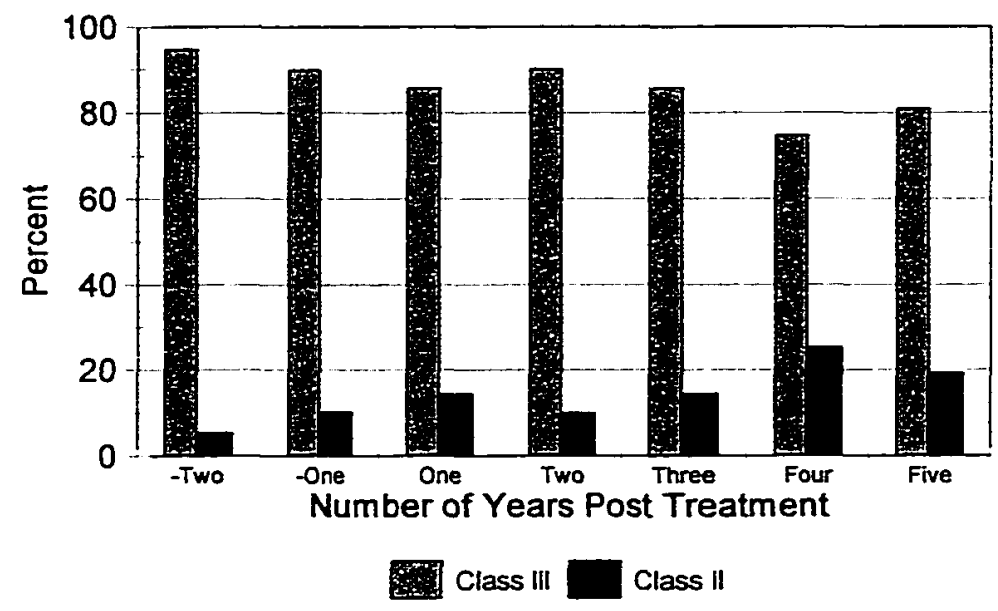

Also, opioid patients who took Class II drugs got fewer prescriptions per year than opioid patients taking Class III drugs. The range in number of annual prescriptions for Class II drugs ran from one to 49 , with a mean of 6.07 prescriptions, a median of three per year, and a mode of one per year. In comparison, Class III drugs ranged from one to 129 prescriptions in one year, with a mean of 7.72 prescriptions, median of four, and mode of one $(p<.001)$

No differences were detected within the program participation categories. Separated into three types of program participants (i.e., attended, dropped, and never registered(never came to class), attended patients were categorized as having attended at 
least five classes, dropped patients as opting out of the program (four or fewer classes attended), or never registered/never came to class patients as not coming to any class. Using a one-way ANOVA with attendance as the factor, there was no difference between the class of opioid medications filled at an HMO pharmacy $(F=1.032, p=.357)$, the total number of pills dispensed $(F=1.00, p=.369)$, or the number of prescriptions filled $(F=$ $1.02, p=.362)$

\section{Prescriptions and Doctor Office Visits}

By merging DOV data with aggregated prescription information, certain correlations come forth, albeit of minor importance. For example, the higher the number of DOVs, the more likely:

- Questionnaires were returned (Pearson $r=.094, p<.001$ ).

- Patients attended class (Pearson $r=.120, p<.001$ ).

- Patients received Class II medications (Pearson $r=.093, p<.001$ ).

- Patients secured more opioid prescriptions (Pearson $r=.244, p<.001$ )

The group of patients receiving opioid prescriptions was broken down into three categories: 1) Those who received only Class $\amalg$ drugs; 2) those who were prescribed only Class III drugs, and; 3 ) those who obtained some combination of both Class II and Class III opioid medications. Looking at each of the groups, the following statistics came forth:

- Comparing the average number of opioid prescriptions per year, Class II-only and Class III-only patients received nearly the same number of prescriptions $\left(\bar{x}_{\Pi}=7.95\right.$ vs. $\left.\bar{x}_{\mathrm{III}}=7.21, p=.624\right)$. However, patients combining the two types of medications secured an average of 16.53 opioid prescriptions per year, more than 
doubie the number prescriptions filled for long-acting only or short-acting only opioid users $(F=156.94, p<.001)$.

- When comparing the average number of DOVs per year, there were no significant differences in outpatient office visits between Class II-only and Class III-only patients (17.98 vs. 18.88 DOVs respectively, $p=.790$ ). Again, while not statistically significant, Class U-only patients in this sample actually saw their doctors less frequently than did Class III-only patients. As with the average number of annual opioid prescriptions above, those on a combined regimen appeared more unstable, averaging significantly more DOVs per year $(\bar{x}=28.08$, $F=55.26, p<.001)$

Gender also played a role in who and how one utilized medical services. When comparing annualized DOVs and medication data for men and women (an average of 2.54 years, $n=2,342)$ :

- Women had more DOVs $\left(\bar{x}_{\mathrm{w}}=42.85\right.$ vs. $\left.\bar{x}_{\mathrm{m}}=37.40, p=.001\right)$.

- $\quad$ Correspondingly, women cost more per year in DOVs $(\$ 1,562.89$ vs. $\$ 1,430.22, p$ $=.021)$.

- Men were more likely to get Class II medications (14.0\% of men vs. $9.2 \%$ of women, $p<.001)$.

- Men were more likely to get any opioid prescription $\left(\bar{x}_{\mathrm{m}}=19.55\right.$ vs. $\bar{x}_{\mathrm{w}}=15.02, p$ $=.001)$

- Men received more opioid pills than did women (2007.29 vs. $1092.75, t=3.13, p$ $=.002)$. 
- The ratio of men-to-women securing Class III medications mirrored the gender ratio for all pain patients referred to the program. However, men had greater access to the combination of medications and Class II-only medications than did women $(F=14.69, p=.001)$.

\section{Questionnaires and Outcome Data}

When comparing the utilization group to those who completed pre-treatment questionnaires, similar spreads were detected in the number of opioid prescriptions $(\bar{x}=$ 8.44 Rs for the questionnaire group vs. $\bar{x}=8.27$ Rs for non completers). However, the questionnaire-only group failed to achieve any statistical significance $(\mathrm{F}=0.17, p=.683$ ). Also, whether or not one attended the Pain Management Program had no bearing on the number of prescriptions filled $\left(\bar{x}_{\text {attend }}=8.41 \mathrm{R}, \bar{x}_{\text {drop }}=8.95 \mathrm{R}, \bar{x}_{\text {no show }}=8.20 \mathrm{R}, F=1.00\right.$, $p=.369$ ).

However, differences were detected in the number of DOVs in those completing the questionnaire and in class attendance. Those who completed the pre-treatment questionnaire were seen by their providers more often than those who did not complete the questionnaire $\left(\bar{x}_{\text {yes }}=43.59\right.$ visits vs. $\left.\bar{x}_{\text {no }}=36.29 ; t=4.62, p<.001\right)$. Also, those patients who attended any of the classes saw their providers more than those who never came to the program $\left(\bar{x}_{\text {atrend }}=17.10, \bar{x}_{\text {drop }}=18.28, \bar{x}_{\text {no show }}=15.17 ; F=18.49, p<.001\right)$. One possible interpretation is that those who saw their providers more were encouraged, or perhaps required, to attend the program. The higher number of DOVs for those who dropped (while not significantly different from those who attended) could mean that 
patients who dropped were still looking for more evaluation, a cause, and/or a solution to the pain, before learning how to cope with and manage chronic pain.

\section{Can MPI Help Predict the Number of DOVs?}

For this test, the number of annual doctor visits was broken down into ranges of visits by ten. The first category included those patients with between one and ten DOVs, on up to those with more than 80 visits. No discernable differences were appreciated in any of the MPI scales.

\section{Opioid Medication and the MPI}

Not everyone who received opioid prescriptions purchased their medications through the HMO. Therefore, results would not distinguish between those who obtained opioid pain medications through an outside pharmacy, those who did not obtain opioid prescriptions, or those who received prescriptions but did have them filled. However, we can look at the differences between those who received all Class II drugs, those who purchased mostly Class II drugs, those who bought mostly Class III drugs, and those who were received only Class III drugs.

Only three of the 13 MPI scales demonstrated significant differences based on the combination of opioid medications. In all three cases, the progression went from Class IIonly, mostly Class II, mostly Class III, and Class III-only:

- Interference. Class II-only patients reported significantly higher levels of interference than those taking Class III-only medications, $\bar{x}_{\mathrm{II}}=4.69$ vs. $\bar{x}_{\mathrm{mI}}=4.23$, $\mathrm{F}(3,952)=6.97, p<.001$ 
- Support. Conversely, those patients taking only Class $\Pi$ medications reported significantly higher levels of support from spouses and significant others, $\bar{x}_{\Pi}=5.02$ vs. $\overline{\mathrm{X}}_{\mathrm{III}}=4.20, F(1,922)=5.56, p=.001$.

- General Activity Level. While no discernable difference arose within the four individual activity scales, the overall activity level was significantly lower in post hoc testing for those taking only Class II medications over those with only Class III medications, $\bar{x}_{\mathrm{II}}=1.92$ vs. $\bar{x}_{\mathrm{III}}=2.35, p<.05$.

Noticeably missing from significant results was any correlation between the Pain Severity Scale and the class of medications prescribed. While Class II-only patients rated pain severity higher than the Class III-only patients, $\bar{x}_{\mathrm{II}}=4.69$ vs. $\overline{\mathrm{x}}_{\mathrm{III}}=4.35$, this difference was not enough to be meaningful $(p>.05)$.

\section{Chemical Dependency Visits and Opioid Medications}

Of the 186 patients that were seen in CDRP, 154 purchased opioid medications through the HMO pharmacies. In order to figure out who goes to CDRP, the ratio of Class $\Pi$ opioids received was compared to the Class III opioids received. While Tarascon (2000) identified Class II opioids as having higher addiction potential, one would expect those supplied with a higher number of Class II opioids would be seen more often in CDRP. However, that was not the case. The average patient seen in CDRP received more Class III opioids than Class II opioids and there was no difference in the mix of opioid medications from the remaining patients not seen in $\operatorname{CDRP}(t=1.916, p=.057)$.

Next, the research looked at the number of prescriptions filled and the number of pills dispensed through the HMO, comparing them to those both seen and not seen in 
CDRP. Here, major differences appeared. Patients seen in CDRP received almost twice as many opioid prescriptions than their counterparts $\left(\bar{x}_{y o s}=28.15 \mathrm{R}\right.$ total, $\bar{x}_{n o}=14.96 \mathrm{R}$ total; $t=-4.392, p<.001)$. Also, those patients seen in CDRP received more pills $\left(\bar{x}_{\text {yes }}=\right.$ 1,994 pills total, $\overline{\mathrm{x}}_{\mathrm{no}}=1,269$ pills total; $t=-2.469, p<.001$ ).

Finally, the research looked at any differences in the number of prescriptions and the number of CDRP visits, as well as the mix of Class II and Class III opioids compared with the number of visits to see if either had an influence on the length of time needed for CDRP intervention. Once again, no differences were detected. Recoding the number of visits and prescriptions into quartiles, those with the highest number of visits had the least number of prescriptions, but these differences were not significant $(F=1.54, p=.21)$. Also, patients receiving more Class $I I I$ opioids tended to be seen the most in CDRP, but failed to achieve significance $(F=0.22, p=.88)$. 
Chronic Pain 134

Excuses for inadequate pain control appear to have run their course and will no longer be accepted because poor pain control is unethical, clinically unsound, and economically wasteful.

Leadership Summit on Pain Management July 2000 


\section{CHAPTER 5}

\section{Discussion}

\section{Introduction}

The data collected for this study provides insight into the lives of chronic pain patients and the frustration of the health care industry in attempting to offer effective treatment while controlling the costs of this expensive patient population. As wise committee members warned, the enormity of the data collected could easily keep one busy for years; there are more years of analyses and reporting than one could ever cover in one dissertation study. Because available data was used, this study serves as a starting point for a more refined understanding of how pain affects all stakeholders: patients, providers, managed care organizations, and insurance companies.

\section{Presentation of Results}

The data captured in this study offered limited information on a varying number of patients referred to the Pain Management Program. Because of mortality, loss of employer-sponsored health insurance coverage, or changes in health care organizations, to name a few, the size of the referred population $(n=2,561)$ was larger than the utilization group, those with available DOV data $(n=2,430)$. The utilization group represented patients using the HMO's services over a 44-month period, from January 1, 1994, to August 31, 1997. The sample included all patients referred to the Pain Management Program from October 1991 to May 1996. Therefore, the 44-month period of data 
collected represented patient utilization information spanning from two years pretreatment to five years post-treatment. Not all patients covered under this health plan had drug coverage through the HMO, and not all patients received prescriptions for opioid medications. As such, the opioid group $(n=1,860)$ was even smaller than the utilization group. Since only $72.6 \%$ of patients referred to the Pain Management Program completed the pre-treatment questionnaire, only 1,720 questionnaires were located, and, since not all respondents completed every question, a variety of sample sizes was reported in various analyses. Still fewer patients $(n=700)$, responded to the post-treatment survey. Of the post-treatment respondents, only 604 could be matched to the pre-treatment questionnaires. While the changes in sample sizes may be disconcerting, I wanted to report the largest possible sample size for each area under study. For the amount of time spent gathering this information and the size of available data, this study presents the largest group in each category rather than analyzing results on the few patients with all available variables.

Regardless of the varying differences in sample sizes, all groups would be deemed large samples. The advantage of large samples is that one may achieve statistical precision. "Increasing the sample size yields a more precise (smaller) estimate of the standard error of the statistic" (Hinkle, et. al., 1998, p. 272). "It is sensible to view research findings based on large samples as more reliable than findings based on smaller samples ... " (p. 310).

Also, large samples make statistical significance much easier to achieve. Critics of inferential testing believe that "Virtually any study can be made to show significant results 
if one uses enough subjects, regardless of how nonsensical the content may be" (Hays, 1973 , p. 415). However, the key to a quality research design comes from attention to the number of variables and outcomes. "In a well-planned research study, in which the variance of the criterion variable is likely to be quite large and the treatment effects rather small, large samples are appropriate and justifiable" (Hinkle, et. al., 1998, p. 310).

Because minor differences can be detected with such large sample sizes, correlational studies report great statistical significance but small correlation coefficients (Pearson $r$ ). Each item fitting this description can be misleading if isolated on its own. However, I reported these differences because of their potential value in multiple regression analysis.

Per Table 5 (p. 56), all of the research literature citing statistics relative to the number of years in pain did so using the mean $(\bar{x})$, a standard choice for large samples of interval or ratio data. However, as seen in Figure 8 (p. 91), the mean can be misleading in distributions with many outliers and those situations where the data do not reflect a normal distribution. In this study, the mean number of years in pain was 8.33 years, the median was 4.0 years, and the mode was one year. While 8.33 years in pain sounds impressive, less than $30 \%$ of this sample had been in pain longer than eight years. By reviewing other studies where the range of years is similarly broad, I purport that using the mean in these instances overstates the problem, thereby violating statistical precision.

\section{Research Questions}

Going back to the original research questions proposed in Chapter 1, the following are responses to those areas of concern based on the following analyses. 
What is the profile of patients referred to the Pain Management Program and how does that profile compare with the research literature on chronic pain?

Using the means, medians, and modes, whichever was more appropriate in each instance, Table 21 below shows the profile of a typical chronic pain patient referred to the Pain Management Program.

Table 21

\section{Profile of a Typical Chronic Pain Patient}

\begin{tabular}{|c|c|c|}
\hline Gender & $\nLeftarrow$ & Female \\
\hline Age & $\nLeftarrow$ & Approaching 53 \\
\hline Marital Status & $\nLeftarrow$ & Married \\
\hline Living with & $\nLeftarrow$ & Spouse \\
\hline Education & $\nLeftarrow$ & Some college or vocational school \\
\hline Employed & $*$ & Full time \\
\hline Mean years in pain & $\nLeftarrow$ & More than eight years \\
\hline Median years in pain & $\nLeftarrow$ & Four (4) years \\
\hline Mode years in pain & $\nLeftarrow$ & One (1) year \\
\hline Pain site(s) & $\$$ & Multiple, both upper and lower body \\
\hline f doctor visits per year & $*$ & More than 16 visits \\
\hline escription pain reliever & $\nLeftarrow$ & Vicodin \\
\hline Level of pain & $\nLeftarrow$ & More than seven on the 11 Point Scale \\
\hline Sexually active? & $\nLeftarrow$ & No \\
\hline Attend class & $*$ & No \\
\hline Activity level & $\nLeftarrow$ & Less than average \\
\hline
\end{tabular}


This study's population, like the other chronic pain research, had disproportionally more women than men, with a ratio of approximately 3:1 overall. Using the other chronic pain studies in Table 5 (p. 56), the combination of all study groups $(n=2,593)$ consisted of $26.8 \%$ male and $73.2 \%$ female. When comparing the gender mix of this study to Table 5, Profiles of Populations in Chronic Pain Research, no discernable difference in gender mix could be found $(z=0.98, p>.05)$. Therefore, no difference in gender mix was seen when comparing this study to a composite of other chronic pain study groups.

From a stereotypical point of view, one might argue that a man's role in society is the breadwinner. Therefore, men would not participate in the program because of real or perceived conflicts with work. If so, there would be differences in the proportion of men to women by work status. To see if this affected the gender-biased referral or attendance in the Pain Management Program, Table 22 displays a chi-square $\left(\chi^{2}\right)$ test for frequencies by work status. 
Table 22

Data and Calculated $\chi^{2}$ Test for Frequency of Gender by Work Status

\begin{tabular}{|c|c|c|c|}
\hline Work Status & $\begin{array}{c}\text { Observed } \\
\text { (Expected) } \\
\text { Male }\end{array}$ & $\begin{array}{c}\text { Observed } \\
\text { (Expected) } \\
\text { Female }\end{array}$ & $\chi^{2}$ \\
\hline Full Time & $123(114.2)$ & $359(367.8)$ & 0.27 \\
\hline Part Time & $23(46.2)$ & $172(148.8)$ & $15.29 * * *$ \\
\hline Unemployed & $32(35.3)$ & $117(113.2)$ & 0.41 \\
\hline Disabled & $110(87.5)$ & $259(281.5)$ & $7.62^{* *}$ \\
\hline Retired & $80(54.5)$ & $150(175.5)$ & $15.62^{* * *}$ \\
\hline Homemaker & $1(29.9)$ & $125(96.1)$ & $36.43 * * *$ \\
\hline Student & $3(4.27)$ & $15(13.73)$ & 0.49 \\
\hline TOTAL & 372 & 1197 & \\
\hline
\end{tabular}

$* p<.05 \quad * * p<.01 \quad{ }^{* * *} p<.001$

As shown in Table 22, there was no difference in the proportion of men to women for those working full time, for those who were unemployed, and for those who were students, when compared to the total group of patients. As one might expect, women dominated as homemakers. Women also were employed part time proportionally more than their male counterparts. A proportionally higher number of men reported being retired or disabled.

The distinction between homemaker, retired, and disabled may be influenced by stereotype, as well. A woman who no longer works because of pain may identify her role as a homemaker, rather than disabled. People on medical retirement may wish to portray their role as retired, or if a woman, as homemaker, rather than being disabled. Still others who have achieved a certain age may wish to consider themselves retired, rather than 
disabled or as a homemaker. To see if semantics played a role, the categories of homemaker, retired, and disabled were combined. Here, $\chi^{2}=2.80, p>.05$. In other words, no differences in frequencies could be detected with these categories combined. Without a more precise definition of the work status categories on the pre-treatment questionnaire, it remains uncertain, but unlikely, that gender played a role in work status and program referral or attendance.

To detect if age and work status were related, an ANOVA test was used to calculate any significant associations between these two categories $[F(6,1562)=$ 139.322, $p<.001]$. Table 23 below demonstrates the significant differences in work status by age.

Table 23

\section{Association between Work Status and Age (Scheffe ${ }^{\text {ab }}$ )}

\begin{tabular}{|c|c|c|c|c|c|}
\hline \multirow[t]{2}{*}{ Work Status } & \multirow[t]{2}{*}{$\mathbf{N}$} & \multicolumn{4}{|c|}{$\begin{array}{c}\text { Age } \\
\text { Subset for alpha }=.05\end{array}$} \\
\hline & & $\mathbf{1}$ & 2 & 3 & 4 \\
\hline Student & 18 & 40.56 & & & \\
\hline Full Time & 482 & & 47.64 & & \\
\hline Unemployed & 149 & & 48.50 & & \\
\hline Part Time & 195 & & 50.22 & & \\
\hline Disabled & 369 & & 52.86 & 52.86 & \\
\hline Homemaker & 126 & & & 57.89 & \\
\hline Retired & 230 & & & & 72.41 \\
\hline Sig. & & 1.000 & .200 & .242 & 1.000 \\
\hline
\end{tabular}

Means for groups in homogeneous subsets are displayed.

a. Uses Harmonic Mean Sample Size $\mathbf{= 8 2 . 8 7 5}$.

b. The group sizes are unequal. The harmonic mean of the group sizes is used. Type I error levels are not guaranteed. 
To review, Table 23 states the differences between age and work status. Retired patients were significantly older and students were significantly younger than the average patient. Because of the small number of students $(n=18)$, students were removed from the calculation and the differences were even more dramatic [harmonic mean $=207.550, F$ $(5,1550)=163.079, p<.001]$. Without students, no differences could be detected between Full Time, Unemployed or Part Time. Likewise, there were no significant differences in age between Part Time and Disabled, even though disabled patients appeared older than those who worked. Homemakers were yet older than any other category except for Retired, significantly the oldest group. Considering that women's work status as homemaker was more universal in years past, a possibility exists that identifying oneself in a particular role may be influenced by one's age and culture.

Accordingly, did working full time affect either program referral or attendance? The highest proportion of patients referred to and participating in the program worked full time $(30.7 \%)$. The proportion of men-to-women working full time was essentially the same as the gender mix in the study population. Therefore, working full time did not appear to be a reasonable explanation of why women were referred more often than men.

While the average age $(\bar{x}=52.87$ years $)$, was similar to the research projects in chronic pain in Table 5 on page 56 (from $\bar{x}=39$ years to $\bar{x}=53.1$ years), this study's pain patients were older than the aggregated ages in the other studies. Also, the study population was older than the total adult population of the HMO.

For a more complete understanding of this study's population, Chapter 4 included detailed demographic information. As to how that compared to other study populations, 
research and journal articles similar to those in Table 5 (p. 56) typically lacked such itemized specifications. However, reviewing the presenting conditions stipulated in Table 5, the Pain Management Program's population adequately reflected the multitude of pain conditions researched in the field of chronic pain management.

Does referral to or participation in the Pain Management Program influence a patient's ability to self-manage chronic pain?

The findings of this study demonstrated that people who were referred to this education-based, cognitive-behavioral pain management program reported significantly less pain on the 11 Point Box Scale post-treatment when compared to the same scale asked pre-treatment $(n=604$, mean difference $=1.453, t=13.48, p<.001)$, a reduction in pain by $20.8 \%$ overall. However, reported levels of pain pre-treatment and posttreatment were no different among those who attended, dropped, or never came to class. Below, Table 24 compares the differences in pain levels by program attendance.

Table 24

Difference in Reported Pain Levels by Program Attendance

\begin{tabular}{|l|c|c|c|}
\hline & $\begin{array}{c}\text { Pre-Treatment } \\
(\boldsymbol{n})\end{array}$ & $\begin{array}{c}\text { Post-Treatment } \\
(\boldsymbol{n})\end{array}$ & $\begin{array}{c}\text { Difference } \\
(\boldsymbol{n})\end{array}$ \\
\hline Attended & 7.13 & 5.55 & 1.42 \\
& $(783)$ & $(453)$ & $(388)$ \\
\hline Never Came & 7.28 & 6.12 & 1.41 \\
& $(519)$ & $(148)$ & $(133)$ \\
\hline Dropped & 7.41 & 5.90 & 1.28 \\
& $(279)$ & $(84)$ & $(71)$ \\
\hline Statistics & $F(2,1578)=2.47$ & $F(2,682)=3.21$ & $F(2,589)=.085$ \\
& $p>.05$ & $p=.04$ & $p>.05$ \\
\hline
\end{tabular}


While the ANOVA comparing post-treatment pain levels to class attendance indicated significant differences (presumably between those who attended and those who never came), this statistic did not hold up in the post-hoc Scheffé $(p=.054)$. Subjects who attended the Pain Management Program and responded to the follow-up survey reported almost identical results as those who never attended the program. Patients who dropped out (e.g., attend class between one and four times) showed the least improvement, but not enough to achieve statistical significance.

Patients referred to the Pain Management Program used health care services less often over time. As shown in Table 19 (p. 123), the average number of annualized DOVs ranged from an average high of 21.88 DOVs one year pre-treatment to a low of 13.29 DOVs five years post-treatment. Also, differences were detected between the annualized average number of DOVs and class attendance. Below, Table 25 shows the variation by program participation.

Table 25

Average Annual DOVs by Program Attendance (Scheffe ${ }^{\mathrm{ab}}$ )

\begin{tabular}{|l|r|r|r|}
\hline \multirow{2}{*}{$\begin{array}{c}\text { Program } \\
\text { Attendance }\end{array}$} & \multirow{2}{*}{$\mathbf{N}$} & \multicolumn{2}{c|}{$\begin{array}{c}\text { Average Annual DOVs } \\
\text { Subset for alpha =.05 }\end{array}$} \\
\cline { 3 - 4 } & & 1 & 2 \\
\hline Never came & 1170 & 14.8156 & 17.0653 \\
\hline Attended & 857 & & 17.8958 \\
\hline Dropped & 315 & & .538 \\
\hline Sig. & & 1.000 & \\
\hline
\end{tabular}

Means for groups in homogeneous subsets are displayed.

a. Uses Harmonic Mean Sample Size $=577.349$.

b. The group sizes are unequal. The harmonic mean of the group sizes is used. Type I error levels are not guaranteed. 
In this scenario, patients who never came to class had significantly fewer DOVS than those who attended or dropped $[F(2,2339)=11.65, p<.001]$, a difference of between two and three DOVs per year. In other words, those patients who came to the Pain Management Program saw their doctors more often than those who did not comp.lete the questionnaire, did not sign up for class, or scheduled class but never came. This may suggest that doctors influenced high-utilization patients to attend the program, possibly as a condition of getting medications. However, it could also signal that patients who frequented their health care providers were more likely to go to class than those who dild not go as often. Recalling that, on average, all HMO patients visited their health care providers an average of 1.338 times per year, we see that chronic pain patients, regardfless of attendance, were still a substantial drain on health care resources.

To understand the difference in patients' 11-Point Box Scale over time, pain differences were reordered into three categories: worse (a pre-pain minus post-pain ressult less than -1.00), the same (between -1.00 and 1.00), and better (more than a 1.00 improvement in pain over time). No disparities in demographics could account for pairn level outcomes, with the exception of gender. Using a non-parametric chi-square test for frequencies, patients with differing marital status $\left(\chi^{2}=1.069\right)$, levels of employment $\left(\chi^{2}=\right.$ $0.896)$, age $\left(\chi^{2}=0.121\right)$, support systems $\left(\chi^{2}=0.745\right)$, educational level $\left(\chi^{2}=0.075\right)$, and number of years in pain $\left(\chi^{2}=1.352\right)$ experienced essentially the same level of pain: improvement over time (all $p>.05$ ). Therefore, non-gender demographic information did not appear to influence the net variations in pre-treatment and post-treatment levels of pain. 
Looking at gender, women $\left(\bar{x}_{w}=1.59\right)$ reported significantly higher improvement in reported pain than did men $\left(\bar{x}_{\mathrm{m}}=0.96, t=-2.326, p=.02\right)$, even in light of the fact that men received more pain prescriptions $\left(\bar{x}_{\mathrm{m}}=19.55 \mathrm{R}\right.$ vs. $\left.\overline{\mathrm{x}}_{\mathrm{w}}=15.02 \mathrm{R}, t=3.09, p<.01\right)$, stronger pain medications $(z=-4.166, p<.001)$, and more pills $\left(\bar{x}_{m}=2,007\right.$ vs. $\bar{x}_{w}=$ $1,094, t=3.13, p<.01$ ), over time. Nevertheless, there was no difference by gender in those who got worse, stayed the same, or improved $\left(\chi^{2}=3.924, p>.05\right)$.

'If extreme scores are used in a pretest-posttest design, they have on the average a greater probability of shifting toward the mean for a distribution because the scores are at the extreme of the distribution" (Huck, et al, 1974, p. 237). As such, there was a regression toward the mean when comparing the net difference in pain levels to reported pre-treatment and post-treatment pain. Those whose pain was worse over time reported the lowest levels of pre-treatment pain, while those whose pain was better reported the highest levels of pre-treatment pain $\left(\chi^{2}=91.43, p<.001\right)$. Likewise, those whose pain was worse reported the highest levels of post-treatment pain, while those whose pain was better reported the lowest levels of post-treatment pain $\left(\chi^{2}=229.32, p<.001\right)$.

Continuous quality improvement questions on the post-treatment survey disclosed that those patients who attended class reported high levels of satisfaction with the Pain Management Program. Also, attendees found the pain management tools useful. Those who dropped out and those who never came to class did not find these tools helpful. However, patients who did not complete the program were neutral when asked if they were satisfied with the Pain Management Program. In other words, they were not dissatisfied that such a program was offered. 
What is the economic impact of referring patients to the Pain Management Program, particularly the costs of and possible savings to the medical provider?

Financial outcomes were similar among patients who attended the program, those who dropped out, and those who never attended class. As a group, chronic pain patients taxed health care resources at a rate of at least four times that of the average population.

When comparing the improvement in levels of pain to the total number of DOVs $\left(\chi^{2}=8.39\right)$, the total cost of DOVs $\left(\chi^{2}=7.84\right)$, the average annual DOVs $\left(\chi^{2}=9.33\right)$, and the average annual cost of DOVs $\left(\chi^{2}=8.77\right.$ ), significant differences occurred (all $p<$ .05). Performing a Kruskal-Wallis One-Way ANOVA for each category, those who reported their pain as worse over time saw their physicians more often than those whose pain remained the same, therefore burdening the health care system at a higher rate. Those who reported better, or a lower level of pain over time, had the fewest DOVs and the lowest costs.

The obvious conclusion is that people who had more pain simply went to their doctors more often than those who had less pain. However, a contributing factor could be that some patients were still looking for a cure, even though one was unlikely. They might have feet the need to retell their story, hoping at last to say it correctly so that something would be done to fix the pain. They may have been bargaining with providers, as if conveying that a certain amount of suffering was enough to warrant a cure. Furthermore, those who reported improved levels of pain could also have reflected some component of acceptance, therefore not looking to the health care system to fix the pain problem. 
In looking at the interactions between gender, medication, and utilization over time, conflicts in outcomes were more the rule than the exception. Women reported significantly more improvement in pain but also saw their health care providers $14.57 \%$ more often than men. This statistic was not unusual as women in general have a higher morbidity rate than men. In other words, women tend to be sicker and visit health care providers more than their male counterparts. A review of the 1997 Membership Utilization Report (1998) confirmed this phenomenon. This document stated that, of the entire HMO population, females of all ages saw physicians and other professional providers on average 5.93 times in 1997 while all males were seen an average of 4.13 times. In other words, women were seen 1.44 times more often than men. In comparing the utilization of this study's patients to the total population by gender, women in the study group saw professional health care providers on average 42.85 times, a rate of 7.23 times more often than all females in the HMO. Men in the study visited their providers 37.40 times on average, a rate of 9.06 times more often than all males in the HMO. Adjusting for underlying differences in morbidity, men in the study group saw their health care providers at a rate of 1.25 times higher than women.

While women in the study saw health care providers more often than men, the average cost of the DOV was less $\left(\bar{x}_{w}=\$ 93.48, \bar{x}_{m}=\$ 94.45, F=3.916, p=.048\right)$. This suggests that women may have accessed or been diverted to lower-cost providers more often than men (i.e., more nurse practitioners and physicians' assistants appointments instead of physicians, more general practice visits than in speciality departments). Because 
of the large sample size, this difference may be negligible, even though it was statistically significant. More investigation is needed before firm conclusions may be drawn.

Men in the study reported less improvement in pain but had greater access to opioid pain medications, both in quantity and strength. Women in the study were more likely to be referred to the Pain Management Program, complete questionnaires, and attend classes.

As a group, patients disclosed that their pain conditions did not improve over time and, in fact, reported that they were slightly worse years after their referral, as related in the post-treatment survey. However, these same patients reported than their perceived pain was less. Therefore, it would appear that a big key to reducing costs and utilization in this group would be to improve effective pain management and coping skills.

\section{Outcome Data and the MPI}

Certain associations came to light when comparing the demographic information to the Multidimensional Pain Inventory (MPI). For example, seven of 13 scales appeared to be influenced by gender. Table 26 shows the extent of scale differences by gender using a two-sample case for the mean, independent samples. 
Table 26

Associations Between Gender and the MPI

\begin{tabular}{|c|c|c|c|}
\hline MPI Scale & $\underset{\text { (male/female) }}{\mathbf{N}}$ & $\begin{array}{c}\bar{x} \\
\text { (male/female) }\end{array}$ & $t$ value \\
\hline Support & $\begin{array}{c}356 \\
1,098\end{array}$ & $\begin{array}{l}4.65 \\
4.07\end{array}$ & $7.00 * * *$ \\
\hline $\begin{array}{l}\text { Punishing } \\
\text { Responses }\end{array}$ & $\begin{array}{c}335 \\
1,065\end{array}$ & $\begin{array}{l}2.05 \\
1.84\end{array}$ & $2.19 *$ \\
\hline $\begin{array}{l}\text { Solicitous } \\
\text { Responses }\end{array}$ & $\begin{array}{c}319 \\
1,012\end{array}$ & $\begin{array}{l}3.62 \\
3.43\end{array}$ & $2.61^{* *}$ \\
\hline $\begin{array}{l}\text { Distracting } \\
\text { Responses }\end{array}$ & $\begin{array}{c}324 \\
1,047\end{array}$ & $\begin{array}{l}2.45 \\
2.08\end{array}$ & $4.15^{* * *}$ \\
\hline Household Chores & $\begin{array}{c}394 \\
1,249\end{array}$ & $\begin{array}{l}2.63 \\
3.73 \\
\end{array}$ & $-12.74 * * *$ \\
\hline Outdoor Work & $\begin{array}{c}404 \\
1,254\end{array}$ & $\begin{array}{l}1.95 \\
1.33\end{array}$ & $8.81 * * *$ \\
\hline $\begin{array}{l}\text { General Activity } \\
\text { Level }\end{array}$ & $\begin{array}{c}379 \\
1,175\end{array}$ & $\begin{array}{l}2.23 \\
2.40\end{array}$ & $-3.01 * *$ \\
\hline
\end{tabular}

$* \mathrm{p}<.05 \quad * * \mathrm{p}<.01 \quad * * * \mathrm{p}<.001$

On a Likert scale with zero being never and six being very often, men with chronic pain reported higher levels of support, solicitous responses, and distracting responses, but also reported more punishing responses than did women. Along stereotypical gender lines, women with chronic pain reported doing more household chores than did men. Men reported performing more outdoor work, although outdoor work did not appear to be a regular activity among any of the pain patients. Also, women reported a higher general activity level than their male counterparts. 
Conversely, six MPI scales did not vary by gender: Pain Severity, Interference, Life Control, Affective Distress, Activities Away from Home, and Social Activities. Platitudes that women may exaggerate pain, may have a higher psychological component of pain, or report that they suffer more than men did not materialize. No differences could be detected by gender in any of these areas.

While a difference in age was not associated with a difference in the 11 Point Box Scale, age was associated with nine of the 13 MPI scales: Life Control, Affect Distress, Punishing Responses, Solicitous Responses, Distracting Responses, Household Chores, Social Activities, and General Activity Level. Reviewing Table 12 (p. 101), the elderly reported more life control, less affective distress, fewer punishing responses, and decreases in household chores, social activities, and general activity level than those in their twenties. Also, the elderly reported more support and fewer solicitous and distracting responses than their middle-aged counterparts.

These age-related differences in MPI scores cannot necessarily be attributed to pain. In the adult developmental process, later adulthood is marked by senescence, or "The period of life during which losses in physical abilities and capacity are most common" (Kaplan, 1993, p. 454). Examples of senescence could explain the decreased level of physical activity seen in household chores, social activities, and general activity level.

According to Erikson's (1982) major stages in psychosocial development, the last stage, called old age, is marked by reassigning qualities of the past into new values. "The last stage finds one relatively freer of neurotic anxiety" (p. 64). The shift from adulthood 
to old age (last stage) is marked by changes in basic strengths, from a point of caring for and contributing, to a position of wisdom. In binding ritualizations, adulthood focuses on mentoring and mutual caretaking whilie old age rituals are more philosophical. Erikson's life cycle could help explain the differences seen in the age-related scores of life control, affective distress, and punishing respo.nses.

For those receiving Class II pain medications, the MPI scores were higher in the interference scale and support scale, but lower in general activity. Notice that pain severity could not be correlated to those receiving Class $\amalg$ medications. However, a major reason to prescribe Class II medications would be to improve function. As such, those who have higher support levels and where pain significantly interferes with function would be logical candidates for this form of therapy.

As one might expect, the higher the 11 Point Box Scale, the higher the reported pain severity. Along with higher levels of pain, patients rated interference and affective distress as higher, while levels of life control and activity were lower.

\section{Prescription Pain Medications and Outcomes}

The most obvious finding of this study involved the lack of long-term opioids being administered on a long-term basis as a tool for managing chronic pain, despite the recommendations of pain experts, nurmerous and current research articles, professional websites, and pain conference presenters extolling the benefits of this form of therapy. Of the 1,851 patients for whom pharmacy information was available (those who purchased an opioid prescription through the HMO pharmacy), only 445 patients (24.0\%) were identified as having had the opportunity to try at least one Class II medication over a 44- 
month period. Of 38,210 non-liquid opioid pain prescriptions distributed, Class II medications accounted for only $11.1 \%$ of the opioid prescriptions dispensed.

If long-acting opioid therapy is touted as a powerful long-term tool in managing chronic pain, then one would expect to see a substantial number of frequent but regular prescriptions filled within the HMO pharmacy. Because long-term opioid use has its own set of side effects, this method of treatment is certainly not for everyone. However, a trial would appear to be in order, especially for those who frequent the health care system with complaints of unrelieved pain.

Since no provider could write a prescription in excess of a 100-day supply, one would expect to find at least four Class II prescriptions per year or 13 prescriptions over the utilization period. If found, this might indicate that a Class $I$ medication was being dispensed on an ongoing basis (although a cursory review of the database indicated that Class II medications were more often dispensed at monthly intervals). However, of the 445 patients who obtained Class II medications, 152 patients $(34.2 \%)$ received only one prescription, while another 113 patients (totaling $59.6 \%$ of the 445 patients) received between two and four prescriptions. Only 106 patients $(23.9 \%$ of those who purchased Class II medications through the HMO pharmacy, or $5.7 \%$ of all patients receiving opioid medication through the HMO pharmacy), had 13 or more prescriptions for Class II medications. Of those patients receiving 13 or more Class II prescriptions, 16 patients obtained more than 44 prescriptions, a possible red flag suggesting either stabilization problems or potential abuse. Therefore, only 90 patients $(20.2 \%$ of patients with access to Class II medications or $4.9 \%$ of those receiving opioid prescriptions through the HMO 
pharmacy) received enough prescriptions to indicate long-term willingness on the part of the prescriber and long-term effectiveness on the part of the patient in using this form of therapy.

To the contrary, 1,816 patients $(98.1 \%)$ had access to short-term, Class III pain medications, especially hydrocodone with acetaminophen (better known by its trade name Vicodin()). Of those who received any opioid pain medication through the HMO pharmacy, only 35 patients (1.9\%) did not obtain any Class III prescriptions. Of the opioid pain medications dispensed, generic Vidodinß alone accounted for $77.6 \%$ of all prescriptions.

For those patients obtaining Class III medications, 302 patients (16.6\%) filled only one prescription through the HMO pharmacy. Another 406 patients (40.0\% combined) obtained between two and four prescriptions. Two hundred and forty patients (13.2\%) filled 45 or more prescriptions, a figure that again might suggest problems with sustained pain relief, unwillingness on the part of the prescriber to dispense effective medications for long range treatment, or potential abuse.

While Class III pain medications are recognized for effective management of acute pain, problems with physical tolerance are well known with this type of preparation. To the contrary, "Tolerance, or decreasing pain relief with the same dosage over time, has not proven to be a prevalent limitation to long-term (Class II) opioid use" (Haddox et al., p. 4).

Why Class III medications appeared so readily available to chronic pain patients and Class II medications were not is ov concern. Heit (2000) suggested that "The medical 
profession and government have done an inadequate job of educating physicians about the laws in prescribing schedule II medications" (p. 2). According to the American Society of Addiction Medicine, 'Physicians' concerns regarding possible legal, regulatory, licensing or other third party sanctions related to the prescription of opioids contribute significantly to the under treatment of pain. Physicians are obligated to relieve pain and suffering in their patients. Though many types of pain are best addressed by nom-opioid interventions, opioids are often required as a component of effective pain treatment" (ASAM, 1997, p.1). The Society goes on to recommend, "Physicians who are practicing medicine in good faith and who use reasonable medical judgement regarding the prescribing of opioids for the treatment of pain should not be held responsible for the willful and deceptive behavior of patients who successfully obtain opioids for non-medical purposes" (p. 2).

As presented in Chapter 4, gender was another issue in revealing which patients had access to opioid medications. Men were more likely to get opio id pain medications, received almost twice the number of pills, filled significantly more prescriptions (with significantly less DOVs), and, received more Class II drugs than women. While any association between access to medications for pain management and substance abuse was not studied, men were more likely to be seen in Chemical Dependency and women were more likely to be seen in Psychiatry.

\section{Point Box Scale}

One major flaw in using the 11 Point Box Scale was that it represented the level of pain perceived by the patient at a particular moment in time. As such, very few associations could be found with overall outcome data using this measurement. If 11 Point 
Box scales were administered routinely, specifically at each DOV, then time series evaluations could provide rich data to fashion and fine tune treatment regimens.

The 11 Point Box Scale was secured from both the pre-treatment and posttreatment surveys. These scales asked patients to rate their level of pain, but completion of these questions did not correspond to any particular DOV, prescription, or change in treatment. As such, the reported severity of pain was not statistically associated with the sum of DOVs or opioid prescriptions over time. In other words, patients with higher reported levels of perceived pain did not see their health care providers any more often nor did they receive any more pills or prescriptions than those who reported lower levels of pain.

"One of the difficulties associated with the assessment of pain behavior is that it is nearly impossible to distinguish whether patients exhibit pain behaviors in response to positive or negative reinforcement or their pain behaviors are a response to physiological signs" (Turk \& Okifuji, 1997, p. 261). In this study, a positive correlation was demonstrated between the physiological 11 Point Box Scale and pain affect as measured by the PDS $\left(n=1,478\right.$, Adjusted $\left.r^{2}=.142, F=245.11, p<.001\right)$. While modest, the association between the factors of perceived pain and pain affect demonstrated that the higher the 11 Point Box score, the more suffering a patient reported as measured by the PDS.

\section{$\underline{\text { Review of Stakeholders }}$}

Referring back to Table 4, this study provided some insight into whether the measurements of success were achieved by various stakeholders. Since no worker's 
compensation or other disability records were available, no conclusions could be drawn from an insurance carrier's standpoint.

The goal of patients was to eliminate or reduce pain and reduce emotional distress. Over time, patients did report lower levels of perceived pain, as seen on the pre-treatment and post-treatment surveys with the 11 Point Box Scales and the Pain Severity portion of the MPI. Using the screening version of the MPI post-treatment, patients also reported lower levels of interference and affective distress, as well as an increase in life control, when compared to the MPI questions asked at the time of referral. The total quality questions on the post-treatment survey indicated that patients' pain conditions were slightly worse than when they were originally referred. Also, the techniques taught to manage pain were not useful to those who did not attend or to those who dropped.

Success for the managed care organization could be measured by decreased utilization of the health care system. Using Table 19, Summary of DOVs (p. 123), patients did see their health care providers less often over time. However, at five years posttreatment, this group still taxed the health care system at a rate of more than four times $(409.0 \%)$ that of the systemwide average.

The goal of doctors was to reduce opioid use, most likely because of the myths of addiction, secondary gain, and perceived sanctions by regulatory agencies. However, this goal was not realized. There was no significant difference in the number of prescriptions filled at the HMO pharmacy over time. The only difference detected was in the number of pills dispensed by the HMO pharmacy and then only between two years pre-treatment and four years post-treatment $\left(\overline{\mathrm{x}}_{-2 \mathrm{yrs}}=476.49\right.$ vs. $\left.\overline{\mathrm{x}}_{4 \mathrm{yrs}}=1,007.03, \mathrm{~F}=2.727, p=.012\right)$. 
Logically, if patients' pain conditions do not improve over time, then managing pain is the only available option. With better pain management, the demand for health care services should decrease with time. Therefore, it appears that patients' and managed care's objectives are consistent with each other. However, if the goal of physicians is to restrict access to opioid pain medications, then their goal is incongruous with patients' demands and managed care's objectives. As long as these goals are at cross purposes, the ability to manage pain patients will not be effective. Until all tools to effective pain management are provided, no stakeholder really wins.

\section{Obstacles in the Study}

The complexity of adult development, the influence of psychosocial and spiritual variables, the human condition, especially in one with chronic pain, are all too perplexing to be answered in one modest study. Evaluating only the influence of one eight-week pain management program over seven years of stratified data neglected too many variables to grasp the essence of successful treatment.

While the Pain Management Program was based on cognitive-behavioral theory, the classes were not cognitive-behavior therapy in the strictest sense. With medical experts facilitating the program rather than mental health therapists, it remained difficult to separate the overall outcomes and attribute results to the effects of cognitive-behavioral theory, the passion and personality of the program's staff, influences both within and outside of the health care system, family dynamics, societal beliefs, and many of the other variables needed to paint a clear understanding in the successful (or unsuccessful) management of chronic pain. 
In other instances, variables were not controlled for because to do so would be unethical. Medical research walks a fine line between the rigors of scientific study and the Hippocratic oath to do no harm. Digging deeper to obtain more information (e.g., accessing psychological records), could violate basic privacy rights, pitting an individual's protection against the standards of good research design. Finally, a multiplicity of data presented itself here, but the scope was too broad for one study.

Prediction equations, while statistically significant, did not produce high correlations. Of question would be whether this was due to the large sample size or due to the complexity and interaction of numerous variables that help explain human behavior.

\section{Implications of the Study}

A large sample size does not necessarily make for a better study. However, it does provide rich information not assembled anywhere else. While proving statistical significance was easier with a large data set, not finding significance also confirmed that there were truly no differences or associations. With an appetite to get as much data included and analyzed as possible, one drawback of this study was its assortment of sample sizes. However, the breadth of variables studied still makes respectable contributions to the field of pain management.

In addition to answering the three research questions proposed for this study, important evidence emerged about potential gender bias, particularly in the distribution of opioid medications. While the ratio of specialty visits was similar by gender, the quantity and quality of opioid pain relievers were different. Metabolism, not weight, is the key to dosing opioid medications. As such, one would expect that women would require more 
pills than men. However, that was not the case. The findings here confirm the latest information coming from pain researchers today: that chronic pain in general is under treated, and that women are discriminated against in access to pain medications, even though there is no discernable difference in pain levels, interference, affective distress, or life control.

The progression of chronic pain disorders over time resulted from much more than those factors explored in the Pain Management Program. It remains difficult to assess one's improvement as the result of the pain program when serious barriers to effective treatment exist in the health care system.

\section{Future Research}

To better understand the volume and scope of DOVs, more information needs to be gathered on pain-related utilization. One way to get a clearer understanding of the role of chronic pain and its treatment would be to record reported pain levels (e.g., 11 Point Box Scale) at each DOV or change in treatment. With pain now encouraged to be the fifth vital sign, new standards for assessing pain are presently being adopted and charted as part of routine patient care. The evolution of paperless charts, preferably formatted into relational data bases, could improve the scope and depth of available information.

If this study's data were updated, three more years of utilization information could provide rich, large, longitudinal information so desperately lacking in pain research. Improved data gathering may create more insight into the association between many individual variables in chronic pain, psychosocial contributions, single versus multiple pain conditions, and the complexity of both pain and non-pain related disorders. Still, smaller 
and more comprehensive studies with qualitative components may help pinpoint themes possibly overlooked. Also, newer assessment tools tailored especially for chronic pain patients could be incorporated with routine assessments to see if new measures may better explain the chronic pain experience.

Furthermore, studies should delve into gender differences and gender bias with the perception and treatment of chronic pain. The attitudes and beliefs of patients and their health care providers should be explored to ensure that treatment is given equitably.

Future study could compare patients who have the option of taking Class II medications with those who cannot or chose not to use this treatment option. By comparing utilization, satisfaction, quality of life, perceived pain, affective pain and other variables discussed in this study, a clearer understanding may develop as to why and under what conditions Class II medications increase function and benefit patients. Also, antidepressants and other non-opioid medications helpful in the treatment of chronic pain could be explored.

A study could be done exploring providers' perspectives on medications, assessing their patients' confidence and satisfaction with treatment and care (especially through primary care), and designing clinical guidelines to better manage chronic pain patients. After that, education programs for providers could update their skills, provide the latest information on chronic pain treatment, increase proficiency in recognizing addiction versus pseudoaddiction, and examine costs and patient satisfaction after training.

Other related studies could focus on the higher incidence of depression in those with chronic pain. Of interest would be whether mental illness is more prevalent with 
chronic pain than with other physical disorders. Also, a study could view how other chronic illnesses compare to chronic pain in terms of utilization, medication, other costs, patient functioning and well-being.

Along the same vein, a study of the impact of tailored treatment programs for chronic pain patients and coordinated pain services through the use of a case manager could be statistically matched to those who negotiate the health care system on their own. If collaborative relationships were formed, would one find a difference in the efficacy of treatment?

A statistical critique advanced in this study was the prevalence of researchers who present data using means without considering outliers. While appearing scientific, these figures are misleading and not all statistics fit a normal distribution. Consumers of research data would be wise to secure a basic understanding of statistics and keep a wary eye on methodology.

Chronic pain is a complex issue with no obvious or easy solutions. Pain patients do not fit the model of medicine's scientific precision and mastery over nature. As a group, chronic pain patients do not get better. They show up frequently at doctors' offices, a reminder to providers that medicine does not have all the answers. As shown in this study, one cognitive-behavioral program worked by improving patients' satisfaction with the health care system. However, this alone is far from the solution. Chronic pain must be attacked from a variety of fronts: comprehensive evaluation, appropriate medications, cognitive restructuring, alternative therapies, and biopsychosocial support from medical providers, complimentary medicine, and the community at large. 
Chronic Pain 163

... That's all, Folks

Porky Pig

Reproduced with permission of the copyright owner. Further reproduction prohibited without permission. 


\section{REFERENCES}

American Society of Addiction Medicine (ASAM). (1997, April). Public Policy of ASAM: Rights and responsibilities of physicians in the use of opioids for the treatment of pain. Available: www.asam.org/ppol/opioids.htm.

Arbuthnott, D. (1994). Emotional and behavioral management of chronic pain. Pain Clinic, 7 (1), 39-43.

Barkin, R. L., Lubenow, T. R., Bruehl, S., Husfeldt, B., Ivankovich, O., \& Barkin, S. J. (1996a). Management of Chronic Pain. Part I. Disease-a-Month, 42 (7), 388-454.

Barkin, R. L., Lubenow, T. R., Bruehl, S., Husfeldt, B., Ivankovich, O., \& Barkin, S. J. (1996b). Management of Chronic Pain. Part II. Disease-a-Month, 42 (8), 469-507.

Barnett, E. H. (1999, September 2). Case marks big shift in pain policy. The Oregonian, 1-4.

Bates, M. S. (1996). Biocultural dimensions of chronic pain: Implications for treatment of multi-ethnic populations. Albany, NY: SUNY Press.

Bernstein, I. H., Jaremko, M. E., \& Hinkley, B. S. (1995). On the utility of the West Haven-Yale Multidimensional Pain Inventory. Spine, 20 (8), 956-963.

Brody, D. S., Hahn, S. R., Spitzer, R. L., Kroenke, K., Linzer, M., deGruy, F. V., \& Williams, J. B. W. (1998, December 7/21). Identifying patients with depression in the primary care setting: A more efficient method. Archives of Internal Medicine, 158, 24692475 . Collins.

Brand, P., \& Yancey, P. (1993). Pain: The gift nobody wants. New York: Harper-

Brookoff, D. (1999a, August). Legal ramification of opioid use in chronic pain patients. In B. McCarberg (Chair), 1999 Pain management symposium. Symposium conducted at a meeting of the Department of Clinical Services (Kaiser Permanente), Newport Beach, CA.

Brookoff, D. (1999b, August). The science of pain. In B. McCarberg (Chair), 1999 Pain management symposium. Symposium conducted at a meeting of the Department of Clinical Services (Kaiser Permanente), Newport Beach, CA.

Brown, W. A. (1998, June). The power of the placebo: Here's how physicians can make greater use of it - without violating patients' trust. Hippocrates, 47-52. 

107-116.

Brown, W. A. (1998, July 15). Harnessing the placebo effect. Hospital Practice,

Cassem, N. H. (1998). Managing depression in medically ill patients. Primary Care \& Cancer, $18(10), 10$.

Corey, G. (1990). Theory and practice of group counseling. (Rev. ed.). Pacific Grove, CA: Brooks/Cole.

Depression Guideline Panel. (1993). Depression in primary care: Volume 2. Treatment of major depression. (No. 93-0551). Maryland: U. S. Department of Health \& Human Services.

Donovan, M. (1999, August). Chronic pain in primary care. In B. McCarberg (Chair), 1999 Pain management symposium. Symposium conducted at a meeting of the Department of Clinical Services (Kaiser Permanente), Newport Beach, CA.

Donovan, M. I., Evers, K., Jacobs, P., \& Mandelblatt, S. (1999). When there is no benchmark: Designing a primary care-based chronic pain management program from the scientific basis up. Journal of Pain \& Symptom Management, 18(1), 38-48.

Duerksen, S. (1992, March 9). Doctors also face a painful decision: Tough drug laws vs. patients' agony. The San Diego Union-Tribune, A-1.

Emanuel, E. J., Daniels, E. R., Fairclough, D. L., \& Clarridge, B. R. (1998). The practice of euthanasia and physician-assisted suicide in the United States: Adherence to proposed safeguards and effects on physicians. $J A M A, 280(6), 507-513$.

Emanuel, L. L. (1998). Facing requests for physician-assisted suicide: Toward a practical and principled clinical skill set. JAMA, 280(7), 643-647.

Erikson, E. (1982). The Life Cycle Completed. New York: Norton.

Ershoff, D. (1995). Evaluation of chronic pain management program: Behavioral and medical care utilization outcomes. Unpublished manuscript.

Etscheidt, M. A., Steger, H. G., \& Braverman, B. (1995). Multidimensional pain inventory profile classifications and psychopathology. Journal of Clinical Psychology, $51(1), 29-36$.

Flor, H., \& Birbaumer, N. (1993). Comparison of the efficacy of electromyographic biofeedback, cognitive-behavioral therapy, and conservative medical 
Chronic Pain 166

interventions in the treatment of chronic musculoskeletal pain. Journal of Consulting \& Clinical Psychology, 61(4), 653-658.

Press.

Frankl. V. E. (1985). Man's search for meaning. New York: Washington Square

Good, M. D., Brodwin, P. E., Good, B. J., \& Kleinman, A. (1992). Pain as human experience: An anthropological perspective. Berkeley: University of California Press.

Haddox, J. D., Joranson, D., Angarola, R. T., Brady, A., Carr, D. B., Blonsky, E. R., Burchiel, K., Gitlin, M., Midcap, M, Payne, R., Simon, D., Vasudevan, S., Wilson, P., \& Portnenoy, R. K. (1996). The use of opioids for the treatment of chronic pain: $A$ consensus statement from American Academy of Pain Medicine and American Pain Society [On-line]. Available: www.ampainsoc.org/advocacy/opioids.htm.

Hadjistravropoulos, H. D., \& Craig, K. D. (1994). Acute and chronic low back pain: Cognitive, affective, and behavioral dimensions. Journal of Consulting \& Clinical Psychology, 62(2), 341-349.

Heit, H. (2000). Pain Relief Promotion Act [On-line]. Available: www.asam.org/pain/pain_relief_promotion_act.htm.

Harvey, D. L., \& Hoffmann, I. (1997, November/December). The nocebo effect: Its meaning for today's physicians and patients. Primary Care \& Cancer, 33-34. \& Winston.

Hays, W. L. (1973). Statistics for the social sciences. New York: Holt, Reinhart,

Hinkle, D. E., Wiersma, W., \& Jurs, S. G. (1998). Applied statistics for the behavioral sciences ( $4^{\text {th }}$ ed.). Boston: Houghton Mifflin.

Huck, S. W., Cormier, W. H., \& Bounds, W. G. (1974). Reading statistics and research. New York: Harper \& Row.

International Assoc. for the Study of Pain (1999). Desirable characteristics for pain treatment facilities [On-line]. Available: http://www.halcyon.com/iasp/desirabl.html.

Jensen, M. P., Karoly, P., \& Harris, P. (1991). Assessing the affective component of chronic pain: Development of the pain discomfort scale. Journal of Psychosomatic Research, 35, 149-154.

Kaplan, P. (1993). The human odyssey: Life-span development. Minneapolis/St. Paul: West Publishing. 
Karoly, P., \& Jensen, M. P. (1987). Multimethod assessment of chronic pain. Oxford: Pergamon Press.

Kerns, R. D., Turk, D. C., \& Rudy, T. E. (1985). The West Haven-Yale Multidimensional Pain Inventory (WHYMPI). Pain, 23, 345-356.

Kleinman, A. (1988). The illness narratives: Suffering, healing, and the human condition. New York: Basic Books.

Laskin, M. A. E. (1998). Pain management. In L. White \& G. Duncan (Eds.), Medical-surgical nursing: An integrated approach (pp. 205-226). Albany, NY: Delmar.

Ledingham, J., Doherty, S., \&\& Doherty, M. (1993). Primary fibromyalgia syndrome - an outcome study. British Journal of Rheumatology, 32, 139-142.

Lema, M. J., \& Lema, G. M. (1998, May). Alleviate the pain instead of assisting in suicide. Hospital Medicine, 8.

Lowenhaupt, M. T. (1998, June). Breakthrough strategies for difficult patients: When you unmask the underlying causes of difficult behavior, you can improve your relationship. Physician's Management, 28-33. Bartlett.

Lubkin, I. M. (1995). Chronic illness: Impact and interventions. Boston: Jones \&

Marcus, D. A. (2000). Treatment of nonmalignant chronic pain. American Family Physician, 61(5), 1331-1338.

Mayo Foundation for Medical Education and Research (1998, April 24). Medical quackery alive and well [On-line]. Available: http://www.mayohealth.org/mayo/9706/htm/ medical.htm.

McCarberg, B., \& Wolf, J. (1999). Chronic pain management in a health maintenance organization. Clinical Journal of Pain, 15(1), 1-8.

Merriam-Webster, Inc. (1991). Webster's 9th new collegiate dictionary. New York: Author.

Merskey, H. (1990). Body-mind dilemma in chronic pain. In E. Tunks, A. Bellissimo, \& R. Roy (Eds.), Chronic pain: Psychosocial factors in rehabilitation. (pp. 10-20). Melbourne, FL: Krieger. 
Morris, D. B. (1991). The culture of pain. Berkeley: University of California Press.

Nicassio, P. M., Radojevic, V., Weisman, M. H., Schuman, C., Kim, J., Schoenfeld-Smith, K., \& Krall, T. (1997). A comparison of behavioral and educational interventions for fibromyalgia. Journal of Rheumatology, 24(10), 2000-2007.

O’Malley, P. G.., Jackson, J. L., Kroenke, K., Yoon, I. K., Hornstein, E., \& Dennis, G. J. (1998). The value of screening for psychiatric disorders in rheumatology referrals. Archives of Internal Medicine, 158, 2357-2362.

Phillips, D. M. (2000). JACHO pain management standards are unveiled. JAMA, 284 (4) [On-line]. Available: http://jama_ama-assn.org/issues/v284n4/full/jmn0726-3.html.

Robischon, T. (1998, October). A new clinical practice model wants in. Internal Medicine World Report, 21-22.

Rost, J. C. (1991). Leadership for the twenty-first century. Westport, CT: Praeger.

Rothschild, B., \& Vu, J. (1994). Retrospective assessment of fibromyalgia therapeusis. Comprehensive Therapy, 20(10), 545-549.

Rudy, T. E., \& Turk, D.C., Zaki, H. S., Curtin, D. H. (1989). An empirical taxometric alternative to traditional classification of temporomandibular disorders. Pain, $36,311-320$.

Schwartzman, R. J., \& Kerrigan, J. (1990). The movement disorder of reflex sympathetic dystrophy. Neurology, 40, 57-61. Press.

Sheridan, M. S. (1992). Pain in America. Tuscaloosa: University of Alabama

Stirling, G., Reid, D. W., Pollard, J., Ondrack, M. (1996, Summer). Symptoms \& characteristics of CFS: A survey of 875 Ontario residents. CFIDS Chronicle, 73-76

Talarico, L. D. (1998, June 15). Difficult patient or difficult situation? Patient Care, $167-180$.

Tarascon Publishing. (2000). Tarascon Pocket Pharmacopoeia 2000 (Classic ed.). Loma Linda, CA: Author.

Tunks, E., Bellissimo, A., \& Roy, R. (Eds.). (1990). Chronic Pain: Psychosocial Factors in Rehabilitation. Melbourne, FL: Krieger. 
Turk, D. C. (1999, August). Assessing patients with chronic pain: A multiaxial approach. In B. McCarberg (Chair), 1999 Pain management symposium. Symposium conducted at a meeting of the Department of Clinical Services (Kaiser Permanente), Newport Beach, CA.

Turk, D. C., \& Okifuji, A. (1999). Assessment of patients' reporting of pain: An integrated perspective. The Lancet, 353, 1784-1788.

Turk, D. C., \& Okifuji, A. (1998). Treatment of chronic pain patients: Clinical outcomes, cost-effectiveness, and cost-benefits of multidisciplinary pain centers. Critical Reviews in Physical and Rehabilitation Medicine, 10(2), 181-208.

Turk, D. C. \& Okifuji, A. (1997). Evaluating the role of physical, operant, cognitive, and affective factors in the pain behaviors of chronic pain patients. Behovior Modification, 21(3), 259-280.

Turk, D. C. \& Okifuji, A. (1996). Perception of traumatic onset, compensation status, and physical findings: Impact on pain severity, emotional distress, and disability in chronic pain patients. Journal of Behovioral Medicine, 19(5), 435-453.

Turk, D. C., Okifuji, A., Sinclair, J. D., \& Starz, T. W. (1996). Pain, disability, and physical functioning in subgroups of patients with fibromyalgia. Journal of Rheumatology, $23(7), 1255-1262$.

Turk, D. C., \& Rudy, T. E. (1988). Toward an empirically derived taxonomy of chronic pain patients: Integration of psychological assessment data. Journal of Counseling and Clinical Psychology, 26, 233-238.

Tyrer, S. P. (Ed.). (1992). Psychology, psychiatry and chronic pain. Oxford: Butterworth-Heinemann.

Valigra, L. (1998, December 14). Painful realities: The business of pain management has become almost as complex as treating pain itself. American Medical News, pp. 33-36.

Wade, J. B., Dougherty, L. M., Hart, R. P., \& Cook, D. B. (1992). Patterns of normal personality structure among chronic pain patients. Pain, 48, 37-43.

Walter, L., \& Brannon, L. (1991, July). A cluster analysis of the Multidimensional Pain Inventory. Headache (31), pp.476-479. 
Waylonis, G. W., \& Perkins, R. H. (1994). Post-traumatic fibromyalgia: A longterm follow-up. American Journal of Physical Medicine \& Rehabilitation, 73(6), 403-411.

1997 Membership Utilization Data Report (1998, October). Oakland, CA: Kaiser Permanente. 


\section{APPENDIX A}

\section{Pre Treatment Questionnaire}




\section{Questionnaire}

Today's Date: Medical Record Number:

Some information about yourself

Name:

Last

Address:

No. Street City - Zip

Work Phone: Home Phone:

Date of Birth:

Sex: Male $\square \quad$ Female

Marital Status: Married $\square$ Separated $\square$ Divorced $\square \quad$ Widowed $\square \quad$ Single $\square$

With whom are you currently living: (Please check ALL that apply)
Live alone $\square$ Spouse/partner $\square$
Parents $\square$
Children $\square$
Roommate $\square$

Other (please specify):

What is the highest grade or year of school that you completed?

Grade School or less $\square$ Some High School $\square$ High School Graduate $\square$
Some College/Vocational School $\square$ College Graduate $\square$ Post Graduate $\square$

Which best describes your work situation now?
Employed Full Time
Employed Part Time $\square$
Retired
Homemaker
Student $\square$
Unemployed $\square$
Disabled $\square$

When did your pain first start?

\section{Month/Year}

Briefly describe your pain - when did it start, where is the pain, etc.

\section{Page 1}


Siguficantothertion

Throughout the questionnaire which follows, there will be several items that ask about your spouse or significant other. For those of you who are not currently married, we would like to know who you consider to be your significant other. Your significant other should be someone with whom you spend a great deal of time. This person may or may not be currently living with you. For example, your significant other may be your child that lives with you or a close friend who lives next door.

Is your significant other your spouse or someone else?

Spouse $\square$ Someone Else $\square$ Don't have significant other

If your significant other is not your spouse (that is, you checked "someone else" in the question above), please specify the relationship:

(child, parent, other relative, friend, co-worker, etc.)

If you don't have a significant other, please skip Section II (page 6 of the questionnaire).

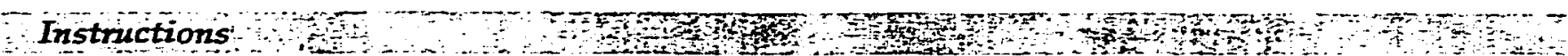

An important part of our evaluation includes examination of pain from your perspective because you know your pain better than anyone else. The following questions are designed to help us leam more about your pain and how it affects your life. Beside each question is a scale to mark your answer. Read each question carefully and then circle a number on the scale beside that question to indicate how that specific question applies to you. An example may help you to better understand how you should answer these questions.

Example:

1. How nervous are you when you ride in a car when the traffic is heavy?

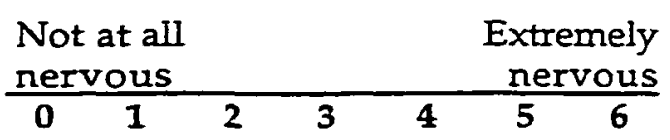

If you are not at all nervous when riding in a car in heavy traffic, you would want to circle the number 0 . If you are very nervous when riding in a car in heavy traffic, you would then circle the number 6 . Lower numbers are for less nervousness, and higher numbers for more nervousness. 
1. Rate the level of your pain at the present moment.

\begin{tabular}{ccccccc} 
No pain & & & \multicolumn{3}{c}{ intense pain } \\
\hline 0 & 1 & 2 & 3 & 4 & 5 & 6
\end{tabular}

2. In general, how much does your pain interfere with your day-to-day activities?

3. Since the time your pain began, how much has your pain changed your ability to work? (Check here, if you have retired for reasons other than your pain. $\square$ )

4. How much has your pain changed the amount of satisfaction or enjoyment you get from taking part in social and recreational activities?

5. How supportive or helpful is your spouse (significant other) to you in relation to your pain?

6. Rate your overall mood during the past week.

\begin{tabular}{ccccccc} 
& & & & $\begin{array}{r}\text { Extreme } \\
\text { change }\end{array}$ \\
No change & & & ren \\
\hline 0 & 1 & 2 & 3 & 4 & 5 & 6
\end{tabular}

\begin{tabular}{|c|c|c|c|c|c|c|}
\hline \multirow{2}{*}{\multicolumn{3}{|c|}{$\begin{array}{l}\text { Not at all } \\
\text { supportive } \\
0\end{array}$}} & & \multicolumn{3}{|c|}{$\begin{array}{l}\text { Extremely } \\
\text { supportive }\end{array}$} \\
\hline & & & 3 & 4 & 5 & 6 \\
\hline \multicolumn{3}{|c|}{$\begin{array}{l}\text { Extremely } \\
\text { low }\end{array}$} & & & \multirow{2}{*}{\multicolumn{2}{|c|}{$\begin{array}{r}\text { Extremely } \\
\text { high }\end{array}$}} \\
\hline 0 & 1 & 2 & 3 & 4 & & 6 \\
\hline
\end{tabular}

\begin{tabular}{|c|c|}
\hline $\begin{array}{l}\text { No } \\
\text { interference }\end{array}$ & $\begin{array}{r}\text { Extreme } \\
\text { interference }\end{array}$ \\
\hline 1 & 5 \\
\hline
\end{tabular}

7. How much has your pain interfered with your No Extreme

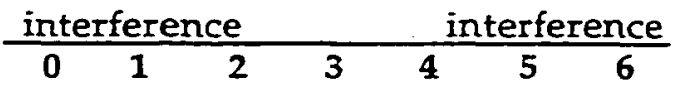
\begin{tabular}{ccccccc} 
No change & & & $\begin{array}{r}\text { Extreme } \\
\text { change }\end{array}$ \\
\hline 0 & 1 & 2 & 3 & 4 & 5 & 6
\end{tabular} ability to get enough sleep?

8. On the average, how severe has your pain been during the last week?

\begin{tabular}{lllllll}
$\begin{array}{l}\text { Not at all } \\
\text { severe }\end{array}$ & & & $\begin{array}{r}\text { Extremely } \\
\text { severe }\end{array}$ \\
\hline 0 & 1 & 2 & 3 & 4 & 5 & 6
\end{tabular}

9. How able are you to predict when your pain will

\begin{tabular}{|c|c|}
\hline $\begin{array}{l}\text { Not at all able } \\
\text { to predict }\end{array}$ & $\begin{array}{l}\text { Very able } \\
\text { to predict }\end{array}$ \\
\hline 0 & 6 \\
\hline
\end{tabular}
start, get better or get worse? 
10. How much has your pain changed your ability to take part in recreational and other social activities?

11. How much do you limit your activities in order to keep your pain from getting worse?

12. How much has your pain changed the amount of satisfaction or enjoyment you get from familyrelated activities?

13. How worried is your spouse (significant other) about you because of your pain?

14. During the past week how much control do you feel that you have had over your life?

15. On an average day, how much does your pain vary (increase or decrease)?

16. How much suffering do you experience because of your pain?

17. How often are you able to do something that helps to reduce your pain?

18. How much has your pain changed your relationship with your spouse, family or significant other?

19. How much has your pain changed the amount of satisfaction or enjoyment you get from work? (Check here if you are not presently working. $\square$ )

\begin{tabular}{lllllll} 
No change & & & $\begin{array}{r}\text { Extreme } \\
\text { change }\end{array}$ \\
\hline 0 & 1 & 2 & 3 & 4 & 5 & 6
\end{tabular}

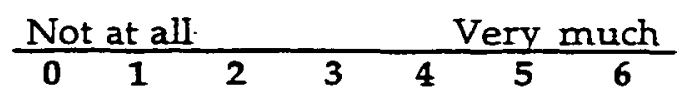

\begin{tabular}{ccccccc} 
No change & & & $\begin{array}{r}\text { Extreme } \\
\text { change }\end{array}$ \\
\hline 0 & 1 & 2 & 3 & 4 & 5 & 6
\end{tabular}

\begin{tabular}{lllllll}
$\begin{array}{l}\text { Not at all } \\
\text { worried }\end{array}$ & & & $\begin{array}{r}\text { Extremely } \\
\text { worried }\end{array}$ \\
\hline 0 & $\mathbf{1}$ & $\mathbf{2}$ & $\mathbf{3}$ & $\mathbf{4}$ & $\mathbf{5}$ & $\mathbf{6}$
\end{tabular}

\begin{tabular}{lllllll} 
No control & & & $\begin{array}{r}\text { Extreme } \\
\text { control }\end{array}$ \\
\hline 0 & 1 & 2 & 3 & 4 & 5 & 6
\end{tabular}

\begin{tabular}{lllllll}
$\begin{array}{l}\text { Remains } \\
\text { the same }\end{array}$ & & & $\begin{array}{r}\text { Changes } \\
\text { a lot }\end{array}$ \\
\hline 0 & 1 & 2 & 3 & 4 & 5 & 6
\end{tabular}

\begin{tabular}{lllllcc}
$\begin{array}{l}\text { No } \\
\text { suffering }\end{array}$ & & & $\begin{array}{l}\text { Extreme } \\
\text { suffering }\end{array}$ \\
\hline 0 & 1 & 2 & 3 & 4 & 5 & 6
\end{tabular}

\begin{tabular}{lllllcc} 
Never & & \multicolumn{3}{c}{ Very often } \\
\hline 0 & 1 & 2 & 3 & 4 & 5 & 6
\end{tabular}

\begin{tabular}{llllllr} 
No change & & & $\begin{array}{r}\text { Extreme } \\
\text { change }\end{array}$ \\
\hline 0 & 1 & 2 & 3 & 4 & 5 & 6
\end{tabular}

\begin{tabular}{ccccccc} 
& & & $\begin{array}{r}\text { Extreme } \\
\text { change }\end{array}$ \\
\hline 0 & 1 & 2 & 3 & 4 & 5 & 6
\end{tabular}

\section{Page 4}


20. How attentive is your spouse (significant other) to you because of your pain?

21. During the past week, how much do you feel that you've been able to deal with your problems?

22. How much control do you feel that you have over your pain?

23. How much has your pain changed your ability to do household chores?

34. During the past week how successful were you in coping with stressful situations in your life?

25. How much has your pain interfered with your ability to plan activities?

26. During the past week, how irritable have you been?

27. How much has your pain changed or interfered with your friendships with people other than your family?

28. During the past week, how tense or anxious have you been?

\begin{tabular}{ccccccc}
$\begin{array}{l}\text { Not at all } \\
\text { attentive }\end{array}$ & & & $\begin{array}{r}\text { Extremely } \\
\text { attentive }\end{array}$ \\
\hline 0 & 1 & 2 & 3 & 4 & 5 & 6
\end{tabular}

\begin{tabular}{ccccccc} 
& & & & \multicolumn{2}{c}{$\begin{array}{c}\text { Extremely } \\
\text { well }\end{array}$} \\
\hline Not at all & & & & \\
\hline 0 & 1 & 2 & 3 & 4 & 5 & 6
\end{tabular}

\begin{tabular}{llllll}
$\begin{array}{l}\text { No control } \\
\text { at all }\end{array}$ & & \multicolumn{2}{c}{$\begin{array}{r}\text { A great deal } \\
\text { of control }\end{array}$} \\
\hline 0 & 1 & 2 & 3 & 4 & 5
\end{tabular}

\begin{tabular}{lllllll} 
No change & & & $\begin{array}{r}\text { Extreme } \\
\text { change }\end{array}$ \\
\hline 0 & 1 & 2 & 3 & 4 & 5 & 6
\end{tabular}

\begin{tabular}{lllllcl}
$\begin{array}{l}\text { Not at all } \\
\text { successful }\end{array}$ & & & \multicolumn{2}{c}{$\begin{array}{c}\text { Extremely } \\
\text { successful }\end{array}$} \\
\hline 0 & 1 & 2 & 3 & 4 & 5 & 6
\end{tabular}

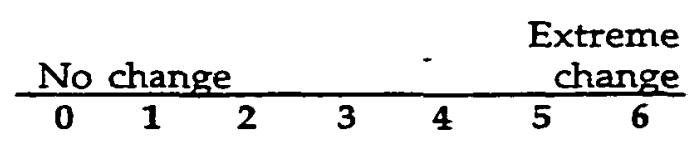

\begin{tabular}{|c|c|}
\hline $\begin{array}{l}\text { Not at all } \\
\text { irritable }\end{array}$ & $\begin{array}{c}\text { Extremely } \\
\text { irritable }\end{array}$ \\
\hline 01 & 5 \\
\hline
\end{tabular}

\begin{tabular}{ccccccc} 
No change & & & $\begin{array}{r}\text { Extreme } \\
\text { change }\end{array}$ \\
\hline 0 & 1 & 2 & 3 & 4 & 5 & 6
\end{tabular}

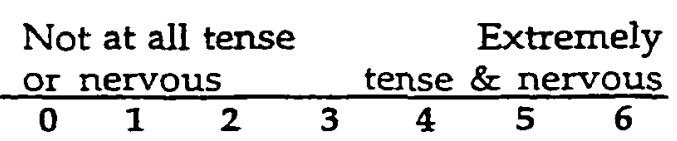


Section II If you don thave a significant other please skip this section.

In this section, we are interested in knowing how your spouse (significant other) responds to you when he or she knows you are in pain. On the scale listed next to each question, circle a number to indicate how often your spouse (significant other) responds to you in that particular way when you are in pain. Please answer all of the 14 questions.

\section{Never}

Verv Often

1. Ignores me

2. Asks me what he/she can do to help

3. Reads to me

4. Gets irritated with me

5. Takes over my job or duties

6. Talks to me about something else to take my mind off the pain

$\begin{array}{lllllll}0 & 1 & 2 & 3 & 4 & 5 & 6 \\ 0 & 1 & 2 & 3 & 4 & 5 & 6 \\ 0 & 1 & 2 & 3 & 4 & 5 & 6 \\ 0 & 1 & 2 & 3 & 4 & 5 & 6 \\ 0 & 1 & 2 & 3 & 4 & 5 & 6 \\ 0 & 1 & 2 & 3 & 4 & 5 & 6\end{array}$

7. Gets frustrated with me

8. Tries to get me to rest

9. Tries to involve me in some activity

10. Gets angry with me

11. Gets me pain medication

12. Encourages me to work on a hobby

13. Gets me something to eat or drink

14. Turns on the TV to take my mind off my pain

$\begin{array}{lllllll}0 & 1 & 2 & 3 & 4 & 5 & 6 \\ 0 & 1 & 2 & 3 & 4 & 5 & 6 \\ 0 & 1 & 2 & 3 & 4 & 5 & 6 \\ 0 & 1 & 2 & 3 & 4 & 5 & 6 \\ 0 & 1 & 2 & 3 & 4 & 5 & 6 \\ 0 & 1 & 2 & 3 & 4 & 5 & 6 \\ 0 & 1 & 2 & 3 & 4 & 5 & 6 \\ 0 & 1 & 2 & 3 & 4 & 5 & 6\end{array}$

\section{Page 6}




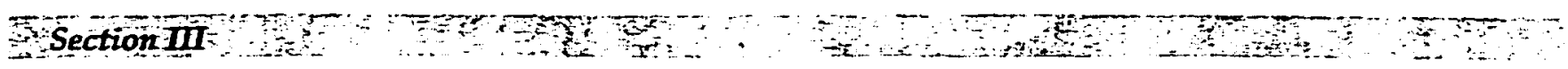

Listed below are 19 daily activities. Please indicate how often you do each of these by circling a number on the scale listed next to each activity. Please complete all 19 questions.

1. Wash dishes

2. Mow the lawn (Check here if you do not have a lawn to mow. D)

3. Go out to eat

4. Play cards or other games

5. Go grocery shopping

6. Work in the garden (Check here if you do not have a garden. $\square$ )

7. Go to a movie

8. Visit friends

9. Help with the house cleaning

10. Work on the car (Check here if you don't have a car. $\square$ )

11. Take a ride in a car or bus

12. Visit relatives (Check here if you do not have relatives within 100 miles. $\square$ )

13. Prepare a meal

14. Wash the car (Check here if you don't have a car. $\square$ )

15. Take a trip

16. Go to a park or beach

17. Do the laundry

18. Work on a needed household repair

19. Engage in sexual activities $\begin{array}{lllllll}0 & 1 & 2 & 3 & 4 & 5 & 6\end{array}$

$\begin{array}{lllllll}0 & 1 & 2 & 3 & 4 & 5 & 6\end{array}$

$\begin{array}{lllllll}0 & -1 & 2 & 3 & 4 & 5 & 6\end{array}$

$\begin{array}{lllllll}0 & 1 & 2 & 3 & 4 & 5 & 6\end{array}$

$\begin{array}{lllllll}0 & 1 & 2 & 3 & 4 & 5 & 6\end{array}$

$\begin{array}{lllllll}0 & 1 & 2 & 3 & 4 & 5 & 6\end{array}$

$\begin{array}{lllllll}0 & 1 & 2 & 3 & 4 & 5 & 6\end{array}$

$\begin{array}{lllllll}0 & 1 & 2 & 3 & 4 & 5 & 6\end{array}$

$\begin{array}{lllllll}0 & 1 & 2 & 3 & 4 & 5 & 6\end{array}$

$\begin{array}{lllllll}0 & 1 & 2 & 3 & 4 & 5 & 6\end{array}$

$\begin{array}{lllllll}0 & 1 & 2 & 3 & 4 & 5 & 6\end{array}$

$\begin{array}{lllllll}0 & 1 & 2 & 3 & 4 & 5 & 6\end{array}$

$\begin{array}{lllllll}0 & 1 & 2 & 3 & 4 & 5 & 6\end{array}$

$\begin{array}{lllllll}0 & 1 & 2 & 3 & 4 & 5 & 6\end{array}$

$\begin{array}{lllllll}0 & 1 & 2 & 3 & 4 & 5 & 6\end{array}$

$\begin{array}{lllllll}0 & 1 & 2 & 3 & 4 & 5 & 6\end{array}$

$\begin{array}{lllllll}0 & 1 & 2 & 3 & 4 & 5 & 6\end{array}$

$\begin{array}{lllllll}0 & 1 & 2 & 3 & 4 & 5 & 6\end{array}$

$\begin{array}{lllllll}0 & 1 & 2 & 3 & 4 & 5 & 6\end{array}$

Page 7 
Sectón I

is a zero (0) means "no pain" and a ten (10) means "pain as bad as it could be," on this. scale of 0 to 10 , what is your level of pain? Put an $X$ through that number.

\begin{tabular}{|l|l|l|l|l|l|l|l|l|l|l|}
\hline 0 & 1 & 2 & 3 & 4 & 5 & 6 & 7 & 8 & 9 & 10 \\
\hline
\end{tabular}

Section

Please indicate by circling the appropriate number whether each of the statements below is more true or false for you. Please answer every question and circle only one number per question. Answer by circling the appropriate number ( 0 through 4 ) according to the following scale.

$0=$ This is very untrue for me.

$1=$ This is somewhat untrue for me.

2 = This is neither true nor untrue for me (or it does not apply to me).

$3=$ This is somewhat true for me.

$4=$ This is very true to me.

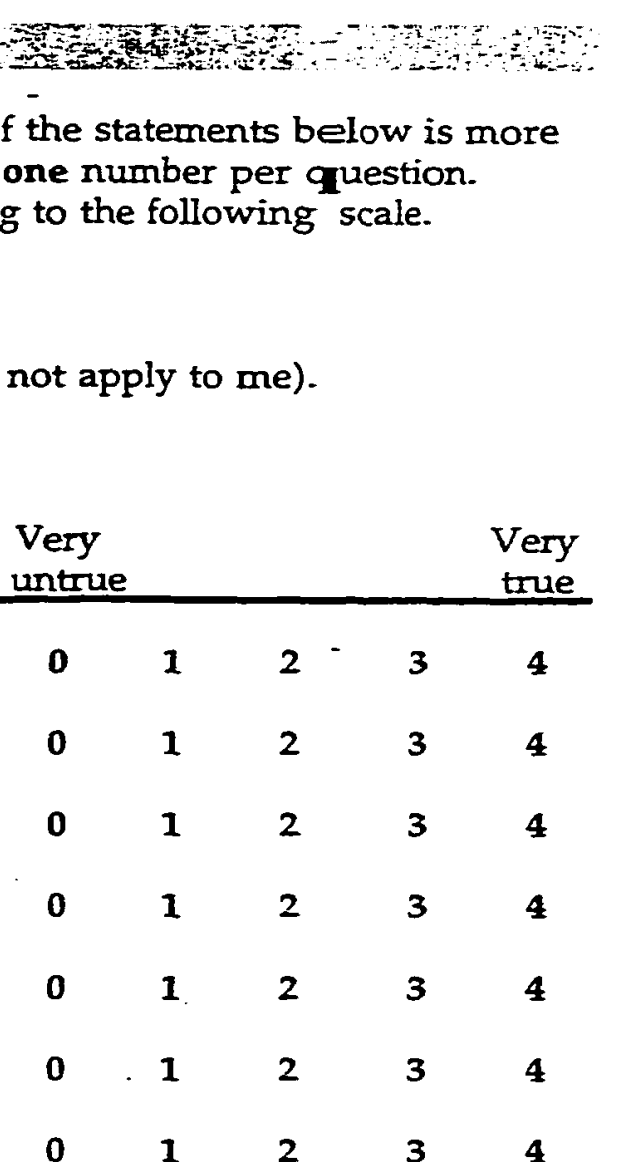

1. I am scared of the pain I feel.

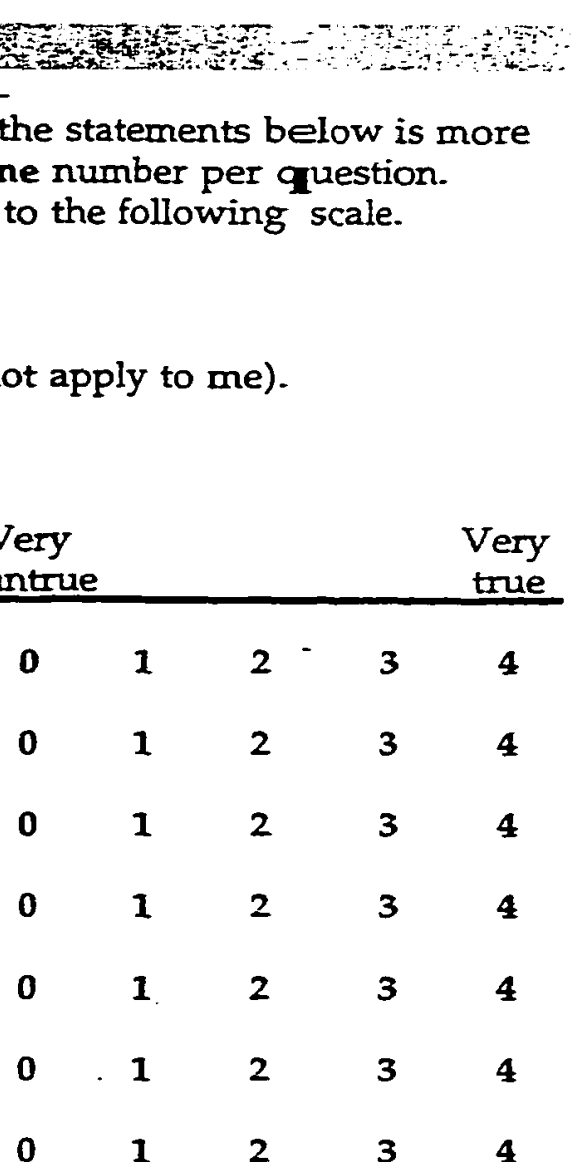

2. The pain I experience is unbearable.

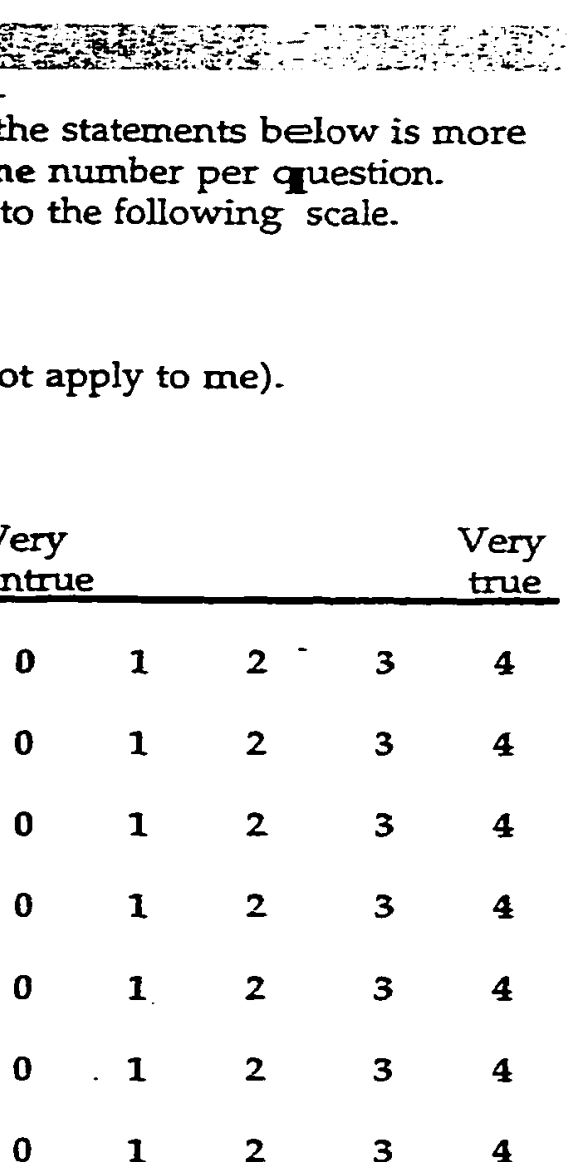

3. The pain I feel is torturing me.

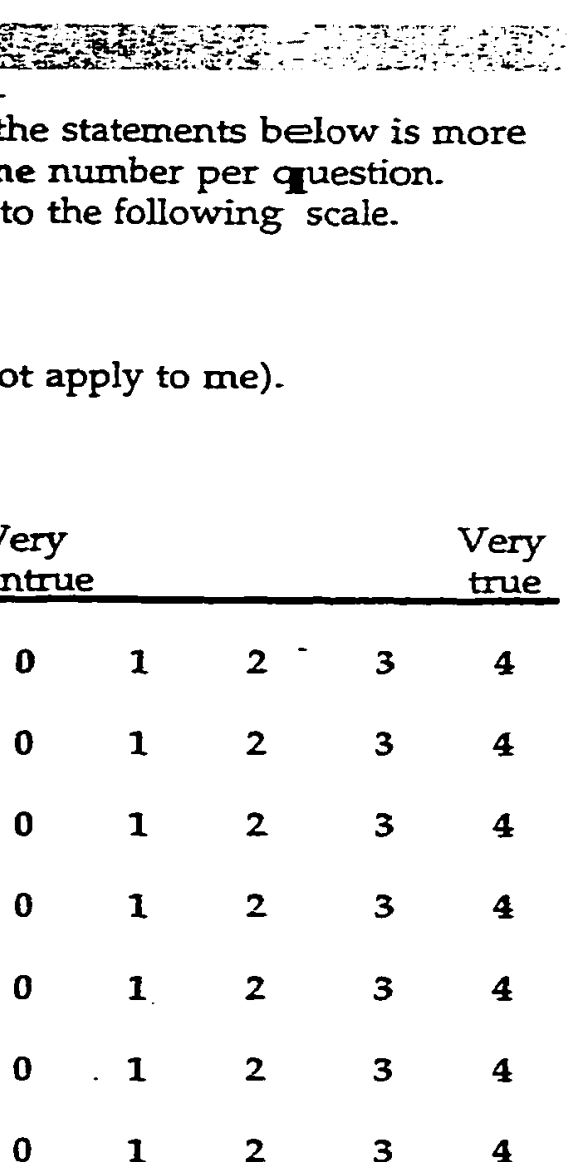

4. My pain does not stop me from enjoying life.

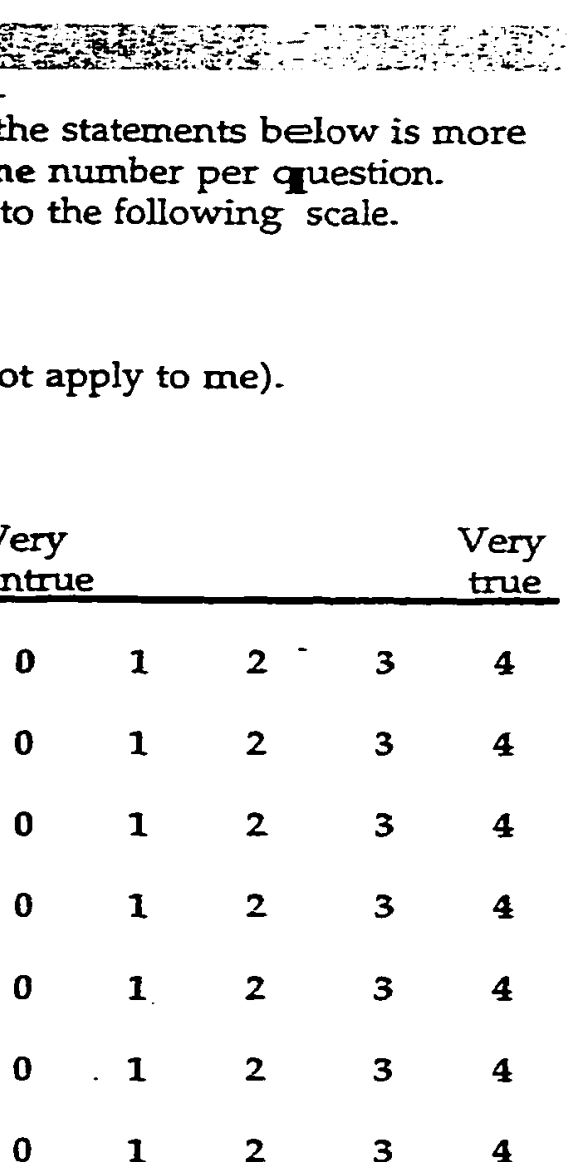

5. I have learned to tolerate the pain I feel.

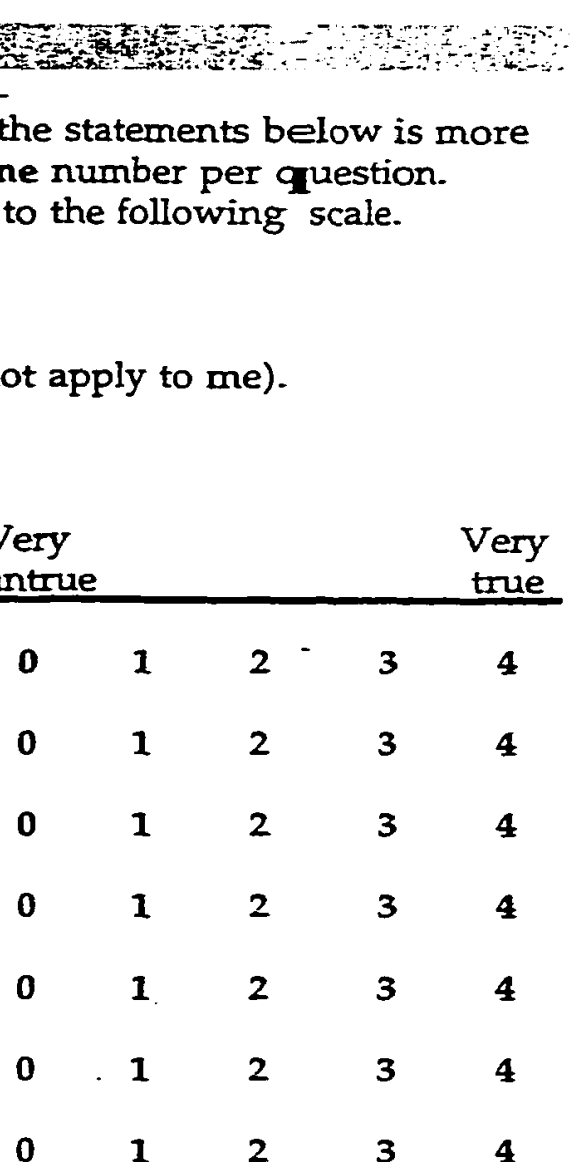

6. I feel helpless about my pain.

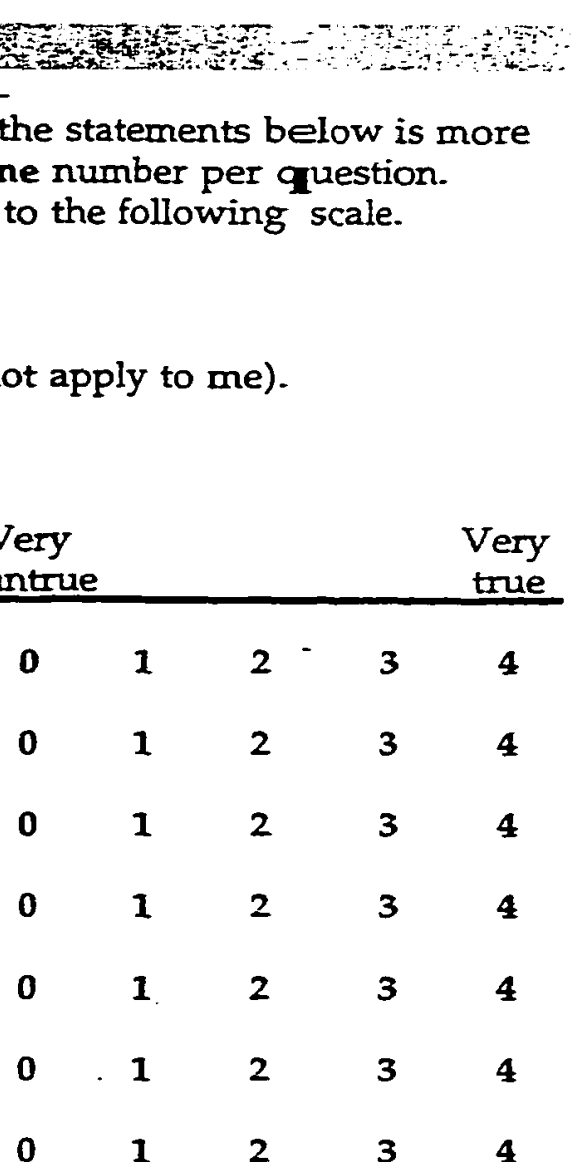

7. My pain is a minor annoyance to me. When I feel pain, I am hurting; but I am not distressed. $\quad \begin{array}{llllll}0 & 1 & 2 & 3 & 4\end{array}$

9. I never let the pain in my body affect my outlook on life. $\quad \begin{array}{lllll}0 & 1 & 2 & 3 & 4\end{array}$

10. When I am in pain, I become almost a different person. $\quad \begin{array}{llllll}0 & 1 & 2 & 3 & 4\end{array}$

\section{Page 8}


APPENDIX B

Post Treatment Survey 


\section{CHRONIC PAIN MANAGEMENT PROGRAM FOLLOW-UP SURVEY}

Below are several questions to help us learn about your pain now and how it affects your life. Under each question is a scale to mark your answer. Read each question carefully and then circle a number on the scale under that question to indicate how that specific question applies to you.

1. Rate the level of your pain at the present moment.

$\begin{array}{rllllll}0 & 1 & 2 & 3 & 4 & 5 & 6 \\ \text { No pain } & & & & & & \text { Very intense pain }\end{array}$

2. How much has your pain changed the amount of satisfaction or enjoyment you get from taking part in social and recreational activities?
0
No change
23
45
6
Extreme change

3. During the past week how tense or anxious have you been?

$\begin{array}{lllllll}0 & 1 & 2 & 3 & 4 & 5 & 6 \\ \begin{array}{l}\text { Not at all } \\ \text { tense or anxious }\end{array} & & & & & & \begin{array}{l}\text { Extremely } \\ \text { Tense and anxious }\end{array}\end{array}$

4. How much has your pain changed your ability to take part in recreational and other social activities?
0
No change
12
34
56
Extreme change

5. During the past week how well do you feel that you've been able to deal with your problems?
0
Not at all
12
$2 \quad 3 \quad 4$
4
56
Extremely well

6. On the average, how severe has your pain been during the last week?

$\begin{array}{ccccccc}0 & 1 & 2 & 3 & 4 & 5 & 6 \\ \text { Not at all severe } & & & & & \text { Extremely severe }\end{array}$

7. During the past week, how successful were you in coping with stressful situations in your life?
$\begin{array}{cc}0 & 1 \\ \text { Not at all successful }\end{array}$
34
5
6
Extremely successful 
8. During the past week how irritable have you been?

$$
\begin{array}{ccccccc}
0 & 1 & 2 & 3 & 4 & 5 & 6 \\
\text { Not at all irritable } & & & & & \text { Extremely irritable }
\end{array}
$$

9. If a zero (0) means "no pain" and a ten (10) means "pain as bad as it could be," on this scale of 0 to 10 , what is your level of pain? Put an $\mathbf{X}$ through that number.

\begin{tabular}{|l|l|l|l|l|l|l|l|l|l|}
\hline 1 & 2 & 3 & 4 & 5 & 6 & 7 & 8 & 9 & 10 \\
\hline
\end{tabular}

10. How useful has the Chronic Pain Management Program been in helping you to manage pain?

$\begin{array}{crrrrrl}0 & 1 & 2 & 3 & 4 & 5 & 6 \\ \text { Not at all useful } & & & & & \text { Extremely useful }\end{array}$

11. How satisfied were you with the Chronic Pain Management Program?

$$
\begin{array}{ccccccc}
0 & 1 & 2 & 3 & 4 & 5 & 6 \\
\text { Not at all satisfied } & & & & & \text { Extremely satisfied }
\end{array}
$$

12. Looking back to the original cause or condition for your referral to the Pain Management Program, how would you rate that cause or condition today?

$\begin{array}{ccccccl}0 & 1 & 2 & 3 & 4 & 5 & 6 \\ \text { Much worse } & & & & & & \text { Much better }\end{array}$

13. What techniques or topics discussed in class have work best for you?

1. In your opinion, what changes would make to the Chronic Pain Management Program better?

15. Comments

Thank you for your participation. We appreciate hearing from you.

Please return this survey form in the enclosed, postage-paid envelope. See over 